\title{
The Future Potential of Wave Power in the United States
}
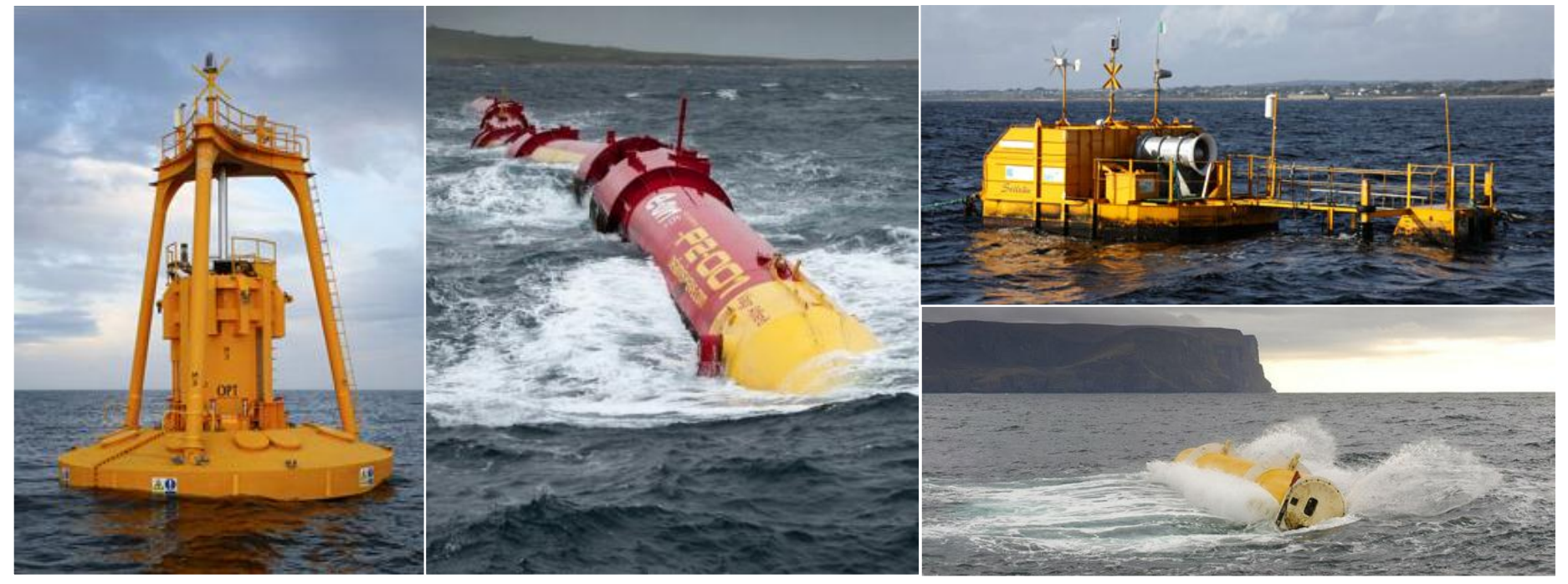

Author: Mirko Previsic

Contributing Authors: Jeff Epler, Maureen Hand, Donna Heimiller, Walter Short, and Kelly Eurek

\section{Prepared by RE Vision Consulting on behalf of the U.S. Department of Energy} August 2012

United States Department of Energy - Wind \& Water Power Technologies Program Office of Energy Efficiency and Renewable Energy 1000 Independence Ave. S.W. Washington, DC, 20585 Phone: 1-877-337-3463 



\section{DISCLAIMER OF WARRANTIES AND LIMITATION OF LIABILITIES}

This document was prepared by the organizations named below as an account of work sponsored or cosponsored by the U.S. Department of Energy (DOE). Neither DOE, RE Vision Consulting, LLC (RE Vision), any cosponsor, the organization(s) below, nor any person acting on behalf of any of them:

(A) Makes any warranty or representation whatsoever, express or implied, (I) with respect to the use of any information, apparatus, method, process, or similar item disclosed in this document, including merchantability and fitness for a particular purpose; or (II) that such use does not infringe on or interfere with privately owned rights, including any party's intellectual property; or (III) that this document is suitable to any particular user's circumstance; or

(B) Assumes responsibility for any damages or other liability whatsoever (including any consequential damages, even if RE Vision or any RE Vision representative has been advised of the possibility of such damages) resulting from your selection or use of this document or any other information, apparatus, method, process, or similar item disclosed in this document.

The views and opinions of authors expressed herein do not necessarily state or reflect those of the United States Government or any agency thereof, or RE Vision. The development of this document was funded by DOE.

Organization(s) that prepared this document:

RE Vision Consulting, LLC

National Renewable Energy Laboratory (NREL)

Analysts from the National Renewable Energy Laboratory (NREL): Maureen Hand, Donna Heimiller, Walter Short, and Kelly Eurek compiled resource information, performed analysis using the ReEDS model to develop the deployment scenarios and developed a simplified electric market assessment to characterize the Alaska and Hawaii electricity markets.

Document Prepared for DOE by:

RE Vision Consulting, LLC

www.re-vision.net

Project Manager: Mirko Previsic

Email: mirko@re-vision.net 


\section{Acknowledgments}

This work would not have been possible without the contributions and input from a wide range of subject matter experts.

Discussions with a wide range of device developers helped us in refining our life-cycle cost profiles, including Aquamarine Power, Pelamis Wave Power, Oceanlinx, Marine Current Turbines, WaveGen, Clean Current, Lunar Energy, Verdant Power, Wave Dragon, Ocean Energy, and Ecomerit Technologies. Complementing the inputs from device developers were numerous discussions with a wide range of offshore service companies. The Electric Power Research Institute (EPRI) supplied data from DOEsponsored wave resource assessments. Finally, this work leveraged the efforts of the reference model program. 


\section{Abbreviations and Acronyms}

$\mathrm{AC}$

AEO

AEP

BA

BAU

BIO

Btu

CAES

Capex

CEC

CES

$\mathrm{CF}$

$\mathrm{CO}_{2}$ coal-CCS

coal-IGCC

COE

CR

CRF

CSP

CT

DECC

DOE

DSIRE

EEI

EIA

EPC

EPRI

ERCOT

FCR

FIT

Gas-CC

Gas-CCS

Gas-CT

GBP

GDP

GEO

HECO

HELCO

HMRC

ICC

IPP

IOU

ISER

$\mathrm{km}$

$\mathrm{kW}$

$\mathrm{kWh}$

L48

COE alternating current

Annual Energy Outlook (Energy Information Administration publication) annual energy production

balancing area

business as usual

biomass

British thermal unit

compressed air energy storage

capital expenses

California Energy Commission

clean energy standard

capacity factor

carbon dioxide

coal with carbon capture and sequestration

integrated gasification combined-cycle coal

levelized cost of electricity

cost reduction

capital recovery factor

concentrating solar power

combustion turbine

Department of Energy and Climate Change (United Kingdom)

U.S. Department of Energy

Database of State Incentives for Renewable Energy

Edison Electric Institute

Energy Information Administration

engineering, procurement, and construction

Electric Power Research Institute

Electric Reliability Council of Texas

fixed charge rate

feed-in tariff

gas combined cycle

natural gas combined cycle with carbon capture and sequestration

gas combustion turbine

pounds sterling

gross domestic product

geothermal

Hawaiian Electric Company

Hawaii Electric Light Company

Hydraulics and Maritime Research Centre

installed capital cost

independent power producer

investor-owned utility

Institute of Social and Economic Research

kilometer

kilowatt

kilowatt-hour

lower 48 states of the contiguous United States

levelized cost of energy 


$\begin{array}{ll}\text { LFG } & \text { landfill gas } \\ \text { m } & \text { meter } \\ \text { MACRS } & \text { Modified Accelerated Cost Recovery System } \\ \text { MB } & \text { merchant-based } \\ \text { MBtu } & \text { A million Btu } \\ \text { MHK } & \text { marine hydrokinetic } \\ \text { MW } & \text { megawatt } \\ \text { NDBC } & \text { National Data Buoy Center } \\ \text { NERC } & \text { North American Electric Reliability Corporation } \\ \text { NETL } & \text { National Energy Technology Laboratory } \\ \text { NOAA } & \text { National Oceanic and Atmospheric Administration } \\ \text { NREL } & \text { National Renewable Energy Laboratory } \\ \text { O\&M } & \text { operations and maintenance } \\ \text { Opex } & \text { operational expenses } \\ \text { OPT } & \text { Ocean Power Technologies } \\ \text { OWC } & \text { oscillating water column } \\ \text { PACI } & \text { Production Area Composite Index } \\ \text { PCM } & \text { power conversion modules } \\ \text { PHS } & \text { pumped hydropower storage } \\ \text { PV } & \text { photovoltaics } \\ \text { RD\&D } & \text { research, development, and deployment } \\ \text { RPS } & \text { renewable portfolio standard } \\ \text { RROE } & \text { rate of return on equity } \\ \text { SEAC } & \text { Strategic Energy Analysis Center (NREL) } \\ \text { SNL } & \text { Sandia National Laboratories } \\ \text { TWh } & \text { terawatt-hour } \\ \text { UPV } & \text { utility photovoltaics } \\ \text { USD } & \text { U.S. dollars } \\ \text { VG } & \text { variable generation } \\ \text { WACC } & \text { weighted average cost of capital } \\ \text { WEC } & \text { wave energy conversion } \\ & \end{array}$




\section{Glossary of Terms}

\begin{tabular}{|c|c|}
\hline Annual Energy Output & The total energy over a year from either the resource or the device \\
\hline Availability & The percentage of time a power plant is operational during the year. \\
\hline Average Power & The average power a device produces over a year \\
\hline Capacity Factor & $\begin{array}{l}\text { The percentage of time over a year that a device operates at its rated } \\
\text { condition or produces the rated power }\end{array}$ \\
\hline Capex & $\begin{array}{l}\text { Capital expenditure of a wave energy plant over a 2-year } \\
\text { construction period; divided by plant rated capacity to give dollars } \\
\text { per kilowatt }\end{array}$ \\
\hline Capital Recovery Factor & $\begin{array}{l}\text { The fraction of the investment and interest that must be returned } \\
\text { each year }\end{array}$ \\
\hline Deployment Density & $\begin{array}{l}\text { The combined effect of device spacing and extraction efficiency } \\
\text { presented as a percentage of wave power that is converted to } \\
\text { mechanical device power }\end{array}$ \\
\hline Device Spacing & The distance between wave energy converter devices \\
\hline Extraction Efficiency & $\begin{array}{l}\text { The device efficiency at turning the wave power into mechanical } \\
\text { device power }\end{array}$ \\
\hline Fixed Charge Rate & $\begin{array}{l}\text { Approximation of the annualized revenues required to recover the } \\
\text { cost associated with financing a plant including bond interest, return } \\
\text { to equity, and tax considerations }\end{array}$ \\
\hline Levelized Cost of Electricity & $\begin{array}{l}\text { The annualized cost to build a power plant divided by the annual } \\
\text { energy production from that plant }\end{array}$ \\
\hline Opex & $\begin{array}{l}\text { Operations and maintenance expenditure of a plant on an annual } \\
\text { basis; divided by the plant rated capacity to give dollars per kilowatt } \\
\text { per year }\end{array}$ \\
\hline Power Conversion Efficiency & $\begin{array}{l}\text { Device efficiency at converting mechanical power into electrical } \\
\text { power }\end{array}$ \\
\hline Practical Resource & $\begin{array}{l}\text { The portion of the technical resource available after consideration to } \\
\text { all constraints such as socioeconomic constraints }\end{array}$ \\
\hline Rated Power & $\begin{array}{l}\text { The maximum power a device can generate limited by design of the } \\
\text { power conversion system and the device }\end{array}$ \\
\hline $\begin{array}{l}\text { Regional Energy Deployment } \\
\text { System model }\end{array}$ & $\begin{array}{l}\text { An electric sector capacity expansion model that optimizes } \\
\text { investments and dispatch decisions for power generation } \\
\text { technologies in the contiguous United States through } 2050\end{array}$ \\
\hline Supply Curve & $\begin{array}{l}\text { A curve that shows the cost of electricity as a function of total rated } \\
\text { power, total average power, or annual energy output }\end{array}$ \\
\hline Technical Resource & $\begin{array}{l}\text { The portion of the theoretical resource that can be captured using a } \\
\text { specified technology }\end{array}$ \\
\hline Theoretical Resource & $\begin{array}{l}\text { The annual average energy production for a specific MHK resource } \\
\text { (wave). }\end{array}$ \\
\hline Wave Power Density $(\mathrm{kW} / \mathrm{m})$ & The wave power per unit width (in meters) of wavefront. \\
\hline Weighted Average Cost of Capital & $\begin{array}{l}\text { A representative discount rate that represents the risk-adjusted time } \\
\text { value of money, which is a function of the equity, debt fraction and } \\
\text { cost, and cost of equity }\end{array}$ \\
\hline
\end{tabular}




\section{Table of Contents}

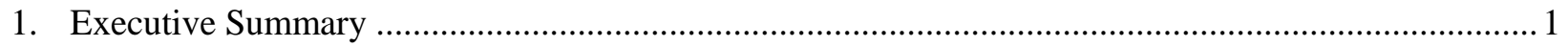

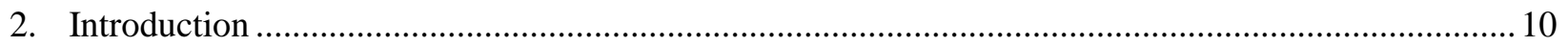

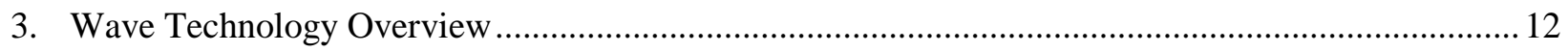

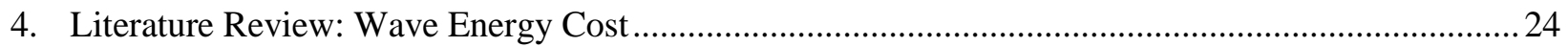

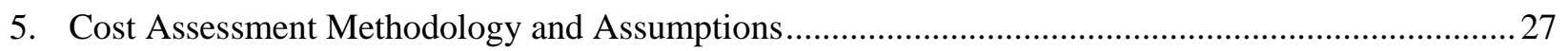

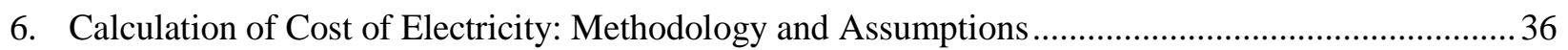

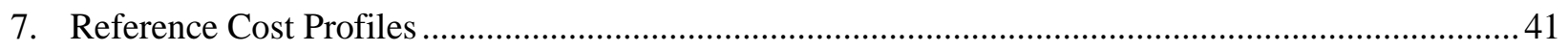

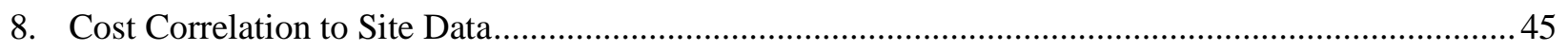

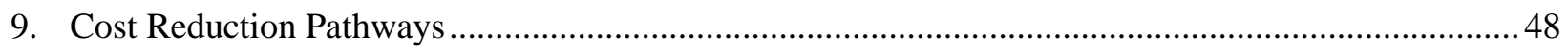

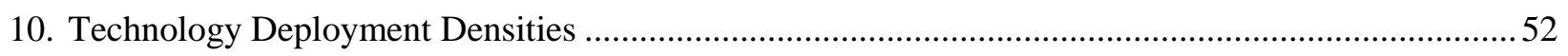

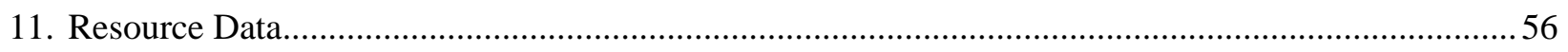

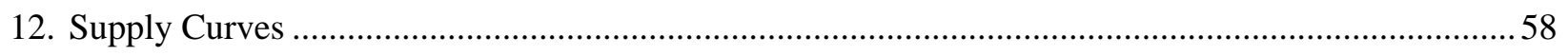

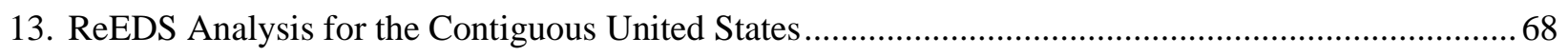

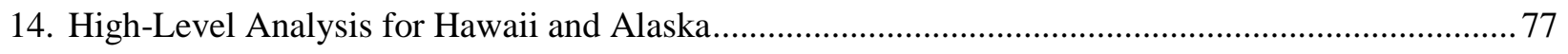

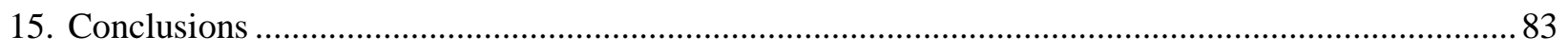

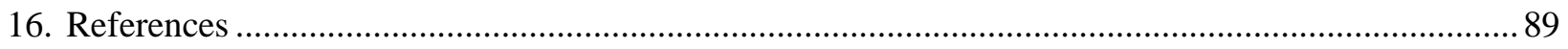

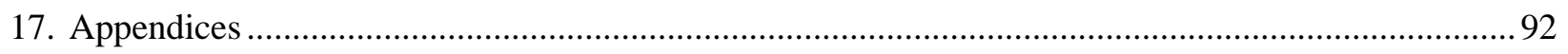




\section{List of Figures}

Figure 1 - National and regional supply curves under $15 \%$ (left) and 70\% (right) scenario

Figure 2 - Cost of electricity reduction and percentage of practical supply curve resource deployed for $70 \%$ scenario

Figure 3 - Optimal scenario capacity expansion in the lower 48 per ReEDS analysis ....................................... 8

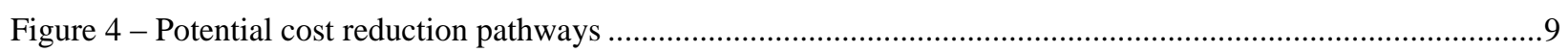

Figure 5 - Pelamis wave power device (Source: Pelamis Wave Power) ........................................................... 12

Figure 6 - Pelamis operation (Source: Pelamis Wave Power) .................................................................13

Figure 7 - Pelamis P750 mooring configuration (Source: Pelamis Wave Power) ............................................14

Figure 8 - Pelamis P2 mooring top view (Adapted from Pelamis Wave Power) ................................................14

Figure 9 - Example array of 10 devices, top view (Adapted from Pelamis Wave Power) .....................................15

Figure 10 - OPT PB150 Power Buoy (Source: Ocean Power Technologies) ..................................................16

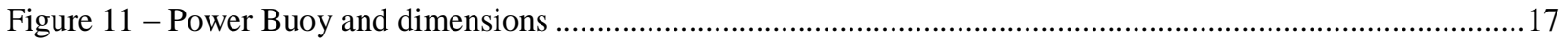

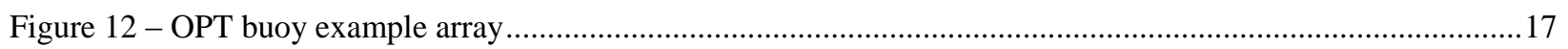

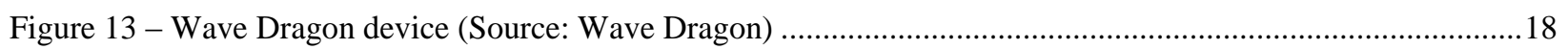

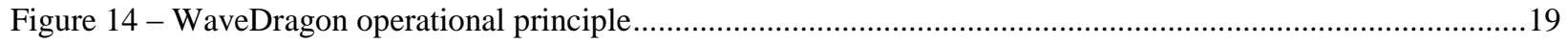

Figure 15 - Major device dimensions (Source: Wave Dragon) ................................................................

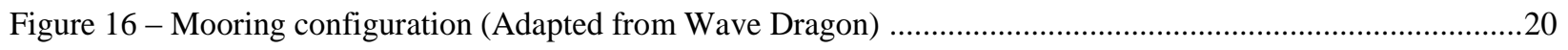

Figure 17 - Oyster 1 prototype operation (Source: Aquamarine Power) ............................................................21

Figure 18 - Oyster 2 basic dimensions (Adapted from Aquamarine) ........................................................22

Figure 19 - Indicative device array and pipeline layout for a 5-MW Oyster 2 farm ........................................23

Figure 20 - Capex from literature review vs. study life-cycle cost profiles at 5-, 20-, and 50-MW capacity ............25

Figure 21 - Opex values from literature review vs. study life-cycle cost profiles at 5-, 20-, and 50-MW capacity....26

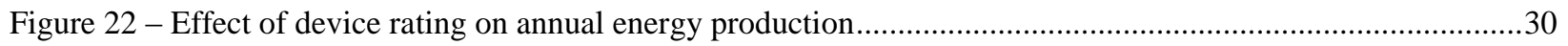

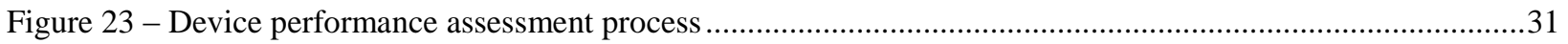

Figure 24 - Unconstrained mechanical power generated (left), power output constrained by rated capacity limit

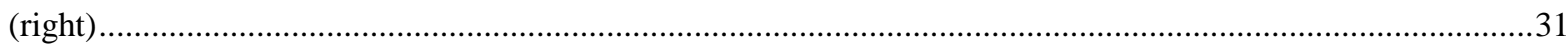

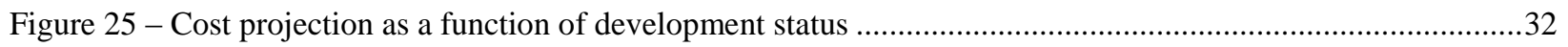

Figure 26 - Historical learning curves (Source: Learning Curves (Source: July 2008 Issue of Project Finance) .......34

Figure 27 - Capital cost breakdown for a typical wave energy technology ..................................................42

Figure 28 - Operational cost breakdown for a typical wave energy technology (in $\$ / \mathrm{kW}$-year) ..........................42

Figure 29 - Cost of electricity as a function of the power density at the deployment site at 50-MW plant scale .......44

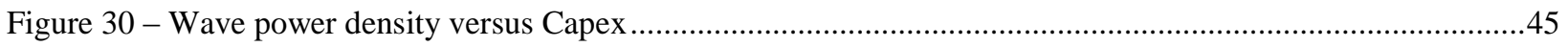

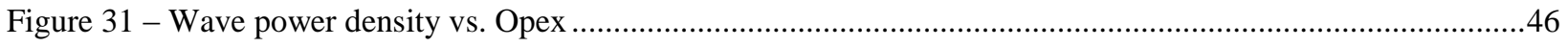

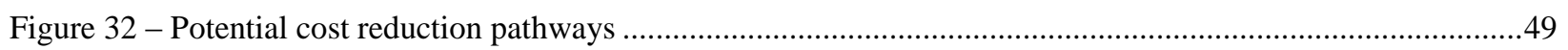

Figure 33 - Artist Illustration of a row of Salter Ducks (Source: www.mech.ed.ac.uk/research/wavepower) ............53 
Figure 34 - Tank test of Salter Duck in narrow tank. One-second exposure shows device motion path and wave particle orbits visualized using tracer particles. (Source: www.mech.ed.ac.uk/research/wavepower) ................53

Figure 35 - Capacity factor as a function of the upper limit of deployment density ...........................................54

Figure 36 - Annual average wave power density $(\mathrm{kW} / \mathrm{m})$ in the contiguous United States ...................................56

Figure 37 - Annual average wave power density $(\mathrm{kW} / \mathrm{m})$ in Alaska ................................................................57

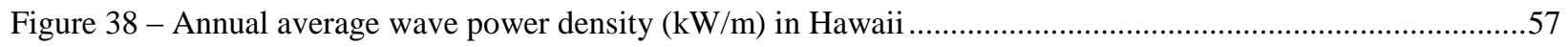

Figure 39 - Washington \& Oregon 100-m depth contour (blue), grid points (black circles) and site areas ...............59

Figure 40 - Wave energy developable sites in the contiguous U.S. at 100-m depth ...........................................61

Figure 41 - Wave energy developable sites in Alaska at 100-m depth ...........................................................62

Figure 42 - Wave energy developable sites in Hawaii at $100-\mathrm{m}$ depth .......................................................62

Figure 43 - COE for the contiguous U.S. wave resource at $100-\mathrm{m}$ depth ...................................................63

Figure 44 - COE for Alaskan wave resource at 100-m depth ................................................................64

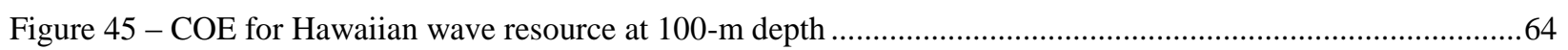

Figure 46 - Wave energy supply curve, $15 \%$ scenario results by region ....................................................65

Figure 47 - Wave energy supply curve, $70 \%$ scenario results by region ..................................................66

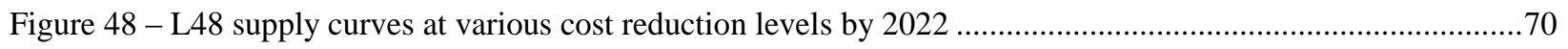

Figure 49 - L48 estimated cumulative wave capacity deployment through 2050 ................................................ 70

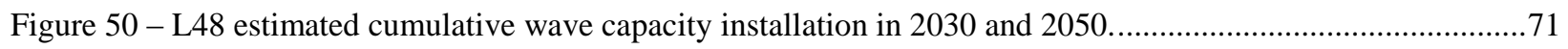

Figure 51 - L48 estimated annual wave energy generation in 2030 and 2050 .............................................72

Figure 52 - Estimated geographical deployment of each MHK technology by 2030 .........................................72

Figure 53 - Estimated geographical deployment of each MHK technology by 2050 ............................................73

Figure 54 - Estimated capacity expansion over time for all generating technologies - 80\% CR - 70\% Scenario ......75

Figure 55 - Estimates for annual and cumulative installed wave capacity through $2050-80 \% \mathrm{CR}-70 \%$............75

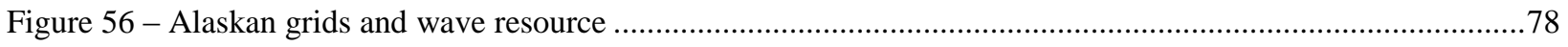

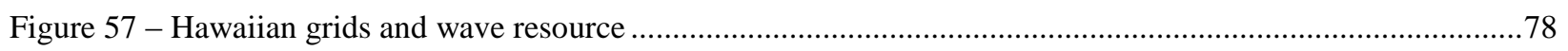

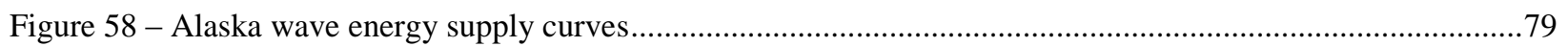

Figure 59 - Monthly wave power variations in Alaska and Hawaii (NDBC) ................................................8

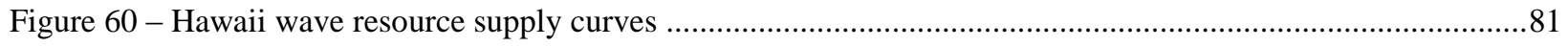

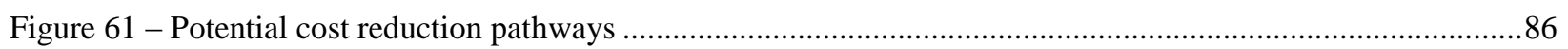

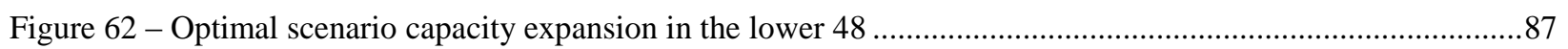

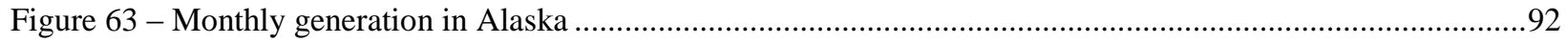

Figure 64 - Monthly generation in Hawaii (Source: data from Ventyx Velocitysuites) ......................................93

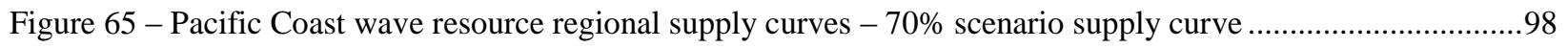

Figure 66 - Pacific Coast region's seasonal and diurnal capacity factors ..........................................................99

Figure 67 - Seasonal/diurnal wave resource correlations between resource regions as a function of region-to-region

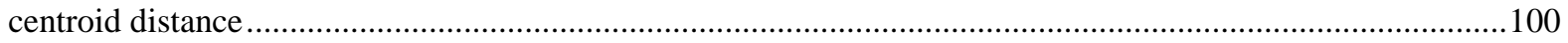

Figure 68 - Comparison of AEO 2011 and ReEDS natural gas and coal prices over time ...............................101 
The Future Potential of Wave Power in the United States

revision

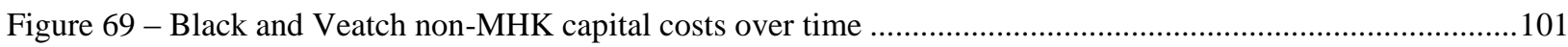

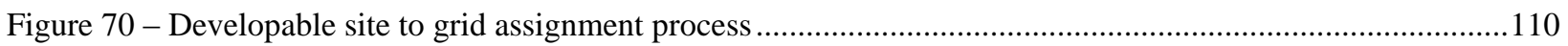

Page ix 


\section{List of Tables}

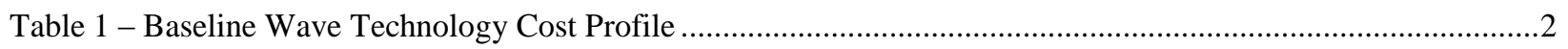

Table 2 - 15\% Scenario Wave Resource Potential (TWh/yr Annual Energy Output) ...............................................

Table 3 - 70\% Scenario Wave Resource Potential (TWh/yr Annual Energy Output) ..................................................5

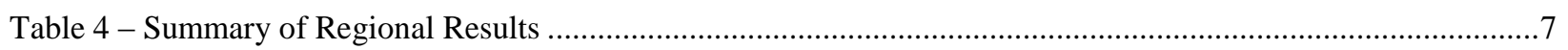

Table 5 - EPRI Cost Estimate Rating Table Showing Cost Uncertainty (in \%) ........................................................32

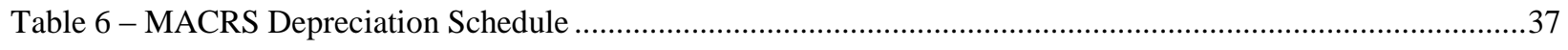

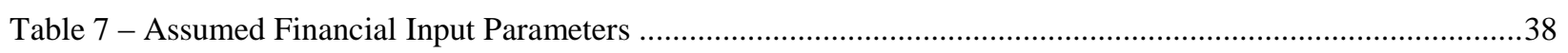

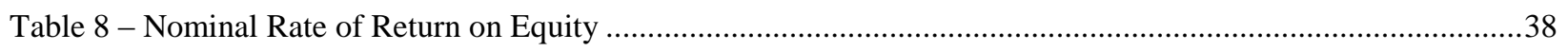

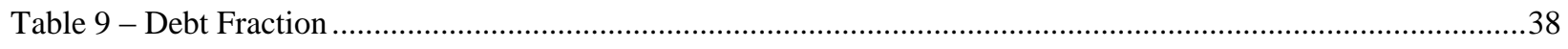

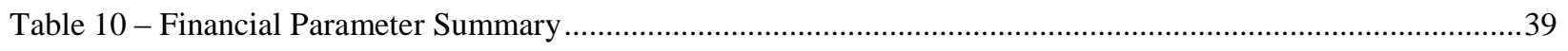

Table 11 - Wave Reference Site Parameters .................................................................................................... 41

Table 12 - Typical Cost, Performance and Economic Profiles for Wave Energy Plants (\$2011) ............................43

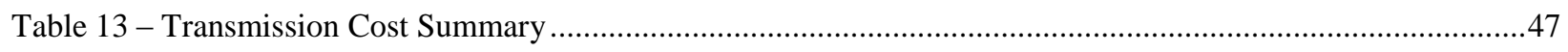

Table 14 - Deployment Densities of Different Technologies Under Development ..................................................52

Table 15 - Upper Limit of Deployment Density at Different Sites Assuming a Capacity Factor of 30\% ..................55

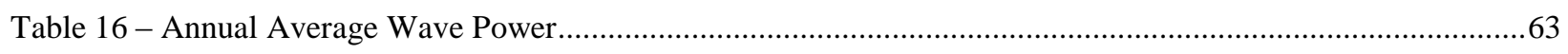

Table 17 - 15\% Scenario Wave Energy Extractable Potential (TWh/yr Annual Energy Output)............................66

Table 18 - 70\% Scenario Upper Limits to Wave Energy Extraction Potential (TWh/yr Annual Energy Output)......67

Table 19 - Independent Effect of Applying Practical Resource Filters for 70\% Scenario (TWh/yr) ........................67

Table 20 - List of Scenario Names for the ReEDS Analysis ............................................................................69

Table 21 - Cost Reduction Scenarios Considered for Each Wave Resource Supply Curve .......................................69

Table 22 - Estimated Wave Capacity Deployment (GW) by 2030 and 2050 for the Various Cost Reduction

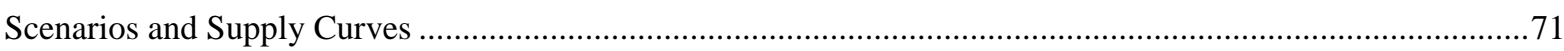

Table 23 - Percentage of Annual Load Met by Wave Energy for States in the L48 Where Wave Energy is Delivered

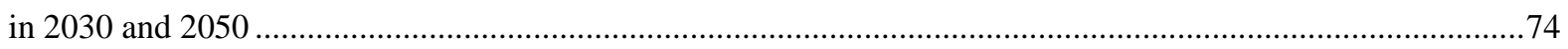

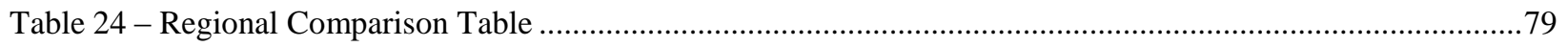

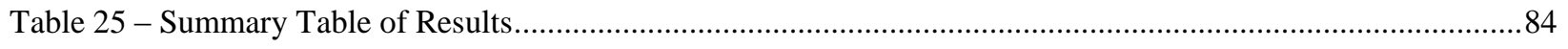

Table 26 - Generation Capacity (MW) by State and Fuel (Source: Ventyx Velocitysuites)......................................93

Table 27 - 2010 Alaska Annual Generation (MWh) by Fuel Type (Source: Ventyx Velocitysuites).........................93

Table 28 - 2010 Hawaii Annual Generation (MWh) by Fuel Type (Source: Ventyx Velocitysuites) ........................94

Table 29 - FIT Rates in Oahu (Source: http://www.heco.com/) .............................................................................

Table 30 - Avoided Costs $(\phi / \mathrm{kWh})$ in Hawaiian Electric Markets ........................................................................95 


\section{Executive Summary}

The theoretical ocean wave energy resource potential exceeds $50 \%$ of the annual domestic energy demand of the United States, is located close to coastal population centers, and, although variable in nature, may be more consistent and predictable than some other renewable generation technologies. As a renewable electricity generation technology, ocean wave energy offers a low air pollutant option for diversifying the U.S. electricity generation portfolio. Furthermore, the output characteristics of these technologies may complement other renewable technologies.

This study addresses the following:

(1) The theoretical, technical and practical potential for electricity generation from wave energy

(2) The present lifecycle cost profile (Capex, Opex, and Cost of Electricity) of wave energy conversion technology at a reference site in Northern California at different plant scales

(3) Cost of electricity variations as a function of deployment site, considering technical, geo-spatial and and electric grid constraints

(4) Technology cost reduction pathways

(5) Cost reduction targets at which the technology will see significant deployment within US markets, explored through a series of deployment scenarios

RE Vision Consulting, LLC (RE Vision), engaged in various analyses to establish current and future cost profiles for marine hydrokinetic (MHK) technologies, quantified the theoretical, technical and practical resource potential, performed electricity market assessments and developed deployment scenarios. RE Vision was supported in this effort by NREL analysts, who compiled resource information, performed analysis using the ReEDS ${ }^{a}$ model to develop deployment scenarios, and developed a simplified assessment of the Alaska and Hawaii electricity markets.

\section{Current Cost Profile at Commercial Deployment Scale for Reference Site}

Cost profiles were assessed at a representative deployment site in Eureka, California (the reference site) to allow the team to benchmark technology cost. The team used a set of technoeconomic models RE Vision has developed using inputs from device manufacturers. A best-of-class performance, cost, and economic profile was established based on leading technologies under development today. Table 1 shows the synthesis of resource and technology capability for the baseline assessment.

\footnotetext{
${ }^{\text {a }}$ See http://www.nrel.gov/analysis/reeds/ for more information.
} 
Table 1 - Baseline Wave Technology Cost Profile

\begin{tabular}{|l|r|}
\hline Reference Site Conditions & $33 \mathrm{~kW} / \mathrm{m}$ \\
\hline Reference Site Power Density & Eureka, California \\
\hline Deployment Site & $70 \mathrm{~m}$ \\
\hline Water Depth & $5 \mathrm{~km}$ \\
\hline Distance to Shore & $50 \mathrm{MW}$ \\
\hline Reference Plant Performance & $30 \%$ \\
\hline Plant Rated Capacity & $95 \%$ \\
\hline Capacity Factor & $98 \%$ \\
\hline Availability & \\
\hline Transmission Efficiency & $\$ 4,347 / \mathrm{kW}$ \\
\hline Normalized Reference Cost & $\$ 163 / \mathrm{kW}-\mathrm{yr}$ \\
\hline Capital Cost & \\
\hline Annualized Operations and Maintenance (O\&M) Cost & 20 years \\
\hline Economic Assumptions & 2 years \\
\hline Plant Life & $12.4 \%$ \\
\hline Construction Period & $27 \mathrm{c} / \mathrm{kWh}$ \\
\hline Real Fixed Charge Rate & \\
\hline Cost of Electricity &
\end{tabular}

The baseline assessment represents the current technology costs assuming a 50-MW plant size and 100 MW of global deployment. No cost reductions resulting from technology improvements are assumed in this baseline cost estimate. Reported costs for smaller early adopter plants being built today are higher, largely the result of three compounding factors: (1) small plant deployment scales, (2) high failure rates because of limited deployment experience, and (3) high financing costs resulting from inherent project and technology risks (Carbon Trust 2011).

\section{Site-Specific Technology Cost}

The team developed site-specific cost estimates from cost-correlation functions for cost drivers including wave power density, distance to shore, and distance to grid. Chapter 7 and chapter 8 of this report provide both methodology and results. Not surprisingly, the primary driver for lowest cost of electricity is the resource power density at the deployment site.

\section{Resource Potential Scenarios}

Deriving the "practical" energy extraction potential from the "theoretical" wave energy resource was a multistep process requiring three intermediate analysis steps. These definitions are consistent with the recommendations of the National Academy of Engineering for standardizing reduction factors in the 
determination of practical energy production (National Research Council 2011). The three intermediate analysis steps follow:

Theoretical Resource - total available wave energy potential derived from computational modeling in conjunction with limited validation using historical data records. The theoretical wave energy potential results reported here were obtained using the wave energy resource database developed by EPRI and funded by DOE (EPRI 2011). These assessments were made at the 100-m water depth in contrast with the EPRI study, which evaluated the wave resource at 50-m and 200-m water depths. The theoretical resource estimated by EPRI came in at 2,610 TWh/yr, compared to the re-analysis of the data in this report, which determined the total resource to be $1,850 \mathrm{TWh} / \mathrm{yr}$. The difference between the two totals can be largely attributed to the differences in the water depth and spatial coverage of the two resource assessments.

Technical Resource - theoretical resource potential reduced by technology conversion filters and constraints including inter-device spacing, wave to mechanical power conversion efficiency, power-train losses, and wave power plant availability. The first two filters are also termed "deployment density" in this report and are expressed as a percentage of the annual wave energy available within a stretch of coastline.

Practical Resource - estimated wave energy that could be delivered to the electric grid. The practical resource is obtained by applying additional reduction filters to the technical resource estimate including (1) exclusion of areas with wave power densities of less than $8 \mathrm{~kW} / \mathrm{m}$ that are considered cost-prohibitive, (2) exclusion of any deployment area that is more than 600 miles from electrical grid infrastructure, and (3) exclusion of marine sanctuaries.

There are numerous wave energy conversion technology approaches, consistent with the early stage development of this emerging industry. As a result, given the number of technology options, a large range of deployment densities must be considered. Deployment density values are largely driven by early conservative mooring system and spacing constraints and are not necessarily representative of the longterm potential with technology maturation.A survey of various wave devices showed deployment densities ranging between $4 \%$ and $30 \%$. Values were found to strongly depend on the technology type. Much higher deployment density values (70\%-80\%) are technically achievable and have been demonstrated. Chapter 10 contains a full explanation of deployment densities, along with a more detailed treatment of this topic and related assumptions. To address this technological diversity, the team defined a $15 \%$ baseline case, which represents a median value of technology deployed today, and a $70 \%$ optimal 
case, representing the future potential of wave technology. Using this scenario-based approach allowed the team to properly benchmark the potential of wave power.

\section{Theoretical, Technical, and Practical Resource Potential for the 15\% Scenario}

In Table 2, the theoretical resource determined from the wave energy along the $100 \mathrm{~m}$ bathymetric contour in the US is shown. The technical resource potential was calculated using a $15 \%$ deployment density, a mechanical to electrical power efficiency of $80 \%$, an availability of $95 \%$, and a transmission efficiency of 98\%. The practical resource was calculated from the technical resource by (1) excluding resource areas where the wave power density was below an economic threshold of $8 \mathrm{~kW} / \mathrm{m}$, (2) the resource was located more than 600 miles from the nearest electrical grid, and (3) the resource was within a marine protected area. The filters applied under the $15 \%$ density scenario reduce the theoretical to practical extraction potential by an order of magnitude.

Table 2 - 15\% Scenario Wave Resource Potential (TWh/yr Annual Energy Output)

\begin{tabular}{|l|r|r|r|r|r|}
\hline & Hawaii & Alaska & Lower $\mathbf{4 8}$ & Total & $\%$ \\
\hline Theoretical Resource & 98 & 973 & 779 & 1,849 & $100 \%$ \\
\hline Technical Resource Filters & 15 & 146 & 117 & 277 & $15 \%$ \\
\hline Deployment Density Filter (15\%) & 11 & 109 & 87 & 207 & $11 \%$ \\
\hline Power Conversion Efficiency and Availability & 9 & 105 & 72 & 186 & $10 \%$ \\
\hline Practical Resource Filters & 9 & 53 & 72 & 135 & $7 \%$ \\
\hline Economic Power Density Filter >8 kW/m & 7 & 53 & 57 & 117 & $6 \%$ \\
\hline 600-Mile Distance to Grid Filter & $\mathbf{7}$ & $\mathbf{5 3}$ & $\mathbf{5 7}$ & $\mathbf{1 1 7}$ & $\mathbf{6 \%}$ \\
\hline Marine Protected Area Filter & $\mathbf{7}$ & 9
\end{tabular}

Theoretical, Technical, and Practical Resource Potential for the $70 \%$ Scenario

Table 3 shows that increasing machine deployment density to the upper bound limit of $70 \%$ has a significant impact on the practical energy extraction. At 70\%, the practical energy extraction is reduced to only $34 \%$ of the theoretical limit. No marine protected area filters were included under this scenario. 
Table 3 - 70\% Scenario Wave Resource Potential (TWh/yr Annual Energy Output)

\begin{tabular}{|l|r|r|r|r|r|}
\hline & Hawaii & Alaska & Lower 48 & Total & \% \\
\hline Theoretical Resource & 98 & 973 & 779 & 1,849 & $100 \%$ \\
\hline Technical Resource Filters & 68 & 681 & 545 & 1,295 & $70 \%$ \\
\hline Deployment Density Filter (70\%) & 51 & 507 & 406 & 964 & $52 \%$ \\
\hline Power Conversion Efficiency and Availability & \multicolumn{5}{|l|}{} \\
\hline Practical Resource Filters & 43 & 488 & 337 & 868 & $47 \%$ \\
\hline Economic Power Density Filter >8 kW/m & 43 & 249 & 337 & 630 & $34 \%$ \\
\hline 600-Mile Distance to Grid Filter & 43 & $\mathbf{2 4 9}$ & $\mathbf{3 3 7}$ & $\mathbf{6 3 0}$ & $\mathbf{3 4 \%}$ \\
\hline Practical Annual Energy Output & &
\end{tabular}

\section{Supply Curves}

Supply curves show the cost of electricity as a function of total energy output. The supply curves for this study were developed using a GIS-based model that considered the site-specific technology cost, deployment density, wave energy resource data, and transmission constraints. Both the baseline and optimal scenario were carried through to the supply curve, with the major difference being the total potential capacity at each cost point. Figure 1 shows the supply curve for the two scenarios considered.

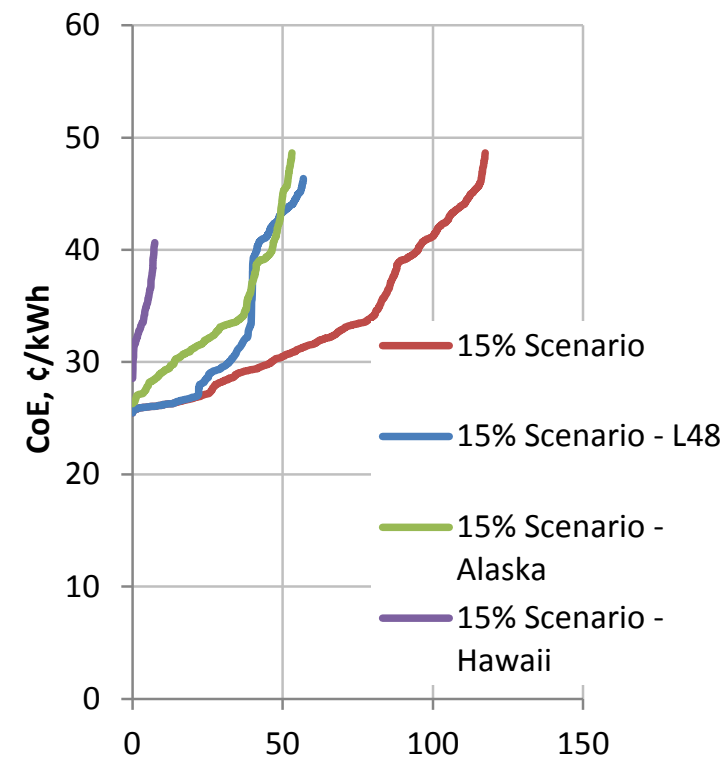

Annual Energy Output, TWh/yr

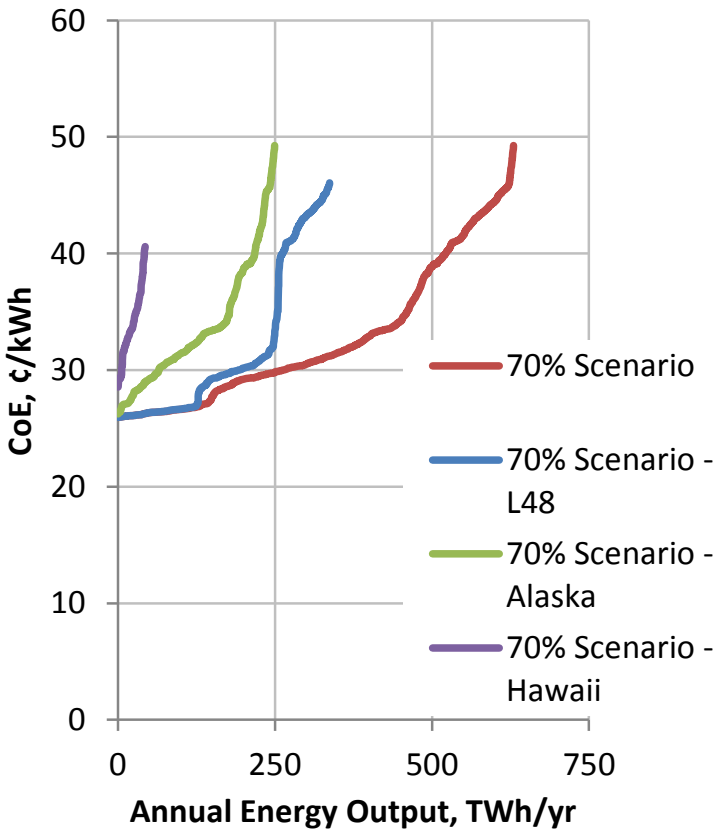

Figure 1 - National and regional supply curves under $15 \%$ (left) and $70 \%$ (right) scenario

It is important to understand that the supply curves do not incorporate any cost reductions that typically occur as technology advances and matures. They represent today's (2011) technology cost. Cost reductions that will occur as this sector matures are considered in the deployment scenarios modeled within ReEDS. 


\section{Determining Cost of Electricity Hurdle Rates}

The team used the ReEDS model to produce deployment scenarios in the contiguous U.S. electric sector. ReEDS model analyses estimated wave technology deployment levels under three different scenarios that achieved $70 \%, 75 \%$, and $80 \%$ cost reductions, respectively, by 2022. Figure 2 shows that if aggressive cost reduction targets can be met, a substantial percentage of the available practical resource from the supply curves would be deployed by 2050 (assuming a 70\% deployment density).

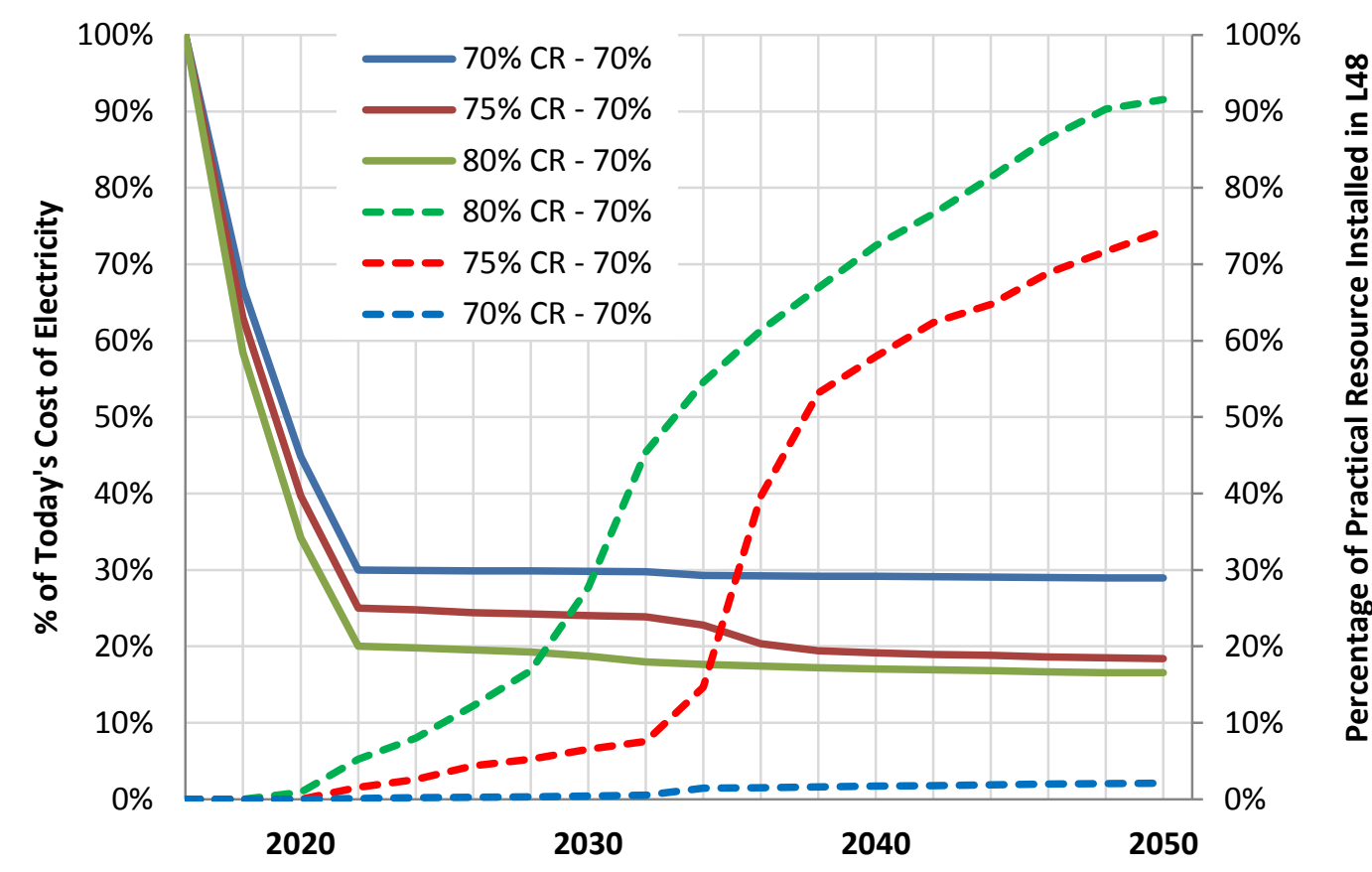

Figure 2 - Cost of electricity reduction and percentage of practical supply curve resource deployed for $70 \%$ scenario $^{\mathrm{a}}$

Because the ReEDS model does not include Alaska and Hawaii, the team used a qualitative analysis for those states. This analysis showed that the Alaskan wave resource in the vicinity of each of the major grid network is significantly larger than each network load. The same is true in the Hawaiian Islands except on Oahu where the largest load center is located. The analysis also revealed that the cost reductions required to make wave power competitive in Alaska are similar to the cost reductions required by the ReEDS model for the contiguous United States $(\sim 75 \%)$. The reductions required to make wave power competitive in Hawaii are not quite as high $(\sim 50 \%)$, because of the higher cost of electricity in Hawaii. As such, Hawaii could serve as an early adopter market for this technology to drive down cost while minimizing

\footnotetext{
${ }^{\mathrm{a}} \mathrm{CR}=$ Cost Reduction, L48 $=$ Lower 48 states of the United States
} 
the need for subsidies. Finally, analysts found that the strong seasonal variation of wave power could limit ultimate penetration in these states because higher levels of deployment will produce more frequent curtailments. Table 4 summarizes results by region.

Table 4 - Summary of Regional Results

\begin{tabular}{|c|c|c|c|c|}
\hline & Hawaii & Alaska & Lower 48 & Total \\
\hline Theoretical Wave Resource Potential by Region & 98 & 973 & 779 & 1,849 \\
\hline \multicolumn{5}{|l|}{ Technical Wave Resource Potential by Region } \\
\hline $70 \%$ Scenario (TWh/year) & 51 & 507 & 406 & 964 \\
\hline $15 \%$ Scenario (TWh/year) & 11 & 109 & 87 & 207 \\
\hline \multicolumn{5}{|l|}{ Practical Wave Resource Potential by Region } \\
\hline $70 \%$ Scenario (TWh/year) & 35 & 247 & 266 & 630 \\
\hline $15 \%$ Scenario (TWh/year) & 7 & 53 & 57 & 117 \\
\hline \multicolumn{5}{|l|}{ Regional Electrical Generation Figures for $2011^{a}$} \\
\hline Regional Installed Generation Capacity (GW) & 2.6 & 2.5 & 1,160 & 1,164 \\
\hline Regional Electric Energy Generated (TWh/year) & 1.6 & 1.2 & 4,106 & 4,109 \\
\hline \multicolumn{5}{|l|}{ Economic Comparison } \\
\hline Market Cost of Electricity Hurdle Rate (\$/kWh) & $13.8^{b}$ & 7 & $6-7^{c}$ & \\
\hline Starting COE within Region ( $\$$ /kWh) & 28.5 & 26.3 & 25.5 & \\
\hline Required Cost Reduction (\%) & $52 \%$ & $73 \%$ & $75 \%$ & \\
\hline
\end{tabular}

The total electrical energy generated in the United States in 2011 was 4,106 TWh/year (EIA 2012), with a total installed generation capacity of 1,164 GW (EIA 2011a). The supply curve developed under the 70\% scenario shows that wave energy could supply up to $630 \mathrm{TWh} / \mathrm{year}$, which corresponds to $15 \%$ of the U.S. electric demand in 2011. ReEDS modeling results showed that roughly half of this practical resource potential would be deployed within the contiguous United States and integrated into the electric grid if cost can be reduced to competitive levels. This is a significant potential contribution, given that the total installed renewable capacity (e.g., conventional hydro, wind, and solar) in the United States is currently meeting about $12 \%$ of the nation's electric energy demand.

Significant cost reductions are required for widespread adoption of wave energy technology in the marketplace. Detailed analyses of the various technology platforms with associated cost reduction potentials is beyond the scope of this report, but these results clearly show that deployment density will be key and should be considered an R\&D priority.

\footnotetext{
${ }^{\mathrm{a}}$ EIA (2011a), EIA (2012)

${ }^{\mathrm{b}}$ Based on base feed-in tariff (FIT); can be significantly higher depending on island and season.

${ }^{\mathrm{c}}$ Strongly dependent on region, but $6-7 \phi / \mathrm{kWh}$ is indicative for regions with good wave energy resources (i.e., California, Oregon, and Washington)
} 
Using the cost reduction profiles shown in Figure 2, wave technology is competitive with other renewable and nonrenewable generation technologies. Analysis using the ReEDS model (see Figure 3) demonstrates the potential deployment of wave technology compared to other technologies out to 2050 using a business-as-usual (BAU) scenario. ${ }^{\text {a }}$

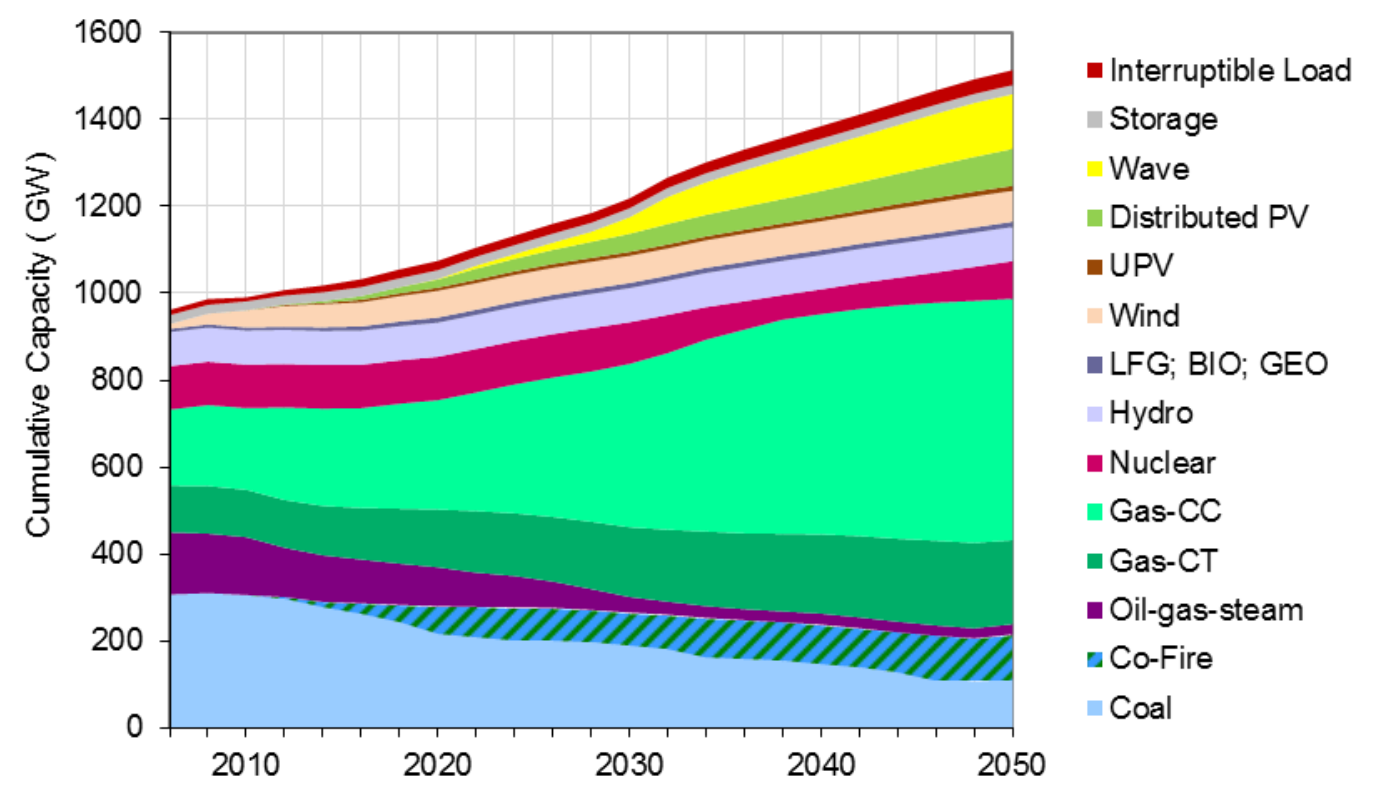

Figure 3 - Optimal scenario capacity expansion in the lower 48 per ReEDS analysis ${ }^{b}$

\section{Cost Reduction Pathways}

One of the key questions is if the cost reduction targets required for large-scale adoption of the technology in the market place can be realistically be met. This question can be studied using two different approaches - learning curves and fundamental analysis of cost reduction pathways.

Learning curves are typically used when predicting longer term cost reductions for an industry. For each doubling of the deployed capacity, a certain percentage cost reduction is attained. Similar renewable energy technologies have historically attained learning rates on the order of $70 \%-90 \%$. Wind technology,

\footnotetext{
${ }^{a}$ The detailed inputs for a standard ReEDS BAU case have been amassed from a variety of sources. Fuel prices and electricity demands are taken from the Energy Information Administration's (EIA's) Annual Energy Outlook (AEO; 2011) reference case values through 2035 and extrapolated to 2050 at the AEO growth rate between 2030 and 2035. See Appendix II for details.

${ }^{\mathrm{b}}$ Definitions: PV=photovoltaics; UPV=utility photovoltaics; LFG=landfill gas; $\mathrm{BIO}=$ biomass; GEO=geothermal; Gas-CC $=$ gas combined cycle; Gas-CT=gas combustion turbine
} 
for example, which is the most closely related analog, has demonstrated progress ratios on the order of $85 \%$. These cumulative cost reductions in industries are tied to diverse factors that drive down costs, such as manufacturing scale, operational efficiencies, improved reliability and availability, and fundamental design changes. A cursory analysis of technologies under development carried out during the course of this study identified several areas that could potentially make dramatic contributions to reducing the cost from this resource. These include among others: performance improvements due to improved control strategies, alternate materials for the absorber structure, and improvements in the operation and maintenance of these devices. The following illustration shows two potential cost reduction pathways and puts them into the context of likely US market hurdle rates.

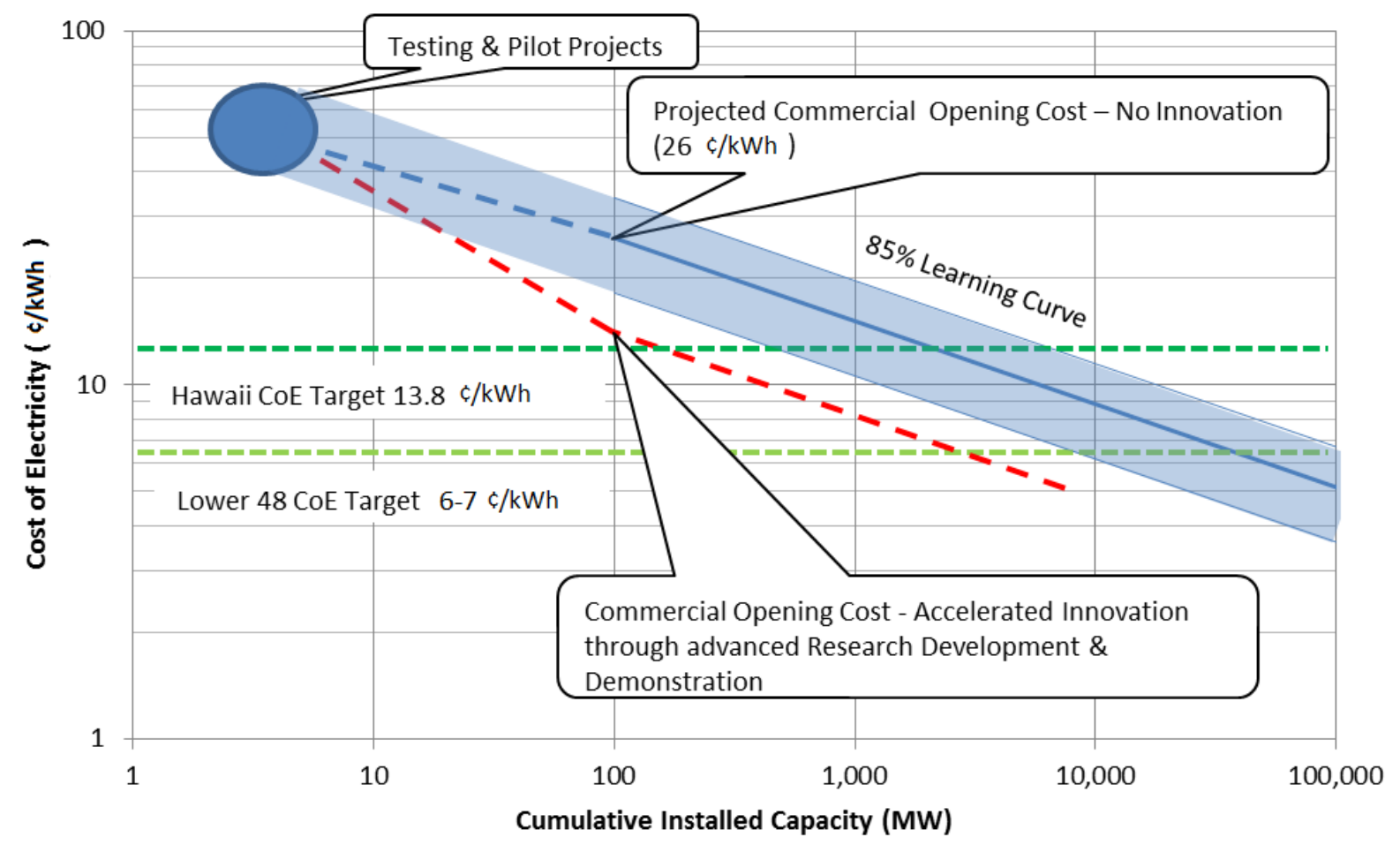

Figure 4 - Potential cost reduction pathways 


\section{Introduction}

In September 2009, DOE awarded a contract to RE Vision under a competitive solicitation to quantify the potential for renewable generation from marine hydrokinetic technologies in the United States. The scope of work included: (1) The theoretical, technical and practical potential for electricity generation from wave energy, (2) the present lifecycle cost profile (Capex, Opex, and Cost of Electricity) of wave energy conversion technology at a reference site in Northern California at different plant scales, (3) cost of electricity variations as a function of deployment site, considering technical, geo-spatial and electric grid constraints, (4) technology cost reduction pathways, and (5) cost reduction targets at which the technology will see significant deployment within US markets, explored through a series of deployment scenarios.

Although work was done in all MHK areas including wave, tidal, river, and ocean-current technologies, this report focuses on wave energy resources and associated extraction technologies only. RE Vision was supported in this effort by NREL analysts, who compiled GIS resource information and performed analysis using the ReEDS model to develop deployment scenarios.

The report relies on a unique combination of resource assessment, technology cost, device performance, and market barrier assumptions to provide future cost and deployment estimates for wave energy. It is important to recognize that the maturity index of this emerging industry is very low making the uncertainties in the final results substantial. Over the coming years significant enhancements and refinements will be adopted as the knowledge-base improves and modeling methods achieve greater fidelity.

Resource assessments identify geographic location and relative strength of a given resource, but there is significant uncertainty around assumptions that associate resource strength with the amount of electrical power generation. To address this issue, two supply curve scenarios were developed. Assumptions about technical and practical resource significantly affect the quantification of the resource potential in ways that could either increase or decrease the estimates presented in this study.

The team developed life-cycle cost projections based on technologies that are in a very early stage of development. Given the limited data available from actual deployments, significant uncertainties-in terms of cost reduction pathways and the potential for accelerating cost reductions-remain to be addressed. 
In addition to technology costs, future electricity sector operation and expansion introduce significant uncertainty in deployment potential. For example, market and other regulatory policies that value lowcarbon emission technologies over traditional fossil-fuel based technologies and/or the acceleration of renewable technologies could dramatically change the future electricity generation mix from the assumed values used in this study. Operation and expansion policies that ease integration of variable generation technologies, such as wind, solar, and some MHK technologies would also result in different regional deployment of these technologies. Fuel prices and generation technology cost assumptions also influence the relative competitiveness of one technology compared to another and will change the relative generation projection mix.

Finally, regional policies such as state renewable portfolio standards (RPS) could also lead to substantial differences in electricity generation choices. Additional analysis of possible future electricity generation scenarios is warranted to understand how sensitive MHK deployment could be to these varied influences. This study does, however, demonstrate that if MHK technologies achieve cost levels comparable to other electricity generation options, deployment of MHK technologies do contribute to cost-optimized electric sector solutions. 


\section{Wave Technology Overview}

The cost profiles used in this study to complete the supply curve and ReEDS analysis were technology agnostic and represented a blend of many wave technologies. For illustrative purposes, though, this section presents photos, specifications, diagrams, and brief descriptions of four technology types.

\section{Pelamis Wave Power}

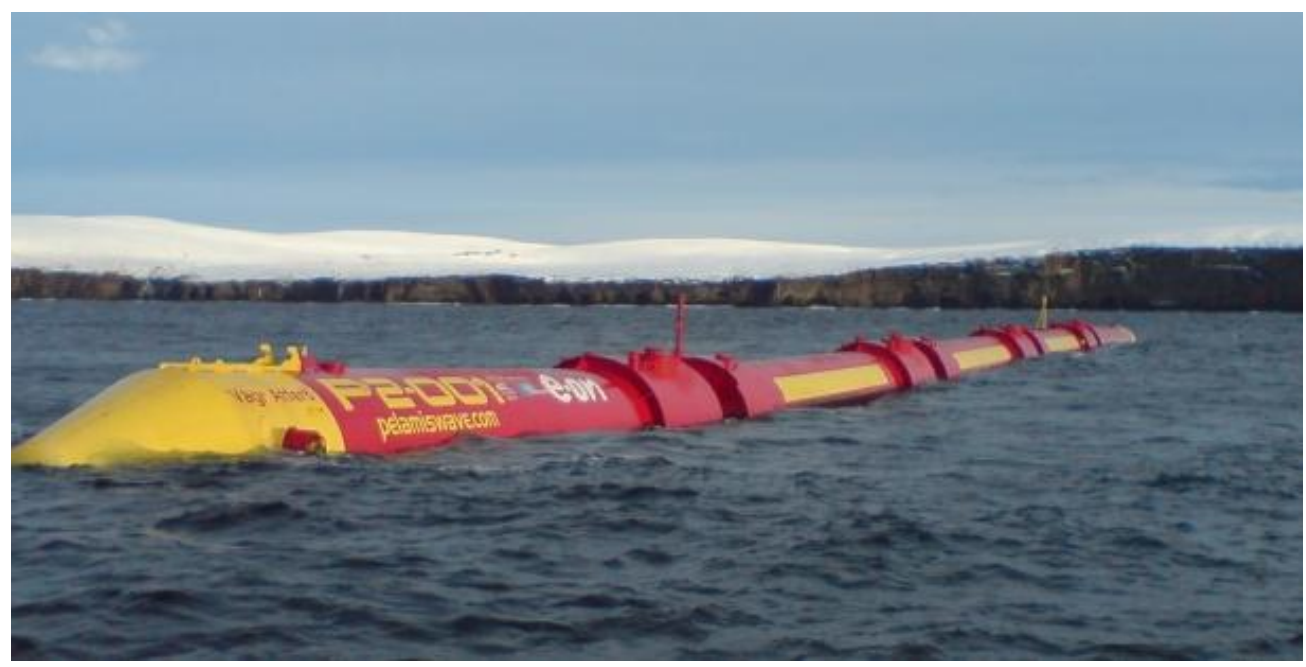

Figure 5 - Pelamis wave power device (Source: Pelamis Wave Power)

\section{Specifications}

Length

Width

Steel Weight

Ballast Weight

Mooring Type

Anchor Type

Total Anchor Weight

Total Mooring Chain Weight

Additional Mooring

Rated Power Output

\section{Company Information}

Company Name

Website
$180 \mathrm{~m}$

$6 \mathrm{~m}$

750 tons

800 tons

Catenary-moored

Stevpris type embedment anchors

14.5 tons

100 tons

20-ton steel-wire rear yaw line and clump weight $750 \mathrm{~kW}$
Pelamis Wave Power

www.pelamiswave.com 
Principle of Operation-The Pelamis P2 is a floating attenuator. The device consists of five tubular sections, connected by four hinged power conversion modules (PCM). Each PCM contains a heave and sway joint, providing two degrees of freedom, as illustrated in Figure 6. The wave-induced motion of each section joint is resisted by sets of hydraulic rams configured as pumps. These pump oil into smoothing accumulators that then discharge at a constant rate through a hydraulic motor coupled to an electrical generator. All hydraulic components are contained within the device cylinders.
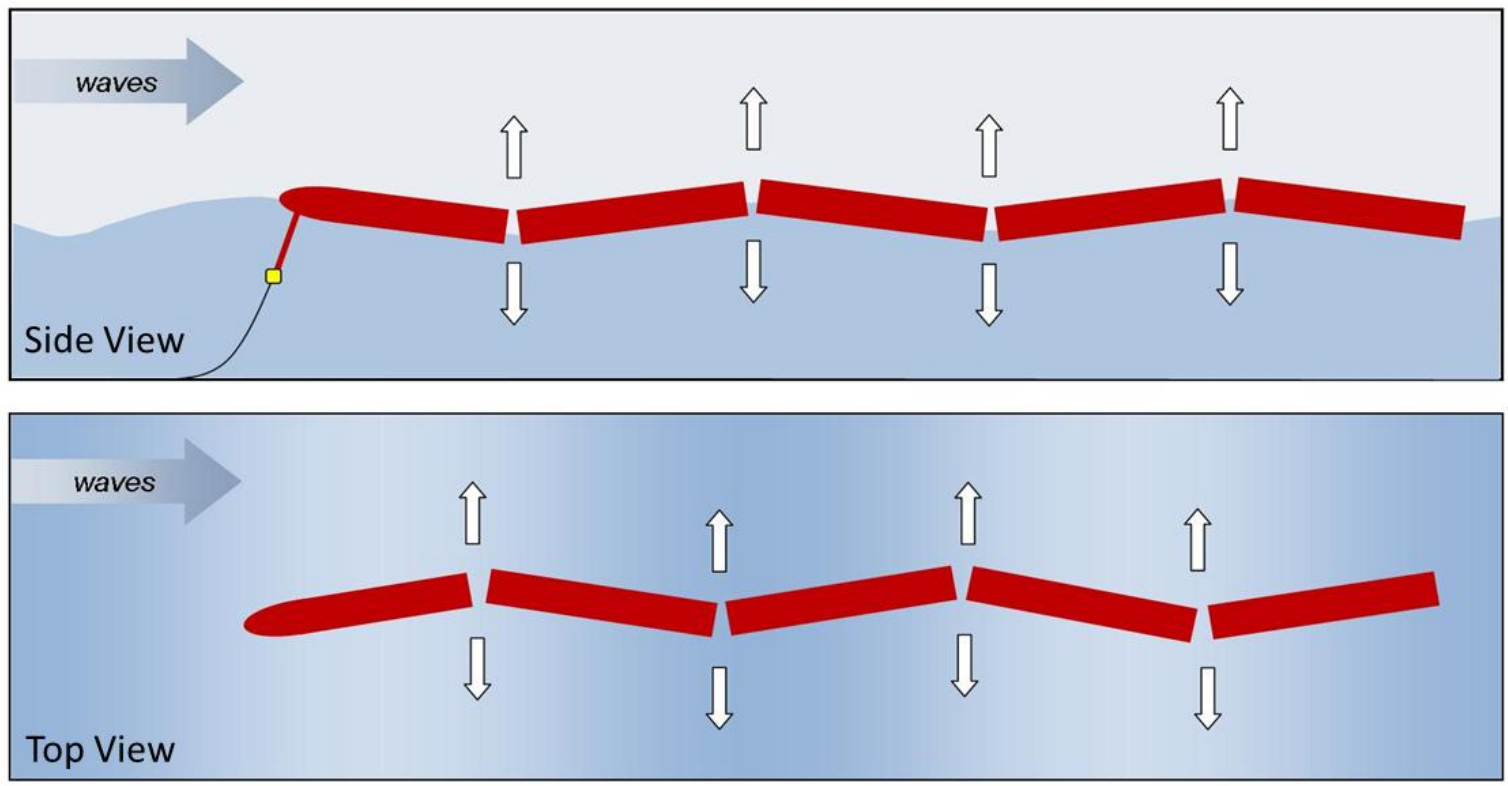

Figure 6 - Pelamis operation (Source: Pelamis Wave Power)

The accumulators are sized to allow continuous, smooth output across wave groups. Oil-to-water heat exchangers are included to dump excess power in large seas and provide the necessary thermal load in the event of loss of the grid. Overall power conversion efficiency (mechanical to electrical) ranges from around $70 \%$ at low power levels to over $80 \%$ at full capacity. Each of the four generator sets are linked by a common 690-V, 3-phase bus running the length of the device. A single transformer is used to step up the voltage to an appropriate level for transmission to shore. High voltage power is fed to the seabed by a single flexible umbilical cable, then to shore via a conventional subsea cable. The design has inherent survivability with a very small frontal area subjected to the hydrodynamic forces of large waves.

Device Anchoring and Footprint-The Pelamis uses a catenary mooring system and is slack-moored. The mooring configuration allows the machine to self-reference and point into the incident waves. Figure 7 depicts an overview of the mooring configuration that has been used for the device. 


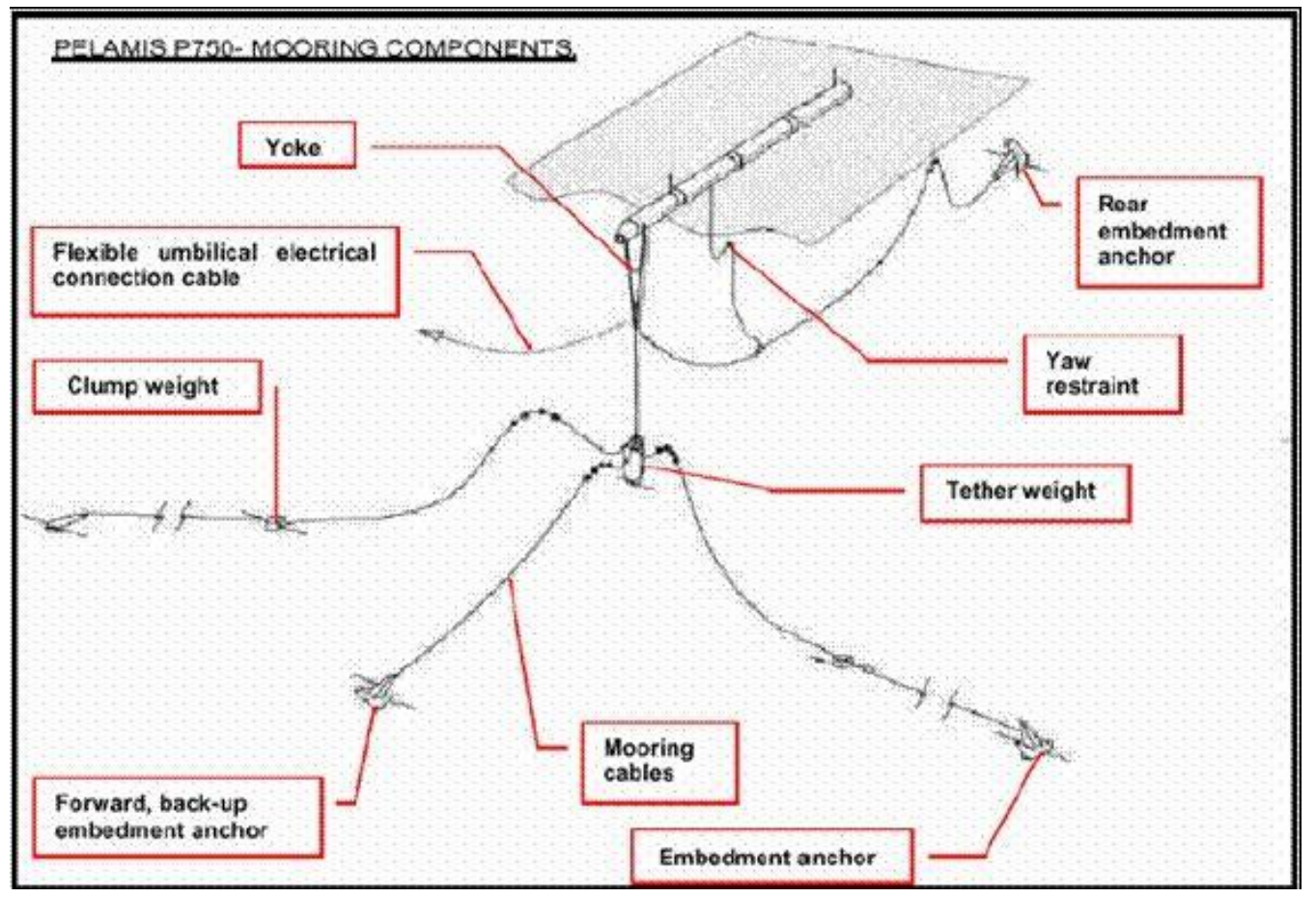

Figure 7 - Pelamis P750 mooring configuration (Source: Pelamis Wave Power)

Multiple systems can be arranged in an array with separation that takes into account the mooring space, yaw, and device surge allowance. Figure 9 shows an example of a two-row array of 10 devices.

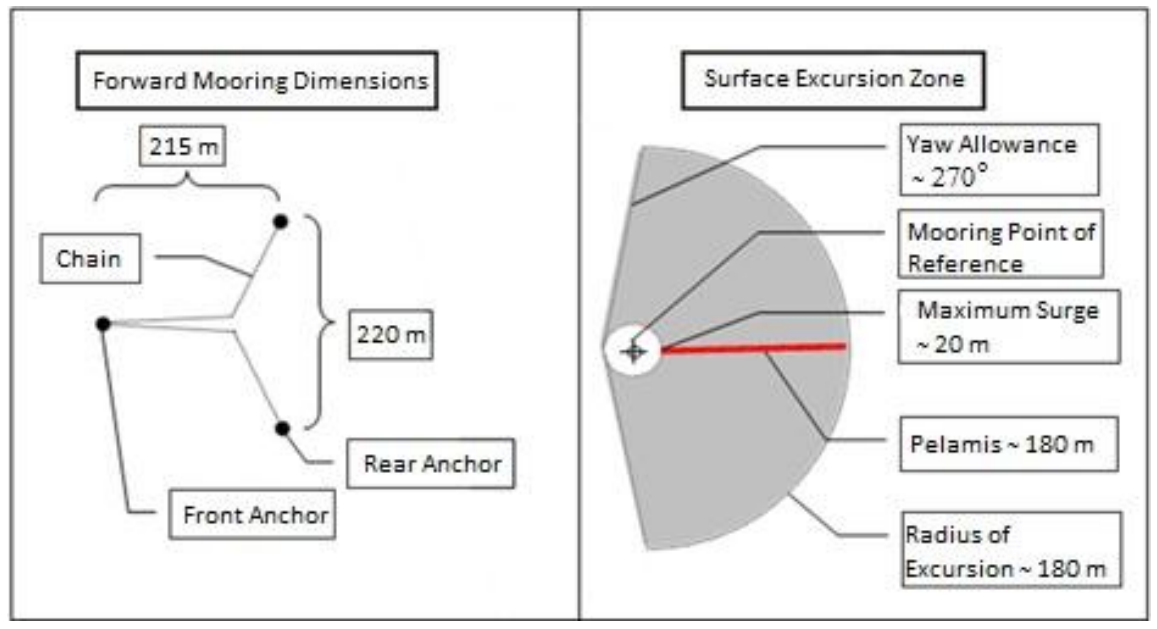

Figure 8 - Pelamis P2 mooring top view (Adapted from Pelamis Wave Power) 


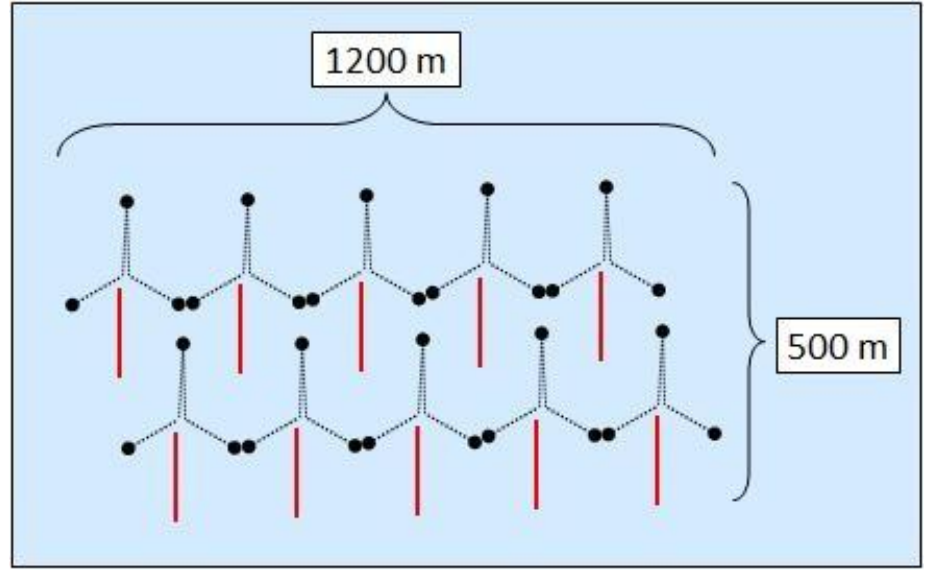

Figure 9 - Example array of 10 devices, top view (Adapted from Pelamis Wave Power) 


\section{Ocean Power Technologies}

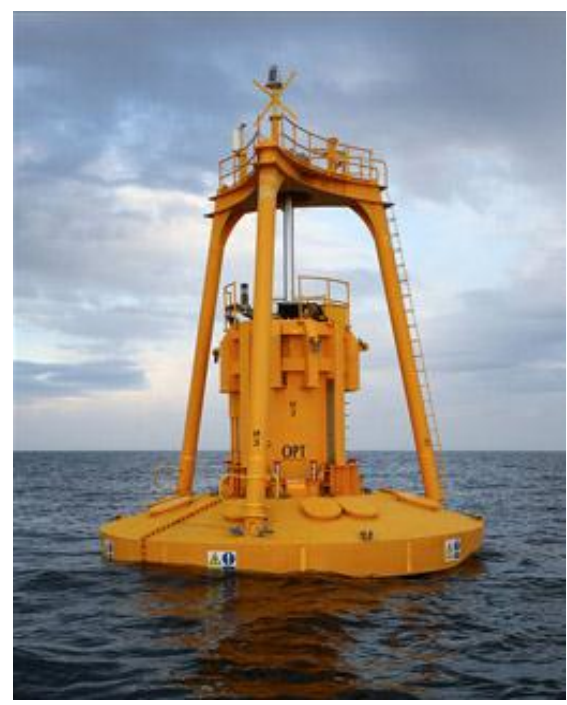

Figure 10 - OPT PB150 Power Buoy (Source: Ocean Power Technologies)

\section{Specifications}

Float Diameter

$11 \mathrm{~m}$

Float Height

$2 \mathrm{~m}$

Height above Water

$8 \mathrm{~m}$

Draft

$36 \mathrm{~m}$

Mass

150 tons

Mooring Type

Catenary-moored

Anchor Type

Concrete block

Anchor Mass

165 tons each

Anchor Dimensions

$6.0 \mathrm{~m} \times 6.0 \mathrm{~m} \times 3.1 \mathrm{~m}$

Average Power

$52 \mathrm{~kW}$ (in Oregon wave climate with power density of $21.5 \mathrm{~kW} / \mathrm{m}$ )

Rated Power $150 \mathrm{~kW}$

Power Conversion

Mechanical

\section{Company Information}

Company Name

Website
Ocean Power Technologies

www.oceanpowertechnologies.com 
Principle of Operation-The Power Buoy is a heaving point absorber, reacting against a subsea reaction plate. The relative movement between the absorber buoy and the reaction plate is converted into electricity using a mechanical power conversion system. The device is catenary-moored in such a way that the mooring allows the device to move unrestricted in heave, but is constrained from drifting. Figure 11 is an illustration of the $150-\mathrm{kW}$ rated Power Buoy.

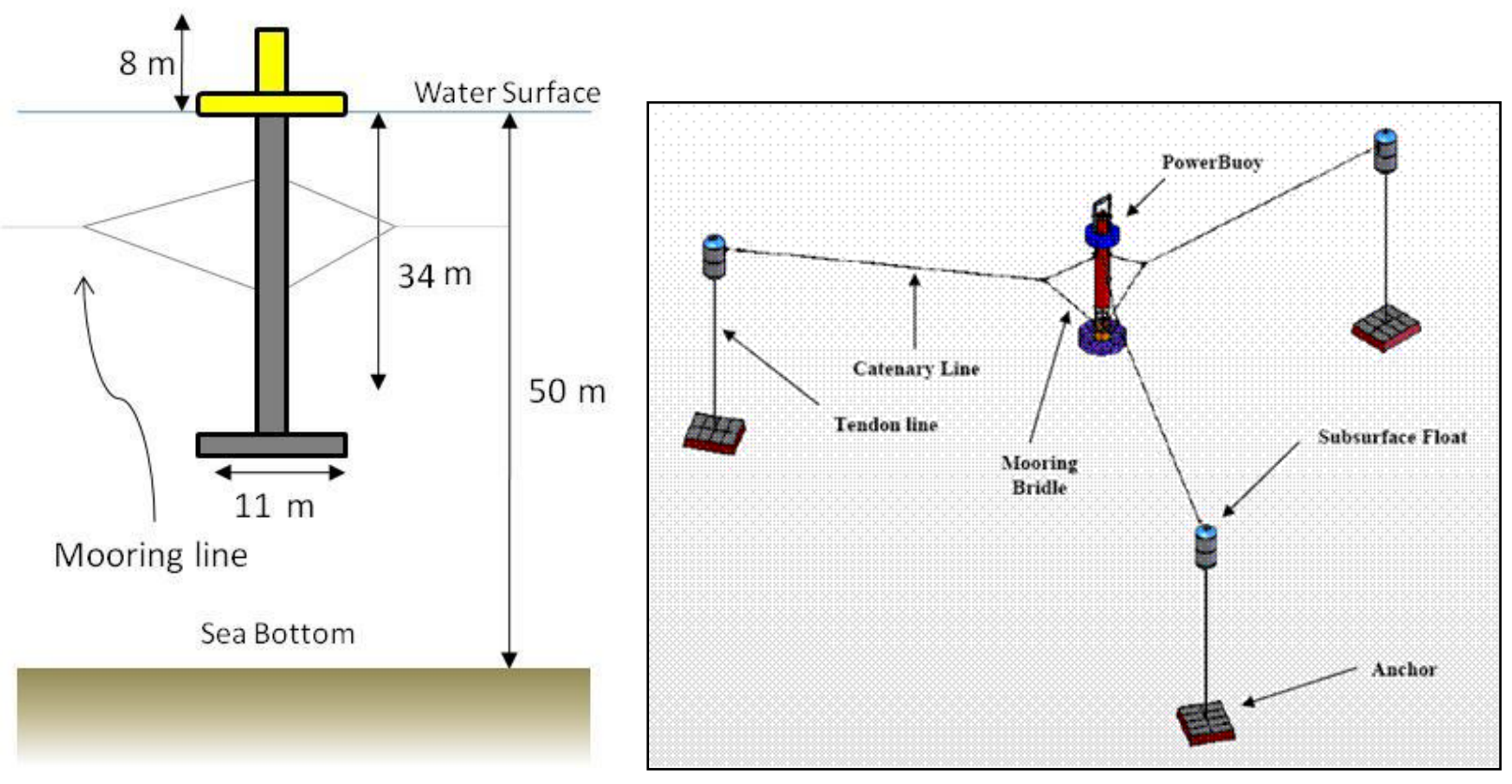

Figure 11 - Power Buoy and dimensions

Device Mooring and Footprint-As shown in Figure 11, the system is moored between three subsurface mooring buoys. The mooring buoys are moored to the concrete block, sitting on the seabed. Figure 12 shows a top view. Pre-tension levels on the mooring lines and the inter-device spacing are likely high enough not to be considered an issue for entanglement.

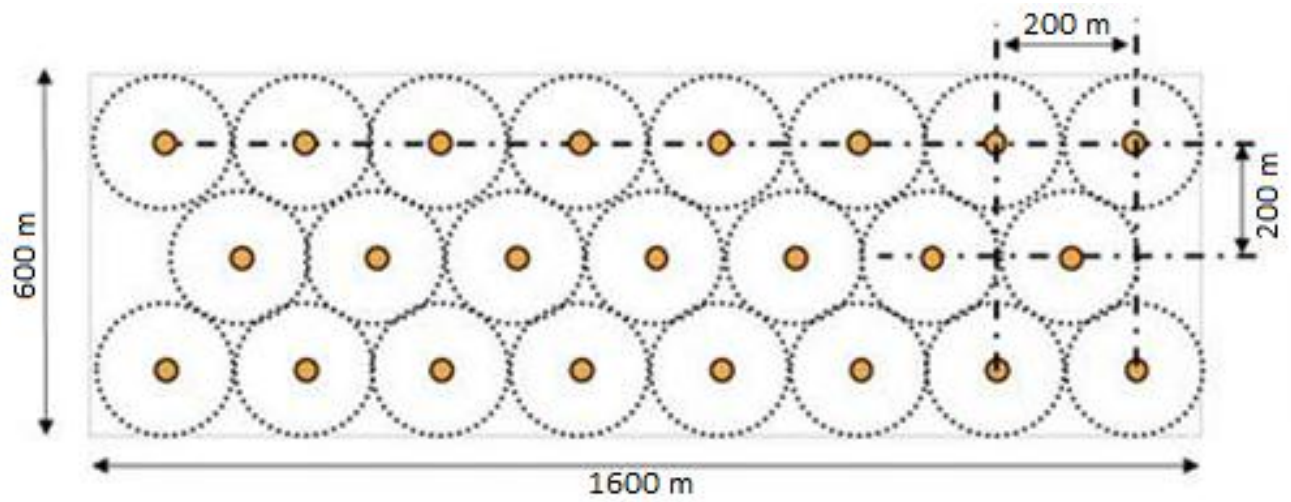

Figure 12 - OPT buoy example array 


\section{Wave Dragon}

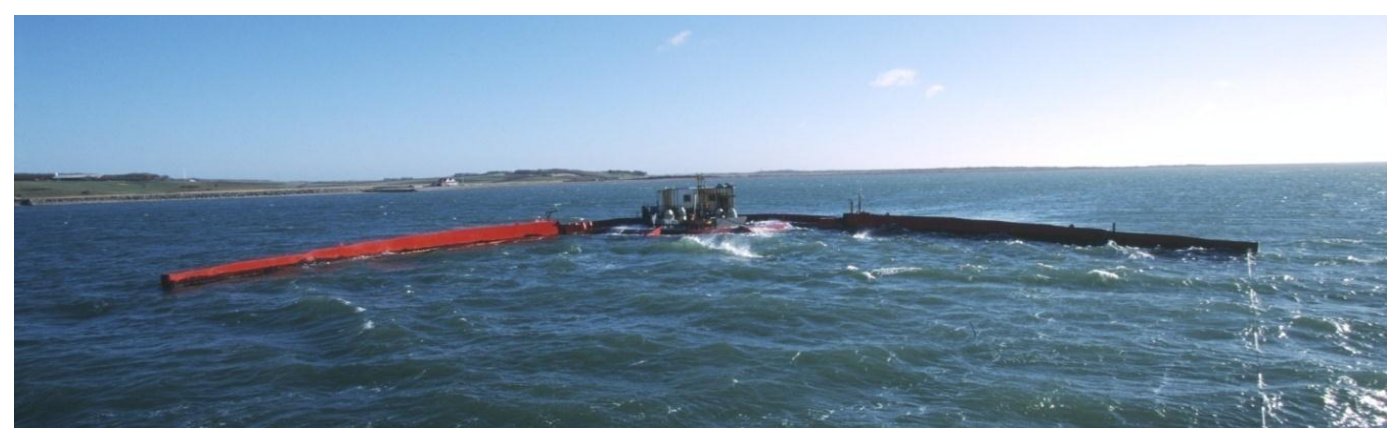

Figure 13 - Wave Dragon device (Source: Wave Dragon)

\section{Specifications}

\begin{tabular}{lllll} 
& $\mathbf{1 2} \mathbf{k W} / \mathbf{m}$ & $\mathbf{2 4} \mathbf{~} \mathbf{W} / \mathbf{m}$ & $\mathbf{3 6} \mathbf{k W} / \mathbf{m}$ & $\mathbf{4 8 k W / m}$ \\
\hline Weight: & $6,500 \mathrm{tons}$ & $22,000 \mathrm{tons}$ & $33,000 \mathrm{tons}$ & $54,000 \mathrm{tons}$ \\
Width & $170 \mathrm{~m}$ & $260 \mathrm{~m}$ & $300 \mathrm{~m}$ & $390 \mathrm{~m}$ \\
Length & $96 \mathrm{~m}$ & $150 \mathrm{~m}$ & $170 \mathrm{~m}$ & $220 \mathrm{~m}$ \\
Wave Reflector Length $84 \mathrm{~m}$ & $126 \mathrm{~m}$ & $145 \mathrm{~m}$ & $190 \mathrm{~m}$ \\
Height & $12 \mathrm{~m}$ & $16 \mathrm{~m}$ & $16.8 \mathrm{~m}$ & $18.1 \mathrm{~m}$ \\
Number of Turbines & 8 & 16 & $16-20$ & $16-24$
\end{tabular}

Generator Type Permanent Magnet Generators

$\begin{array}{lllll}\text { Generator Rating } & 8 \times 185 \mathrm{~kW} & 16 \times 250 \mathrm{~kW} & 16-20 \times 350 \mathrm{~kW} & 16-24 \times 500 \mathrm{~kW} \\ \text { Device Rated Power } & 1.5 \mathrm{MW} & 4 \mathrm{MW} & 7 \mathrm{MW} & 12 \mathrm{MW} \\ \text { Water Depth } & >15 \mathrm{~m} & >20 \mathrm{~m} & >25 \mathrm{~m} & >30 \mathrm{~m}\end{array}$

Mooring Type Single-point mooring with 5-8 legs

\section{Company Information}

$\begin{array}{ll}\text { Company Name } & \text { Wave Dragon } \\ \text { Website } & \text { www.wavedragon.net }\end{array}$

Principle of Operation-The Wave Dragon is an overtopping device that combines a double curved overtopping ramp and two reflector wings, which focus energy onto the overtopping basin (see Figure 14). Variable-speed propeller turbines are used to convert this low-pressure head into electricity. The variable-speed operation allows higher efficiency levels to be attained. 


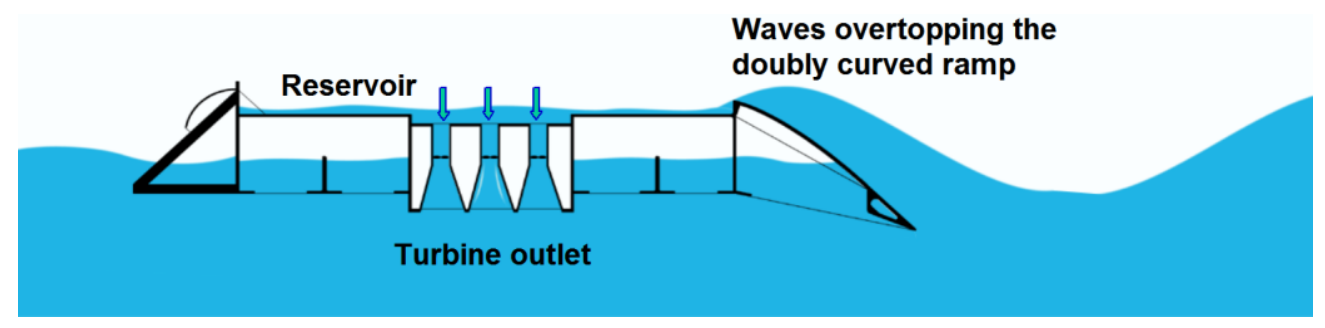

Figure 14 - WaveDragon operational principle

Device output depends on the wave climate and is in the range of 1.5-12 MW. The Wave Dragon is the largest device (by rated capacity and physical size) under development. The device is slack-moored and is able to swivel around its mooring in order to always face the wave direction. The amount of rotation possible is dependent on the wave climate.

Device Anchoring and Footprint-To provide a point around which the device can swivel, a single buoy mooring system is used. The buoy is anchored using a catenary style spread of anchor lines as shown in Figure 15. The number of anchor legs depends on device size and bottom conditions. For the 7MW device, six to eight mooring legs are used.

Devices in an array must be spaced to allow sufficient clearance to avoid collision. Figure 16 shows an example array for the 7-MW case.

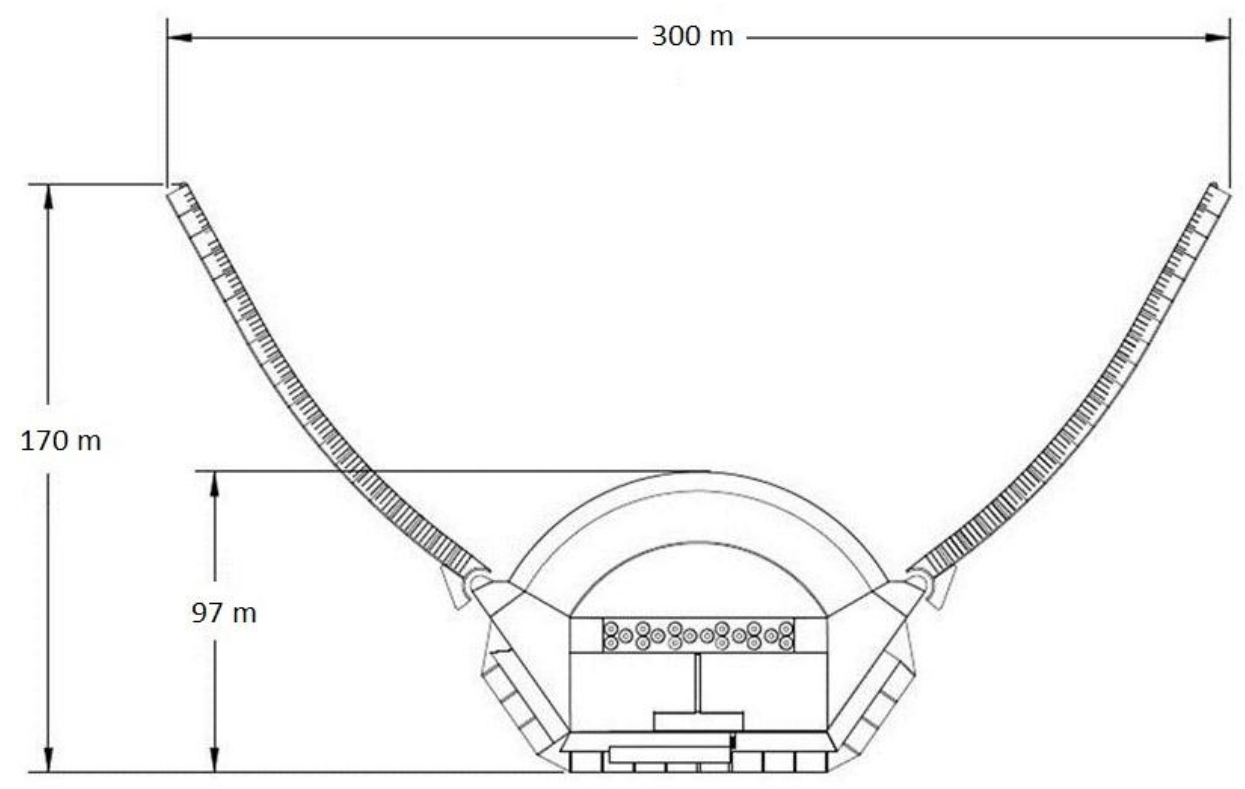

Figure 15 - Major device dimensions (Source: Wave Dragon) 


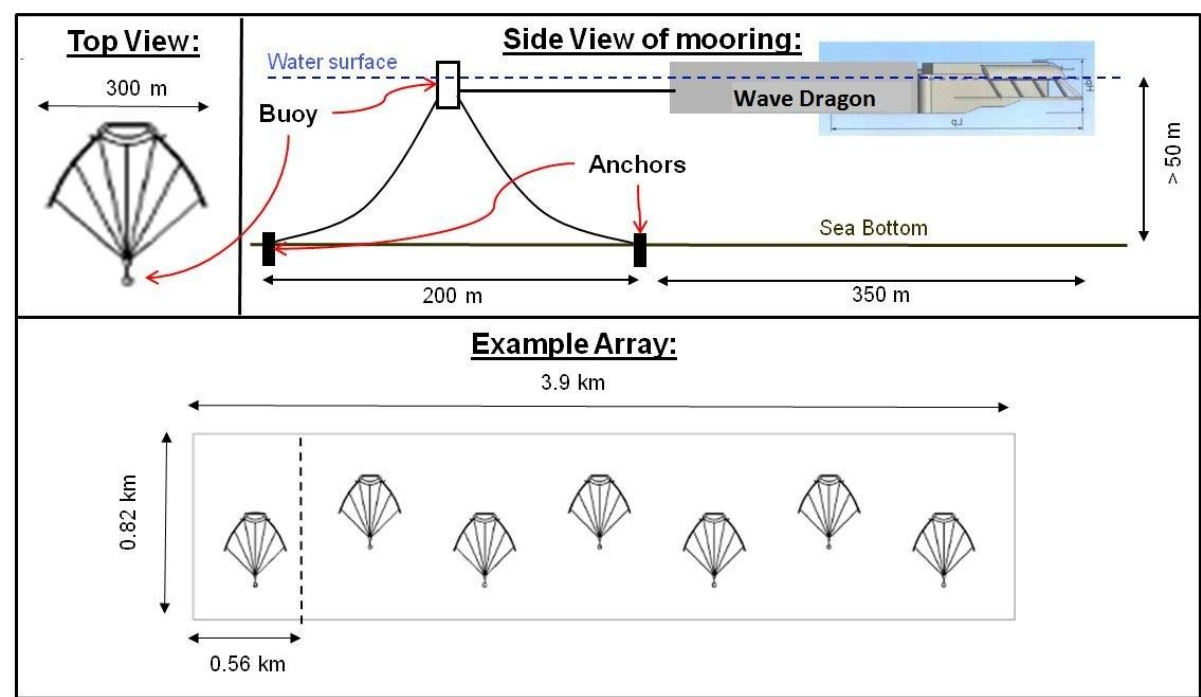

Figure 16 - Mooring configuration (Adapted from Wave Dragon) 


\section{Aquamarine Power}

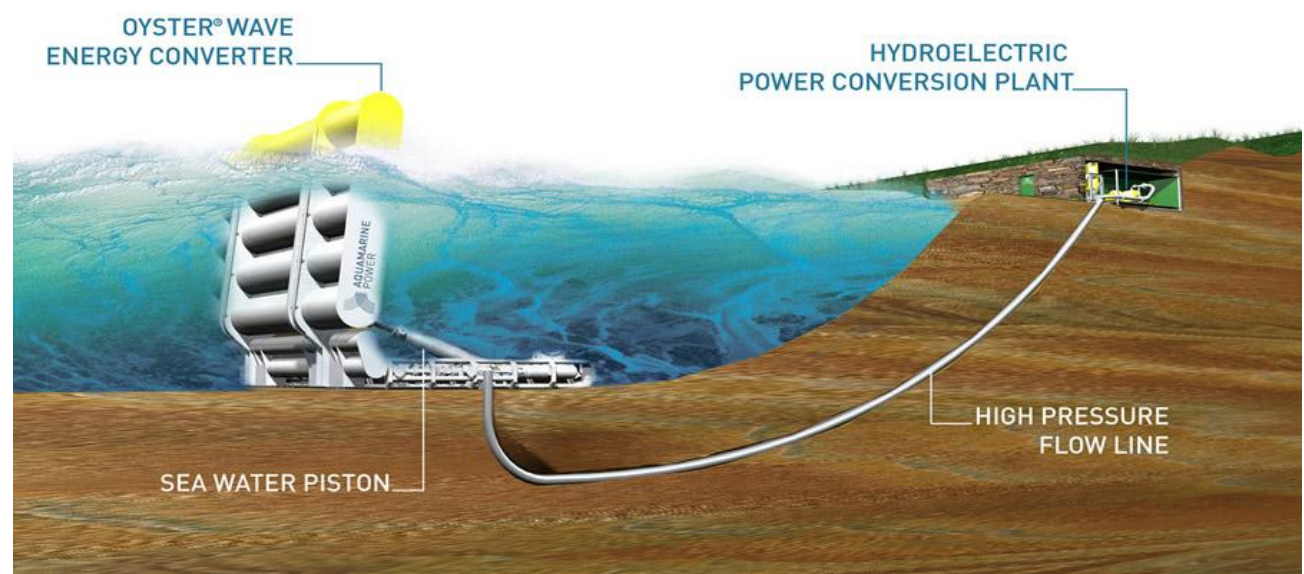

Figure 17 - Oyster 1 prototype operation (Source: Aquamarine Power)

\section{Specifications (Oyster 2)}

Water Depth

Flap Width

Flap Depth

Total Weight

Power Conversion

Generator

Converter

Rated Power Output

Anchor Type

Hydraulic Fluid

\section{Company Information}

Company Name

Website
12-16 m typical, 10-20 m possible

$26 \mathrm{~m}$

$13 \mathrm{~m}$

About 450 tons, including foundations

Water hydraulics

3-phase induction generator

Step-up transformer, to $11 / 33 \mathrm{kV}$

$800 \mathrm{~kW}$ (depending on deployment site)

Site-specific (e.g., a novel tension anchor solution has been developed for hard rock substrates; other substrates such as deep sand will use conventional offshore foundation solutions such as suction cans) Pressurized fresh water (closed-loop system)

Aquamarine Power Limited

www.aquamarinepower.com 


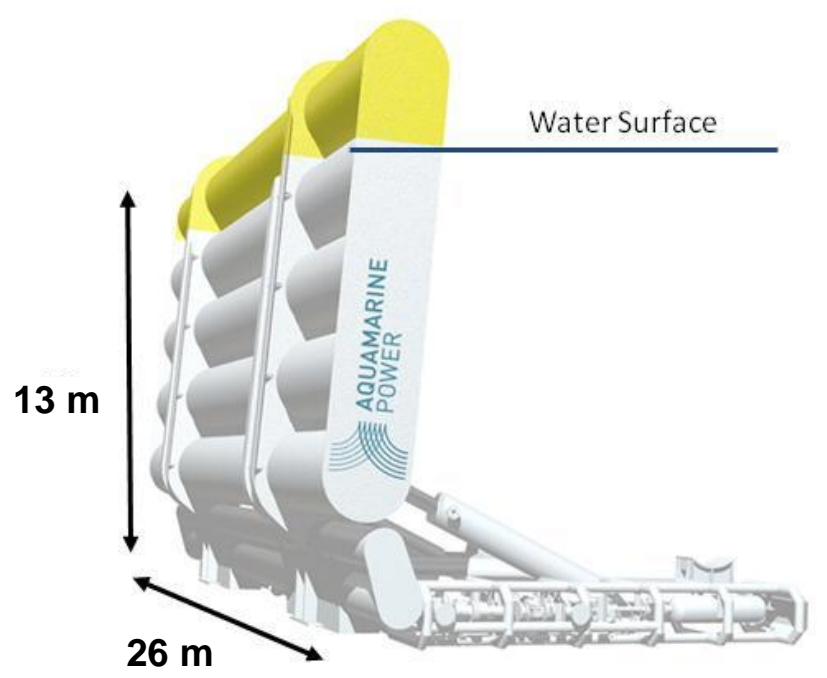

Figure 18 - Oyster 2 basic dimensions (Adapted from Aquamarine)

Principle of Operation-The Oyster concept is a large buoyant oscillator that completely penetrates the water column from the water surface to the seabed. It is a near-shore device, typically deployed in 10 to 20-m water depth, designed to capture the amplified surge forces found in these near-shore waves. The surge component in the waves forces the bottom-hinged "flap" to oscillate, which in turn compresses and extends two hydraulic cylinders mounted between the flap and the subframe, pumping water at high pressure through a pipeline back to the beach.

Onshore is a modified hydroelectric plant consisting of a Pelton wheel turbine driving a variable-speed electrical generator coupled to a flywheel. The Pelton turbine is an impulse turbine, commonly used in the hydropower industry. Impulse turbines are known to have high efficiencies at high pressure levels (typically >20 bars) and are considered proven technology. Power flow is regulated onshore using a combination of hydraulic accumulators, an adjustable spear valve, a flywheel in the mechanical power train, and rectification and inversion of the electrical output. The low-pressure return water passes back to the device in a closed loop via a second pipeline. A key design philosophy is to keep the offshore components as few and as simple as possible. The Oyster device has no major electrical components or active control functions operating in the offshore environment.

Device Anchoring and Footprint-The Oyster wave power device differs from all other wave power devices considered in this project because it is anchored directly to the seafloor and because it operates in relatively shallow water. Figure 19 shows an example device in a 5-MW installation, including device 
footprint size, pipeline layout, and spacing between devices. An initial foundation concept has been developed for rocky substrates, using tension anchors to provide high friction between the device and the seabed. Other foundation solutions are under development for substrates including deep sand and sand over rock.

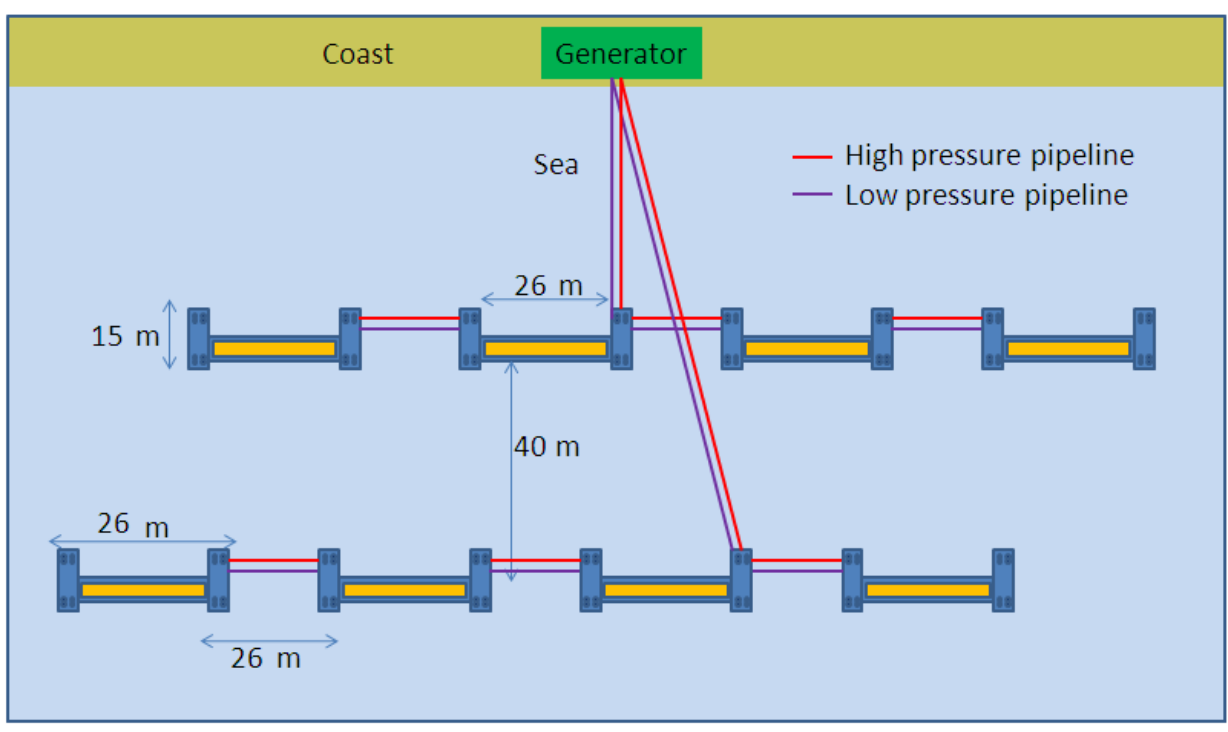

Figure 19 - Indicative device array and pipeline layout for a 5-MW Oyster 2 farm 


\section{Literature Review: Wave Energy Cost}

There have been a limited number of economic assessments of wave technology that include estimates of capital, operational, and levelized costs of electricity. Most focus on generic technology with cost profile details often omitted or incomplete. Furthermore, original works in the public domain are limited, and most studies reuse existing data, highlighting the need for more rigorous assessments.

In 2004, the EPRI began studying the system level design, performance, and costs of wave energy at pilot and commercial scales for five sites in the United States (Hawaii, Massachusetts, Maine, Oregon, and California). The studies resulted in the first comprehensive framework that detailed the installed capital cost of a wave energy device. (see Previsic et al. 2004a, 2004b, 2004c, 2004d, 2004e; Previsic et al. 2005).

The U.K. Carbon Trust (2006) addressed the cost competitiveness and cost reduction potential of both wave and tidal stream energy in an 18-month Marine Energy Challenge designed to accelerate the development of marine renewable technologies. Completed in the summer of 2005, the study estimated the costs of wave energy to be between $26-93 \phi / \mathrm{kWh}^{2}{ }^{\mathrm{a}}$ Costs were broken down into capital (Capex) and operational (Opex) expenses, but little background data detailing device type or resource parameters were provided, which makes the process difficult to reproduce.

In 2007, the U.K. Department of Trade and Industry (2007) assessed the COE ranges for 20 different renewable energy technologies, including wave and tidal. The cost calculation assumed a capacity factor of $30 \%$, a 20 -year plant life, a $95 \%$ progress ratio on capital, and a $90 \%$ progress ratio on operating costs once the United Kingdom reached 20-MW capacity. The cost of electricity was estimated in 2006 to be between 24 and $54 \phi / \mathrm{kWh} .^{\mathrm{b}}$ A best estimate of $38 \phi / \mathrm{kWh}$ represented the majority of both near-shore and offshore technologies.

A 2010 study commissioned by the U.K. Department of Energy and Climate Change (DECC) and the Scottish government (Ernst \& Young 2010) estimated the 2010 cost of generation from the United Kingdom's wave resource. Future project costs were also estimated assuming certain learning rates,

\footnotetext{
${ }^{a}$ Costs converted from pounds sterling (GBP) to U.S. dollars (USD) using the exchange rate from January 1, 2005, and scaled to 2011 USD using the electrical power generation producer price index found at http://data.bls.gov/timeseries/PCU221110221110.

${ }^{\mathrm{b}}$ Costs converted from GBP to USD using the exchange rate from January 1, 2006, and scaled to 2011 USD using the electrical power generation producer price index.
} 
deployment of capacity, and impacts of the United Kingdom's renewable obligation certificates, a program that requires electricity generators to produce an increased proportion of electricity from renewable sources. Commercial deployment costs were determined assuming $160 \mathrm{MW}$ of cumulative deployments globally.

Allan and colleagues (2010) used publicly available data to compare the economics of wave and tidal stream technology to commercial electric generation technologies. The work highlighted the need for additional renewable obligation certificates (incentives) for marine renewables in the United Kingdom to continue the development of wave energy.

At the Hydraulics \& Maritime Research Center, Dalton and Lewis (2011) selected five different device types and compared the energy output and financial returns at the Belmullet test site off the west coast of Ireland. Five devices were chosen for comparison: the Pelamis (attenuator), the Wave Dragon (overtopping), an oscillating water column, a multipoint absorber, and a hydro pump type. Device costs were obtained from communication with device developers and previous reports.

In the following figures, literature review results are compared to the three generic wave technology cost profiles that were independently developed for this study. Costs were normalized to 2011 USD by adjusting for inflation using the U.S. Producer Price Index (NAICS 221110) for electric power generation. $^{\text {a }}$

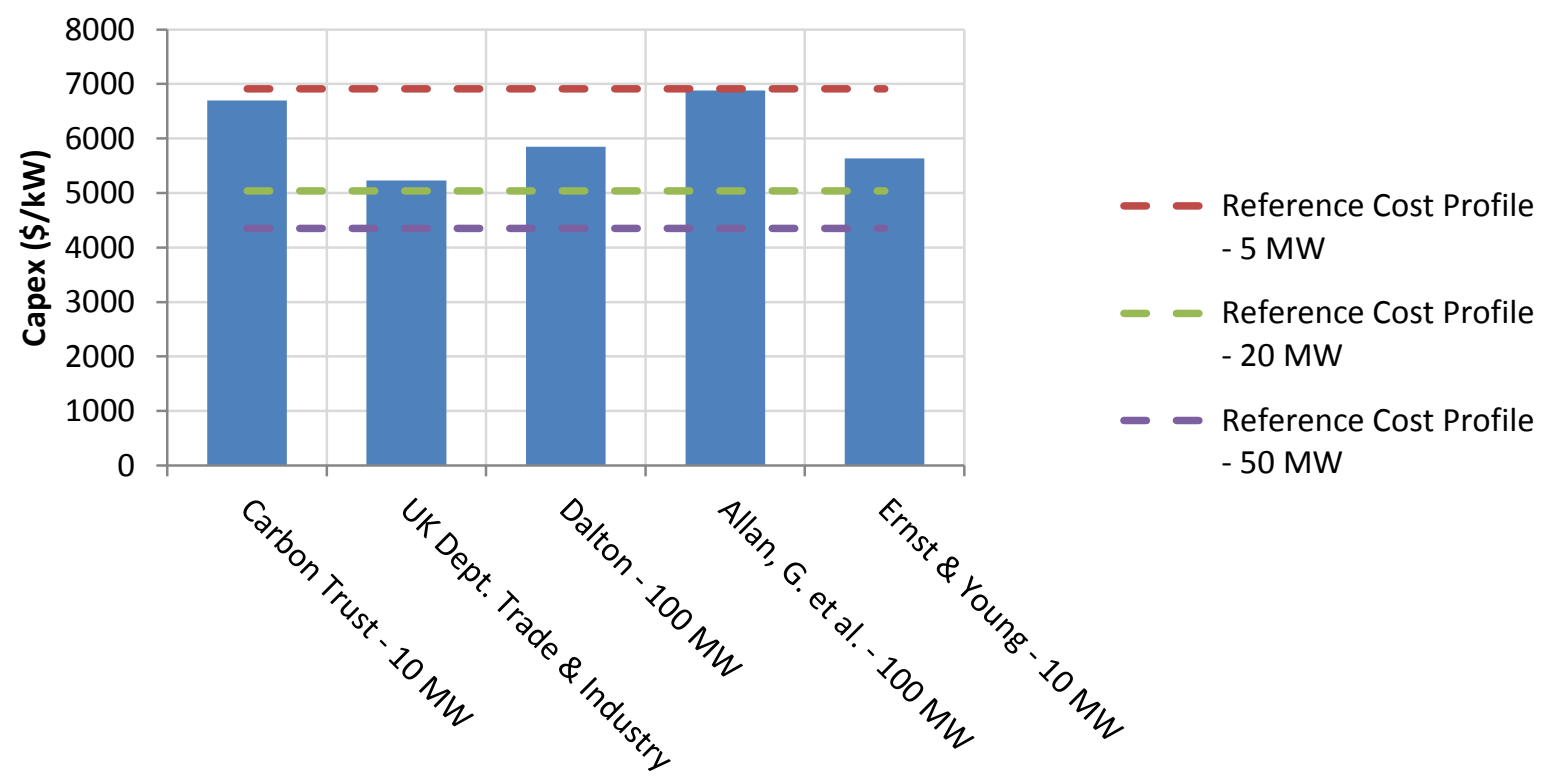

Figure 20 - Capex from literature review vs. study life-cycle cost profiles at 5-, 20-, and 50-MW capacity

\footnotetext{
${ }^{\text {a }}$ See http://data.bls.gov/timeseries/PCU221110221110 for more information.
} 


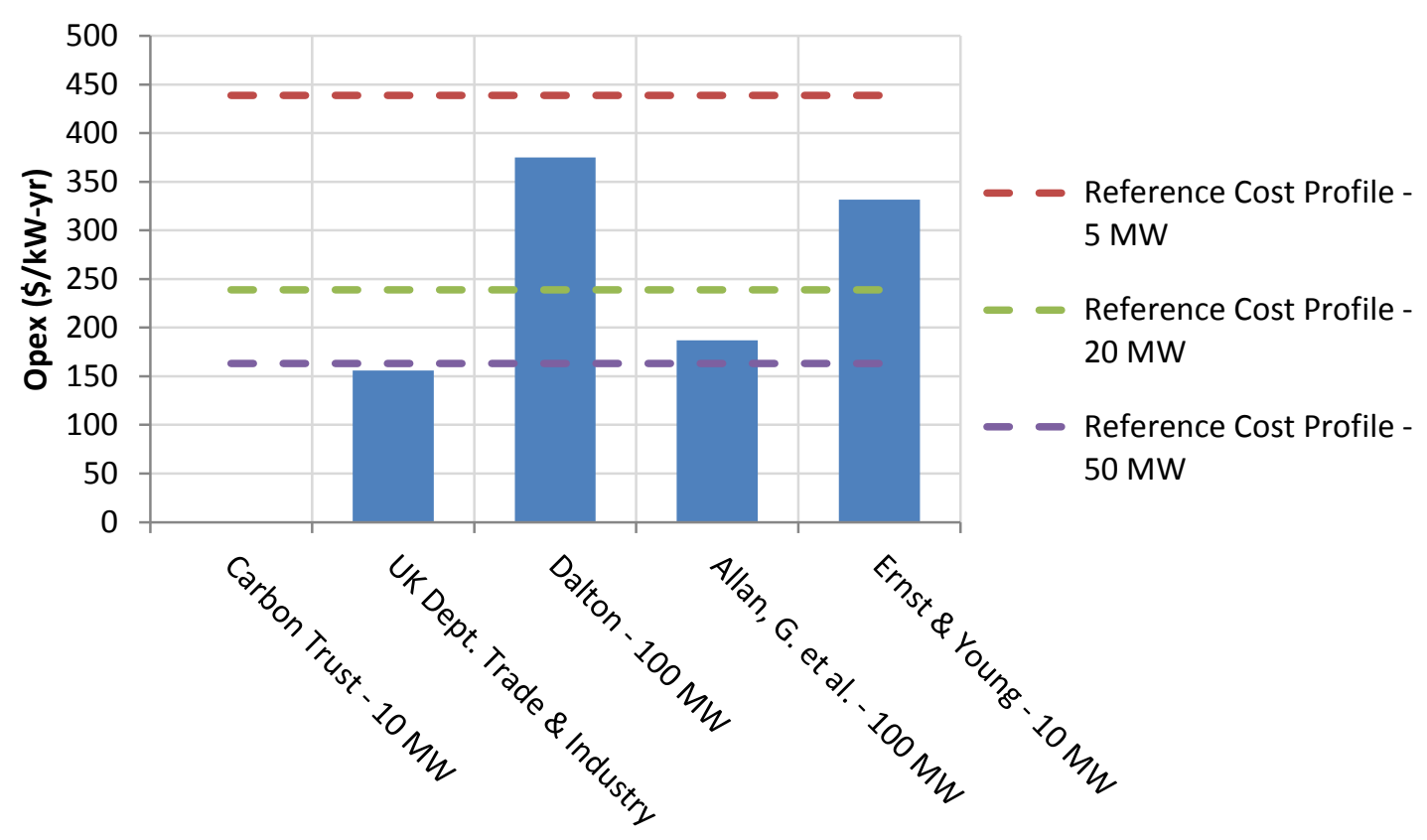

Figure 21 - Opex values from literature review vs. study life-cycle cost profiles at 5-, 20-, and 50-MW capacity

The range of the Capex and Opex costs that were found in this review indicates the high uncertainty with these costs. Further work to narrow these uncertainty bands is essential to establishing the life-cycle costs, but the cost estimates developed in this study are generally within the range of previous cost estimates. 


\section{Cost Assessment Methodology and Assumptions}

There is limited experience with the deployment and operation of MHK technologies. Most full-scale deployments to date are pilot projects that have limited value for identifying commercial cost profiles. Furthermore, most cost profiles in the MHK sector are commercially sensitive; the raw data used in this analysis, were obtained under nondisclosure agreements.

This team's cost assessment differs from more traditional assessments in that it does not rely solely on prototype cost data, but uses pilot plant data to inform and drive techno-economic models. These models assume that initial early-adopter issues are resolved and reliability figures from similar technology used in other sectors are attained. Some technologies have already come to the point where such reliability is proven, but it is expected that, across the industry, such numbers are attained once a cumulative installed capacity base of $100 \mathrm{MW}$ is achieved. To date, cumulative installed capacity of wave technologies is on the order of $5 \mathrm{MW}$.

Cost, performance, and economic assessments are heavily influenced by site conditions. Resource power density drives the cost of electricity, as is the case for most renewable energy generation. Power density for wave energy is measured in kilowatts per meter wave front $(\mathrm{kW} / \mathrm{m})$. This report outlines a typical cost profile the reference site in Northern California. The team subsequently investigated the sensitivity of the cost of electricity to changes in the resource strength.

The typical cost and performance breakdowns were developed from technical specifications supplied by leading device manufacturers. Because commercial wave technology development is in an early stage, technical approaches are significantly diverse, similar to the state of wind turbine industry development in the early 1970s. Significant differences in cost, performance, and economic profiles exist between different technologies being developed Today. Instead of quantifying these differences, this analysis provides cost averages for leading designs that have reached a sufficient level of design maturity to be properly benchmarked. Among the technologies assessed, the team selected the lowest cost contenders and averaged the available data to generate cost profiles representative of the likely cost breakdown. The criteria for selecting these technologies included device performance data, structural details, and design maturity as follows:

- The structural cost assessment assumes that the structural elements of the machines were built from mild steel in a U.S. manufacturing facility. National averages for labor rates and 


\section{revision}

productivity were used to develop the cost breakdown. The team assumed that a three-coat epoxy-based corrosion protection system was used on all surfaces.

- The capital cost assessment of the power train was developed from component cost build-ups using a wide range of cost estimates from suppliers.

- Failure rate assessments were carried out on a component and subsystem level to develop suitable intervention cycles for the different technologies under development. Expert opinions were solicited on the required regular maintenance cycles of different components and subsystems.

- Detailed marine operational procedures required for installing and operating these devices were outlined to determine the installation and operational costs. The team used long-term averages (spanning the past five years) of vessel and crew costs typical for North American marine operational activities in the assessment. Vessel hire rates are driven by demand and fluctuate significantly over time.

- Insurance costs were assumed to be $2 \%$ of device Capex at the single-unit scale, which is consistent with rates used in the offshore industry for one-off construction projects. At commercial scales, the team assumed that these costs were reduced to a level consistent with onshore wind, which is at about $0.5 \%$.

- Cost reduction potential as a function of scale was assessed by evaluating the potential cost reductions that could be borne from increased scales in manufacturing processes and operational efficiencies at different deployment scales.

- No technical improvements in device performance or design were considered.

- All costs given in this report use 2011 as the base year unless specifically stated otherwise.

\section{Data Sources}

Over the past decade, RE Vision has developed a significant number of technoeconomic models on different technologies under development by different industry players. These models were used in more than 30 studies for government organizations, investment firms, and strategic investors. The team incorporated a selected set of these technoeconomic models into this cost study. RE Vision performed an independent cost, performance, and economic assessment of the technologies, instead of relying only on manufacturers' data sets.

A technoeconomic model links design parameters and cost models to allow sensitivity studies on the cost of electricity with respect to different cost drivers such as resource characteristic, design variations, site conditions, and supply chain, among others. Because there is limited design convergence and optimal 
design parameters are not well understood, these models offered insight into the principal cost drivers and helped to correlate and optimize specific technology selections for the deployment sites of interest.

To enhance cost prediction accuracy, the team also included the following elements:

1. A detailed review of U.S. and global steel manufacturing cost profiles

2. Reference model efforts that were integrated into modeling efforts, which included three MHK devices that were assessed in the first year of performance under this programmatic DOE effort

3. Reference model efforts that evaluated the cost for environmental compliance and permitting of different MHK sectors

4. Independent detailed review of installation and operational cost drivers.

\section{Capacity Factors and Device Performance}

Capacity factors are typically a function of resource characteristics (e.g., variability and strength). In reality, however, the designer must balance the device performance against the higher cost of increasing the rated capacity of the power conversion system (which comes at a cost and part-load efficiency penalty) to yield an economic optimal configuration.

Technologies that are deployed by early adopters also tend to be more expensive than their commercial counterparts. As a result, their economic optimal capacity factor tends to be lower. To allow for apples-toapples comparisons between technologies on a dollar per kilowatt basis, the rated capacity of the technologies was adjusted so that the device would yield $30 \%$. These capacity factors were predetermined to be near an economic optimum once these technologies reach a commercial scale.

Figure 22 shows an example of how choosing the rated power affects the annual energy production and capacity factor at the deployment site. It shows diminishing returns in annual energy production by increasing the device rated power (which in turn decreases the capacity factor). 


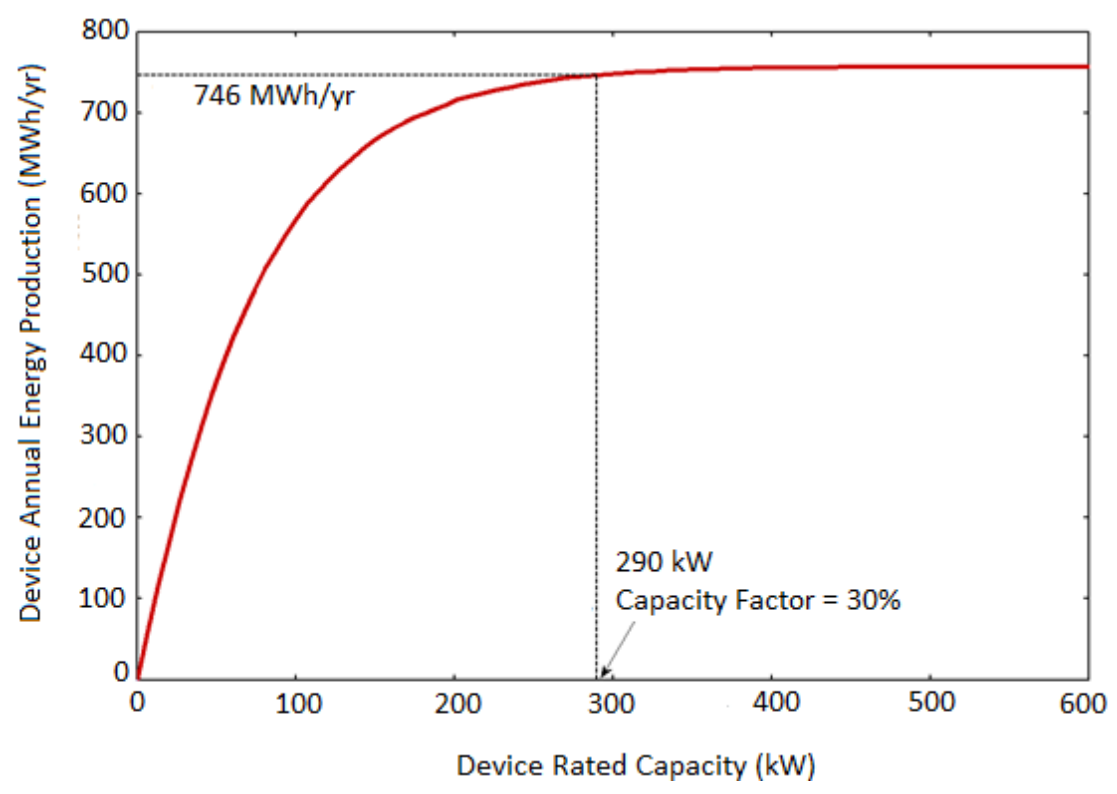

Figure 22 - Effect of device rating on annual energy production

To compute the device performance, a wave-to-wire model was applied to each technology in the following sequence:

1. The performance matrix was obtained from the manufacturer. This performance matrix shows the mechanical power the device generates as a function of the sea state but does not cap at the device's rated power.

2. Power-train efficiencies were applied to account for losses between the mechanical power generated and the electrical power output. Mechanical to electrical efficiency of $80 \%$ was used for devices with a hydraulic power take off and $65 \%$ for oscillating water column (OWC) systems.

3. A power generation limit was superimposed onto the electrical output table, representing the machine rated power of the system. This limits the electrical power output of the device in sea states that generate rated or above rated power.

4. The power generation table was multiplied by the frequency of reoccurrence of each sea state at the reference site in northern California. This step allowed the team to compute device performance using an initially assumed device rated capacity.

5. The final step in the process was to iteratively change the machine rated capacity until the machine capacity factor equals $30 \%$. This study also assumes that the technologies would have an availability of $95 \%$, which is consistent with mature renewable energy technologies. Neglected in this assessment is a cut-in wave height, below which the machine does not generate any power. 
This was neglected because the impact of considering this cut-in limit has a very minor effect on annual energy produced. Figure 23 visualizes the steps in the device performance calculation.

1. Performance Matrix from Device Manufacturer

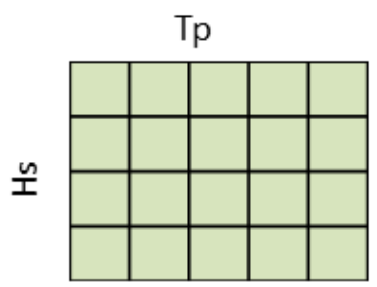

2. Powertrain Efficiency

$$
\eta_{\text {mech } \rightarrow e l e c}
$$

3. Impose a Power Generation Limit

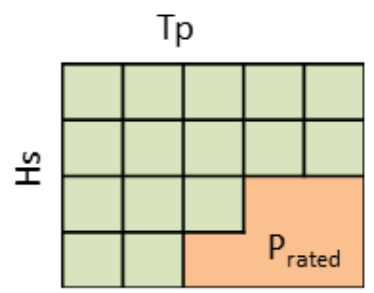

5. Iterate on $\mathrm{P}_{\text {rated }}$ until the machine capacity factor $=30 \%$

1. $P_{\text {rated }} \rightarrow C F=22 \%$

2. $P_{\text {rated }} \rightarrow C F=32 \%$

3. $P_{\text {rated }} \rightarrow C F=30 \%$

Figure 23 - Device performance assessment process

Figure 24 show the effect of imposing a rated capacity on the power matrix.
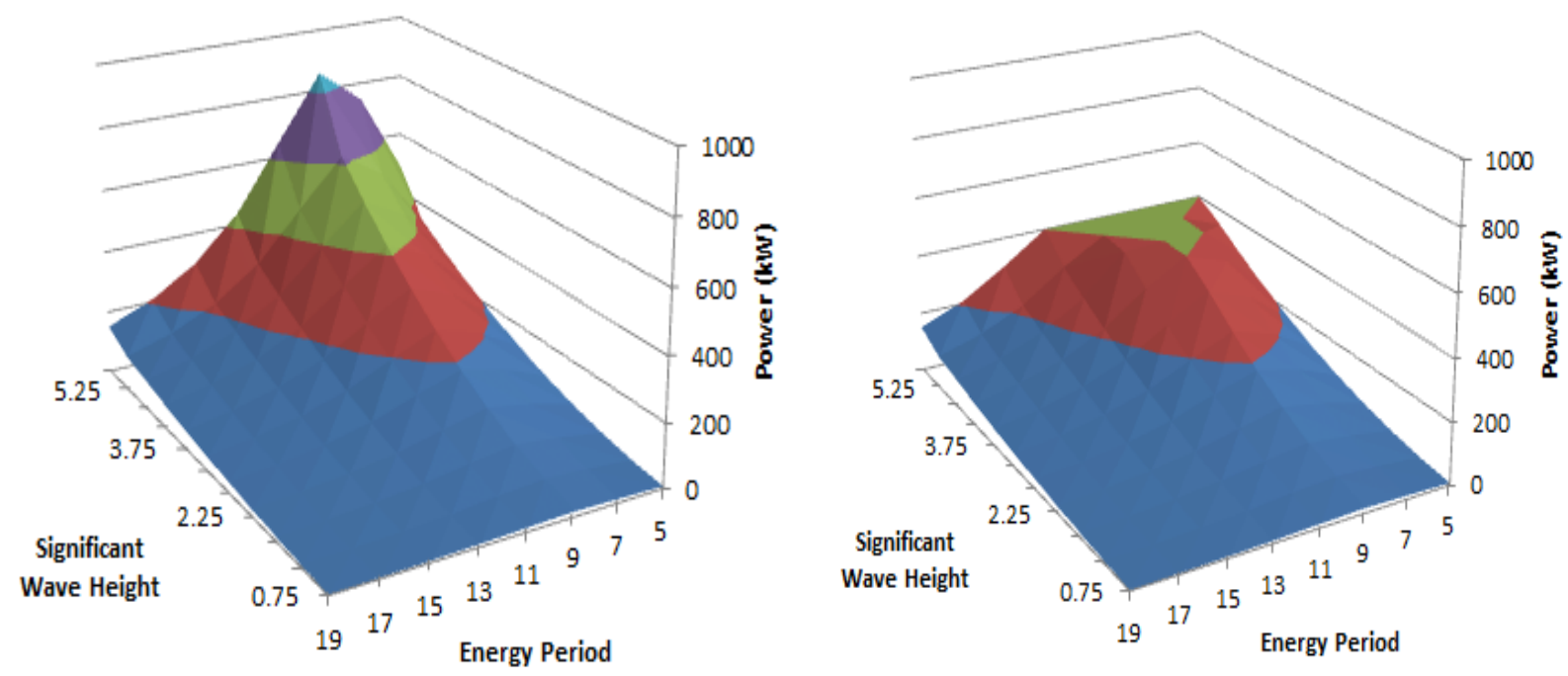

Figure 24 - Unconstrained mechanical power generated (left), power output constrained by rated capacity limit (right) 


\section{Uncertainties in the Cost Estimating Process}

In the early stages of development, costs are typically underestimated, increasing as the technologies move toward commercial maturity. The actual building and operational costs of a pilot device and/or pilot MHK farm will eventually form a better foundation for future cost studies. Once a technology reaches commercial maturity, volume production will start driving down cost. Figure 25 shows the typical cost projection as a function of design maturity.

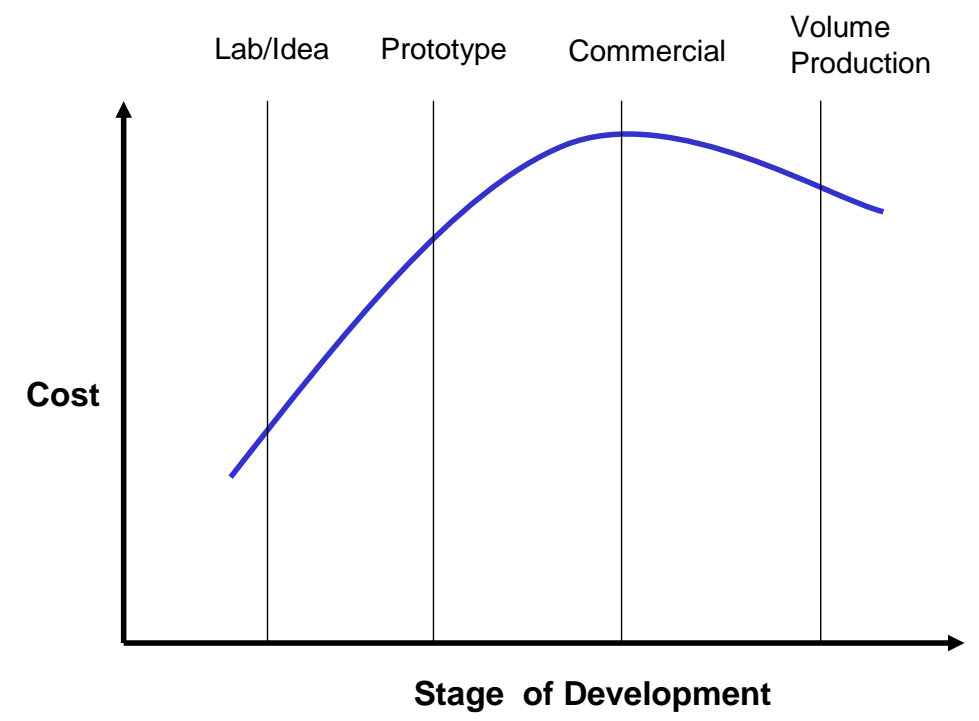

Figure 25 - Cost projection as a function of development status

Based on experience of estimating energy project cost, EPRI has developed a cost estimate rating table (see Table 5), which assesses the likely range of uncertainty based on the technology's design maturity and the amount of detail that figures into the cost estimate.

Table 5 - EPRI Cost Estimate Rating Table Showing Cost Uncertainty (in \%)

\begin{tabular}{|l|c|c|c|c|c|}
\hline $\begin{array}{l}\text { Cost Estimate } \\
\text { Rating }\end{array}$ & $\begin{array}{c}\text { A } \\
\text { Mature }\end{array}$ & $\begin{array}{c}\text { B } \\
\text { Commercial }\end{array}$ & $\begin{array}{c}\text { C } \\
\text { Demonstration }\end{array}$ & $\begin{array}{c}\text { D } \\
\text { Pilot }\end{array}$ & $\begin{array}{c}\text { E } \\
\text { Conceptual } \\
\text { (Idea or } \\
\text { Lab) }\end{array}$ \\
\hline A. Actual & 0 & - & - & - & - \\
\hline B. Detailed & -5 to +5 & -10 to +10 & -15 to +20 & - & - \\
\hline C. Preliminary & -10 to +10 & -15 to +15 & -20 to +20 & -25 to +30 & -30 to +50 \\
\hline D. Simplified & -15 to +15 & -20 to 20 & -25 to +30 & -30 to +30 & -30 to +80 \\
\hline E. Goal & - & -30 to +70 & -30 to +80 & -30 to +100 & -30 to +200 \\
\hline
\end{tabular}

To reduce the uncertainty, this assessment used only data from devices that are well advanced and have undergone testing at sea. Using technical data from moderately mature designs allows the cost assessment to be based on fairly refined designs, thereby reducing uncertainty. Based on Table 5 all the cost numbers 
given in this report have an uncertainty range of $\pm 30 \%$, because engineering data were obtained from devices that have undergone at least some pilot testing and the assessment rating can be characterized as preliminary or simplified.

\section{Economies of Deployment Scale}

To date, only small pilot and early adopter systems have been deployed, and operational experience is limited to a few months of in-ocean testing in most cases (with a few exceptions that have operated continuously for more than a year). The cost of single units deployed can easily be two to three times the cost of a 100-MW commercial system.

As plant size increases, economies of scale can be leveraged in the manufacturing process, installation and O\&M processes, infrastructure costs such as the electrical grid connection, and permitting and environmental monitoring. As a result, the cost drivers for a commercial deployment tend to be very different from those in an early commercial plant.

\section{Cost Reduction as a Function of Cumulative Installed Scale}

Industry-wide cost reduction can be well described using learning curves. Learning curve theory was originally developed to describe economies of scale in manufacturing processes. Investigators observed that every time the total number of parts manufactured doubled, the unit cost was reduced by a certain percentage (Yelle 1979). This theory was later applied to a wide range of other industries, including the electricity generation industry. Figure 26 shows the installed cost per megawatt of installed capacity as a function of the cumulatively deployed capacity for three different technology sectors. 


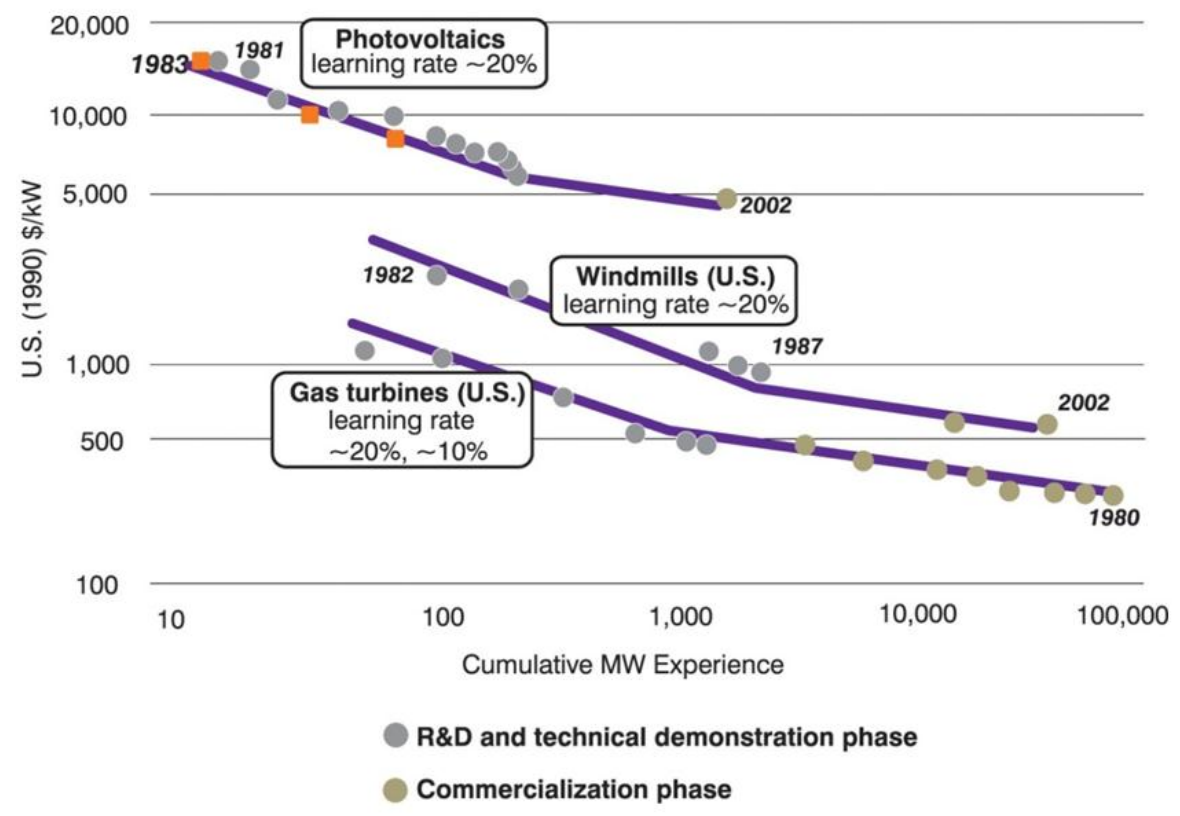

Figure 26 - Historical learning curves (Source: Learning Curves (Source: July 2008 Issue of Project Finance)

To put the cost of electricity from these emerging technologies into perspective, it is important to consider industry-wide cost reductions that have governed the adoption of other renewable technologies and their respective learning rates. Wind technology, for example, has seen industry-wide cost reduction progress ratios on the order of $85 \%$, meaning that the cost of electricity was reduced by $15 \%$ with each doubling of cumulative installed capacity (Junginger and Faaij 2004).

\section{Cost Centers}

For the purpose of this assessment, the team defined a number of cost centers that would allow sufficient detail to provide a solid understanding of the impacts of the major cost drivers. The following categories are included in Capex:

Installation-All costs for activities associated with the plant construction, specifically transport, subseacable installation, mooring installation, and device deployment and commissioning. The plant is assumed to terminate onshore. No cost is included for the interconnection of the plant with the electrical grid.

Permitting and Environmental Compliance-All cost components required to permit a plant. Uncertainties in this cost category are high, because there is limited experience to draw from in the United States. These costs include site baseline assessments, environmental baseline studies, monitoring equipment, and consultant fees. 
Infrastructure-All costs, excluding the cost of the devices and moorings themselves. This includes subsea cables, cable landing to shore, dockside improvements, and specialized vessels used to operate the project.

Mooring-All costs for components required to keep the device on station. This may include, among others, mooring chains, anchors, piled foundations, and shackles and other mooring components.

Structural-Costs for the main structural components, typically built from structural steel, concrete, or fiberglass.

Power Take Off-All costs for components and subsystems required to convert the primary mechanical energy into electricity that can be fed into the electric grid. Subsystems include items such as the generator, the gearbox, the hydraulic system, the frequency converter, the step-up transformer, and the electrical riser cable.

Opex costs are divided into the following cost centers. To normalize costs from operational activities, such costs are brought back to present value, divided by the plant's operational life and the plant's rated capacity, to yield a unit of dollars per kilowatt capacity per year $(\$ / \mathrm{kW}$-year).

Insurance - Typically on the order of $2 \%$ of capital cost for one-off offshore installations. As technology matures and technology-related risks are reduced, insurance costs are expected to reduce to a level similar to those for wind energy today.

Marine Monitoring-Many early-adopter projects expected to require ongoing monitoring of environmental effects from the plant to satisfy regulatory agencies. This includes items such as active and passive acoustic monitoring, fish studies, and sediment transport studies.

Operations - All expenses associated with operating, maintaining, and repairing the plant. This includes, among others, labor costs, fuel costs, management expenses, and facility leases.

Replacement Parts - Costs for all parts that require replacement over the life of a project. Replacement parts cost is computed by using the L50 life of the component as the replacement interval. 


\section{Calculation of Cost of Electricity: Methodology and Assumptions}

As with any capital-intensive project, funds must be financed through a combination of debt and equity. A power producer must earn revenues to pay back the bond principal plus interest to bond holders as well as a return to equity holders. Furthermore, state and federal income taxes are paid on net revenues (gross revenues less debt interest expense and tax depreciation expense). A fixed charge rate (FCR) is used to approximate the annualized revenues required to recover the cost associated with financing a plant including bond interest, return to equity, and tax considerations. For this analysis, the team approximated the FCR as a function of the effective tax rate, present value of depreciation, discount rate, and investment period using the methodology presented (Short et al. 1995).

$$
\begin{aligned}
& \mathrm{FCR}=\frac{\left(1-\mathrm{T} * \mathrm{PV}_{\mathrm{depr}}\right)}{1-\mathrm{T}} * \mathrm{CRF} \\
& \mathrm{CRF}=\frac{\mathrm{d}}{1-\frac{1}{(1+\mathrm{d})^{\mathrm{N}}}} \\
& \mathrm{PV}_{\mathrm{depr}}=\sum_{\mathrm{t}=1}^{\mathrm{N}_{\mathrm{depr}}} \text { MACRS }_{\mathrm{t}} * \frac{1}{(1+\mathrm{d})^{\mathrm{t}}}
\end{aligned}
$$

where

$\mathrm{FCR}=$ fixed charge rate $\mathrm{T}=$ effective rate of income tax $\mathrm{PV}_{\text {depr }}=$ present value of depreciation

$\mathrm{CRF}=$ capital recovery factor

$\mathrm{d}=$ discount rate

$\mathrm{N}=$ investment period (years)

MACRS = annual Modified Accelerated Cost Recovery System (MACRS) depreciation fraction $\mathrm{N}_{\text {depr }}=$ depreciation period (years)

\section{Discount Rate}

The discount rate is assumed to be the after-tax weighted average cost of capital (WACC; Brealey et al. 2008), which is a function of the expected rate of return on debt $-r_{D}$, debt ratio $-D /(D+E)$, effective income tax rate - $T$, expected rate of return on equity - $r_{E}$, and equity ratio - $E /(D+E)$. 
Nominal After Tax WACC $=r_{D} *(1-T) * \frac{D}{D+E}+r_{E} * \frac{E}{D+E}$

where

$r_{D}=$ expected rate of return on debt

$\mathrm{T}=$ effective rate of income tax

$\mathrm{D}=$ market value of debt

$\mathrm{E}=$ market value of equity

$\mathrm{r}_{\mathrm{E}}=$ expected rate of return on equity

The discount rate is used to calculate a CRF. When the CRF is applied to a present value lump sum (e.g., total capital cost), the result is an equivalent uniform annual value in each year of the investment period $(\mathrm{N})$.

\section{Tax Depreciation}

Equipment depreciates over time and the depreciated value may be expensed from gross income to reduce the taxable income. As with tax depreciation schedules for wind and solar technologies, MHK technologies use a 5-year MACRS tax depreciation schedule. Table 6 gives the annual 5-year MACRS depreciation fractions for this analysis (Stermole and Stermole 2009).

\section{Table 6 - MACRS Depreciation Schedule}

\begin{tabular}{|l|r|}
\hline Year & Depreciation \\
\hline 1 & $20 \%$ \\
\hline 2 & $32 \%$ \\
\hline 3 & $19.2 \%$ \\
\hline 4 & $11.52 \%$ \\
\hline 5 & $11.52 \%$ \\
\hline 6 & $5.76 \%$ \\
\hline
\end{tabular}

\section{Financial Input Assumptions}

Table 7, Table 8, Table 9, and Table 10 give the assumptions for the financial input parameters used in this study for MHK technologies. These tables also include the calculated values for the WACC, CRF, and FCR. 
Table 7 - Assumed Financial Input Parameters

\begin{tabular}{|l|r|}
\hline Parameter & Value \\
\hline Evaluation Period - N & 20 years \\
\hline Nominal Rate of Return on Equity (RROE) - $r_{E}$ & $13 \%^{\mathrm{a}}$ \\
\hline Inflation Rate & $3 \%^{\mathrm{b}}$ \\
\hline Debt Fraction & $50 \%^{\mathrm{c}}$ \\
\hline Nominal Debt Interest Rate - $\mathrm{r}_{\mathrm{D}}$ & $8 \%^{\mathrm{d}}$ \\
\hline Nominal Debt Interest Rate During Construction & $8 \%{ }^{\mathrm{e}}$ \\
\hline Corporate Tax Rate (combined federal and state) - T & $40 \%$ \\
\hline Depreciation Schedule (MHK) & 5 -year MACRS \\
\hline
\end{tabular}

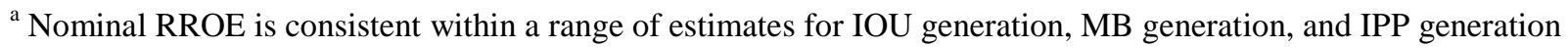
given by EEI (2010), Klein (2009), and NETL (2008).

${ }^{\mathrm{b}}$ Conservative estimate of inflation based on historical U.S. gross domestic product (GDP) deflator data over the last 30 years. See http://research.stlouisfed.org/fred2/data/GDPDEF.txt. Accessed November 2010.

${ }^{\mathrm{c}}$ Debt fraction is consistent with estimates given by EEI (2009), Klein (2009) and NETL (2008).

${ }^{\mathrm{d}}$ The EIA (2010) forecasts a 7.6\% average interest rate for AA rated utility bonds through the year 2035. The cost of debt for IPPs is frequently indexed based on benchmark interest rates like the London Interbank Offered Rate with historical 1-month rates averaging 4.3\% (Wall Street Journal 2010) or the Effective Federal Funds Rate with rates averaging 5.5\% since 1954 (Board of Governors of the Federal Reserve (2010). After applying a mid-point projectspecific risk premium of 3\% (NETL 2008), long-term effective debt interest rates are estimated to exist from $7.3 \%$ to $8.5 \%$.

${ }^{\mathrm{e}}$ The debt interest rate during construction is assumed to be consistent with the term debt (Harper et al. 2007).

Table 8 - Nominal Rate of Return on Equity

\begin{tabular}{|l|r|r|r|}
\hline Source & $\begin{array}{r}\text { Investor-Owned } \\
\text { Utility (IOU) } \\
\text { Generation }\end{array}$ & $\begin{array}{r}\text { Merchant-Based } \\
\text { (MB) Generation }\end{array}$ & $\begin{array}{r}\text { Independent Power } \\
\text { Producer (IPP) } \\
\text { Generation }\end{array}$ \\
\hline $\begin{array}{l}\text { Edison Electric Institute } \\
\text { (EEl; 2010) }\end{array}$ & $\begin{array}{r}10.0-12.9 \%(11.2 \% \\
\text { average) }\end{array}$ & & \\
\hline $\begin{array}{l}\text { California Energy Commission (Klein } \\
\text { 2009) }\end{array}$ & $11.9 \%$ & 14.5 & \\
\hline $\begin{array}{l}\text { National Energy Technology Laboratory } \\
\text { (NETL; 2008) }\end{array}$ & & $\begin{array}{r}20 \% \text { (fossil-based } \\
\text { resources) }\end{array}$ \\
\hline
\end{tabular}

Table 9 - Debt Fraction

\begin{tabular}{|l|r|r|r|}
\hline Source & IOU Generation & MB Generation & IPP Generation \\
\hline EEI 2009 & $59 \%(2008) ; 56 \%(2006-2007)$ & & \\
\hline Klein 2009 & $48 \%$ & $40 \%-60 \%$ & $45 \%-70 \%$ \\
\hline NETL 2008 & $45 \%-70 \%$ & & \\
\hline
\end{tabular}


Table 10 - Financial Parameter Summary

\begin{tabular}{|l|r|}
\hline Parameter & Value \\
\hline Nominal After Tax WACC & $8.90 \%$ \\
\hline Real After Tax WACC & $5.73 \%$ \\
\hline Real CRF & 0.085 \\
\hline Present Value of Depreciation - PV depr & 0.794 \\
\hline Real FCR & 0.124 \\
\hline
\end{tabular}

The WACC is calculated in nominal terms and converted to a WACC in real terms. The real WACC is used to calculate the real CRF and real FCR. Therefore, the simple COE values given in this report are calculated in terms of real 2011 USD.

\section{Cost of Energy Methodology and Assumptions}

The cost of producing energy from a wave energy conversion (WEC) system can be calculated as the total cost for building and operating a plant divided by the total energy produced by the plant over the economic lifetime. Total costs comprise capital, O\&M, and transmission costs. Transmission costs are described in more detail in Section 8.

\section{Annualized Costs of Energy}

For this analysis, the team used the simple annualized cost of energy, or LCOE (in dollars per megawatthour) to develop the wave energy supply curves. LCOE is also referred to in its simplified form as COE in subsequent chapters. In general, the COE for a given technology is defined as the annualized cost to build and operate a plant divided by the annual energy production (AEP) from that plant (Short et al. 1995).

$\operatorname{COE}\left(\frac{\$ / \mathrm{yr}}{\mathrm{kWh}}\right)=\frac{\text { Annualized Cost }}{\text { Annual Energy Production }}$

Annualized Cost $\left(\frac{\$}{\mathrm{yr}}\right)=$ Capacity $*(\mathrm{FCR} * \mathrm{ICC}+\mathrm{CRF} *$ TRANS + OM $)$

$\operatorname{AEP}\left(\frac{\mathrm{kWh}}{\mathrm{yr}}\right)=$ Capacity $* \mathrm{CF} * \eta_{\text {avail }} * \eta_{\text {trans }} * 8760\left(\frac{\mathrm{hr}}{\mathrm{yr}}\right)$

$\operatorname{COE}\left(\frac{\$}{\mathrm{kWh}}\right)=\frac{\mathrm{FCR} * \mathrm{ICC}+\mathrm{CRF} * \text { TRANS }+ \text { OM }}{\mathrm{CF} * \eta_{\text {avail }} * \eta_{\text {trans }} * 8760}$

where

Capacity = plant nameplate capacity $(\mathrm{kW})$ 
$\mathrm{CF}=$ annual average capacity factor

$\mathrm{FCR}=$ fixed charge rate $\left(\mathrm{yr}^{-1}\right)$

$\mathrm{ICC}^{\mathrm{a}}=$ installed capital cost $(\$ / \mathrm{kW})$

TRANS $=$ total transmission cost to connect a plant to the grid/load center $(\$ / \mathrm{kW})$

$\mathrm{CRF}=$ capital recovery factor $\left(\mathrm{yr}^{-1}\right)$

$\mathrm{OM}=$ effective annual operation and maintenance cost $(\$ / \mathrm{kW}-\mathrm{yr})$

$\eta_{\text {avail }}=$ availability of the wave energy plant

$\eta_{\text {trans }}=$ transmission efficiency from the plant to the grid interconnection

\footnotetext{
${ }^{\text {a }}$ Assuming that a 2-year construction period with $50 \%$ of the overnight capital cost (i.e., the previously defined Capex) is financed in each year at an $8 \%$ nominal construction financing rate and a $40 \%$ effective rate of income tax, the present value installed capital cost is calculated to be about 1.05 times the overnight capital cost.
} 


\section{Reference Cost Profiles}

Cost profiles were developed by averaging the cost from different leading designs in this sector. RE Vision used a set of technoeconomic models that it developed over the past decade to establish these cost profiles. The lowest cost technologies were used to develop a "best-of-class" reference cost estimate. In addition, detailed performance, costs, and economic assessment work developed by the SNL-led reference model effort were used to refine the analysis. Because data were obtained from manufacturers under nondisclosure provisions, only aggregated data is presented in this report. However, the data presented was found to be representative of cost competitive devices under development.

The wave energy sector can be subdivided into onshore, near-shore, and deep-water technologies. This cost assessment focuses on devices that are installed in deep water. This sector has the most significant deployment potential because of fewer siting constraints.

The following cost and economic assessments are based on deployment at a hypothetical installation reference site. Table 11 shows the relevant parameters of the reference deployment site. The site was selected because it is representative of commercially viable sites on the U.S. West Coast.

Table 11 - Wave Reference Site Parameters

\begin{tabular}{|l|r|}
\hline Parameter & Value \\
\hline Deployment Area & Eureka, California \\
\hline Average Significant Wave Height (Hs) & $2.38 \mathrm{~m}$ \\
\hline Average Energy Period & $9.3 \mathrm{~s}$ \\
\hline Average Power Density & $33.5 \mathrm{~kW} / \mathrm{m}$ \\
\hline Water Depth & $70 \mathrm{~m}$ \\
\hline Distance to Shore & $5 \mathrm{~km}$ \\
\hline Wave Data Source & Wavewatch III \\
\hline Seabed Sedimentation & Sand/Mud \\
\hline
\end{tabular}

Data from four different wave energy conversion technologies were applied to the site. The team excluded one of the technologies because it showed COE estimates that were about twice the value of the leading contenders. The second device was excluded because there were limited data available to fully understand and validate design data, resulting in limited confidence in the output. The two remaining technologies were subsequently used to establish the baseline cost breakdowns shown in Figure 27 and Figure 28. Device rated capacities for both devices were more than $500 \mathrm{~kW}$ per machine in the reference wave climate. 


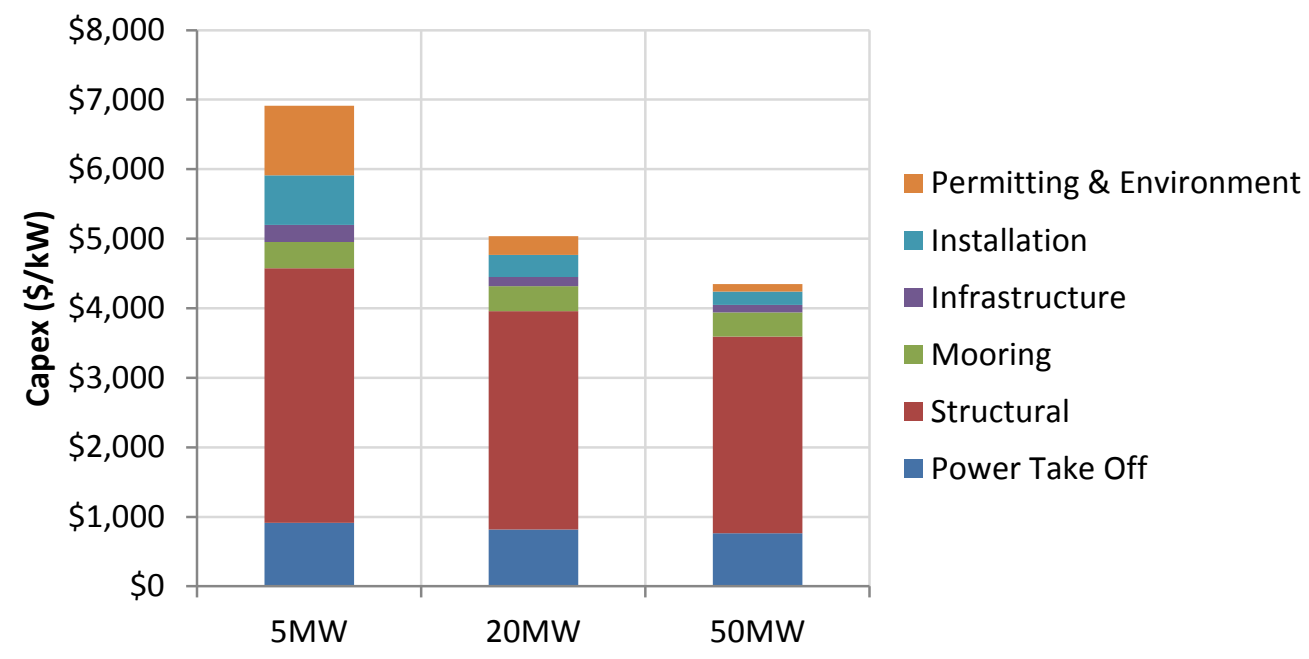

Figure 27 - Capital cost breakdown for a typical wave energy technology

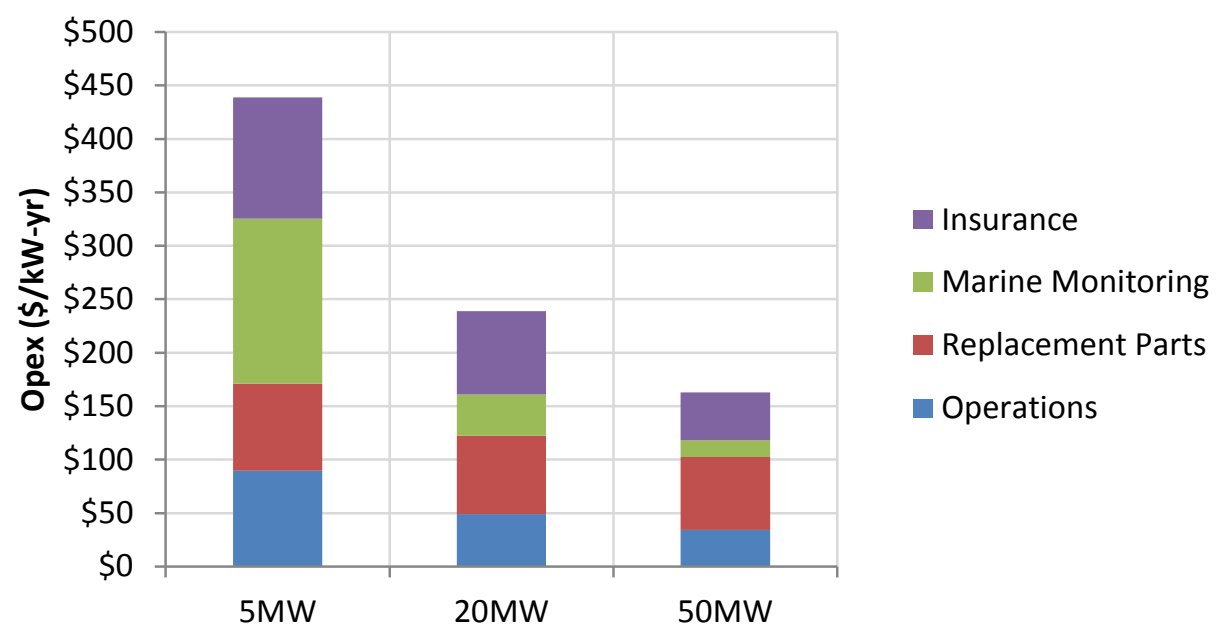

Figure 28 - Operational cost breakdown for a typical wave energy technology (in $\$ / k W$-year)

Table 12 summarizes the Capex and Opex costs for each cost center, the device performance, and the Capex and Opex contribution to the cost of electricity. 
Table 12 - Typical Cost, Performance and Economic Profiles for Wave Energy Plants (\$2011)

\begin{tabular}{|c|c|c|c|}
\hline \multirow{2}{*}{ Capex $(\$ / k W)$} & \multicolumn{3}{|c|}{ Plant Capacity } \\
\hline & $5 \mathrm{MW}$ & $20 \mathrm{MW}$ & $50 \mathrm{MW}$ \\
\hline Power Take Off & $\$ 915$ & $\$ 821$ & $\$ 764$ \\
\hline Structural & $\$ 3,662$ & $\$ 3,134$ & $\$ 2,828$ \\
\hline Mooring & $\$ 375$ & $\$ 360$ & $\$ 351$ \\
\hline Infrastructure & $\$ 249$ & $\$ 133$ & $\$ 103$ \\
\hline Installation & $\$ 708$ & $\$ 318$ & $\$ 194$ \\
\hline Permitting \& Environment & $\$ 1,003$ & $\$ 269$ & $\$ 107$ \\
\hline Total & $\$ 6,912$ & $\$ 5,035$ & $\$ 4,347$ \\
\hline Opex (\$/kW-yr) & $5 \mathrm{MW}$ & $20 \mathrm{MW}$ & $50 \mathrm{MW}$ \\
\hline Operations & $\$ 90$ & $\$ 49$ & $\$ 34$ \\
\hline Replacement Parts & $\$ 81$ & $\$ 73$ & $\$ 68$ \\
\hline Marine Monitoring & $\$ 154$ & $\$ 39$ & $\$ 15$ \\
\hline Insurance & $\$ 113$ & $\$ 78$ & $\$ 45$ \\
\hline Total & $\$ 438$ & $\$ 239$ & $\$ 162$ \\
\hline O\&M Percent of Capex & $6.3 \%$ & $4.7 \%$ & $3.7 \%$ \\
\hline Performance & $5 \mathrm{MW}$ & $20 \mathrm{MW}$ & $50 \mathrm{MW}$ \\
\hline Capacity Factor & $30 \%$ & $30 \%$ & $30 \%$ \\
\hline Availability & $95 \%$ & $95 \%$ & $95 \%$ \\
\hline Cost of Electricity ( $\mathbf{c / k W h )}$ & $5 \mathrm{MW}$ & $20 \mathrm{MW}$ & $50 \mathrm{MW}$ \\
\hline CAPEX Contribution & 30 & 22 & 19 \\
\hline O\&M Contribution & 22 & 12 & 8 \\
\hline Total & 52 & 34 & 27 \\
\hline
\end{tabular}

A brief discussion on the cost reductions for each cost-center follows:

1. Capex Power Take Off - Cost reductions in this category come largely from the ability to purchase parts and subsystems at larger quantities.

2. Capex Structural-This is the most significant contributor to the system. Costs for this category were determined by applying a manufacturing process model to the device CAD geometry. Cost reductions in this category come largely from the ability to spread tooling cost over more devices and process efficiency improvements in volume production.

3. Capex Mooring - Very small cost reductions are possible within this category, largely because of volume purchasing effects. 
4. Capex Infrastructure-These costs are dominated by the subsea electrical collector and transmission system. Cost reductions are largely due to the ability to leverage high initial fixed costs in larger deployments, which drive the total system costs.

5. Capex Installation-These costs are dominated by mobilization costs for small numbers of units. As the capacity per plant grows, it makes sense to mobilize different equipment that allows better deployment efficiencies.

6. Opex-Opex will reduce as a function of (1) increasing device reliability, resulting in fewer replacement parts and operational interventions; (2) reduced insurance costs because of reduced technology risks; and (3) more efficient O\&M processes.

Average power density at the deployment site has a significant impact on device performance and cost and the resulting cost of electricity. Figure 29 shows the COE sensitivity to power density at an installed capacity of $50 \mathrm{MW}$. This sensitivity was evaluated by developing performance cost and economic assessments at different potential deployment sites in the United States and evaluating the performance of the machines under investigation in that environment.

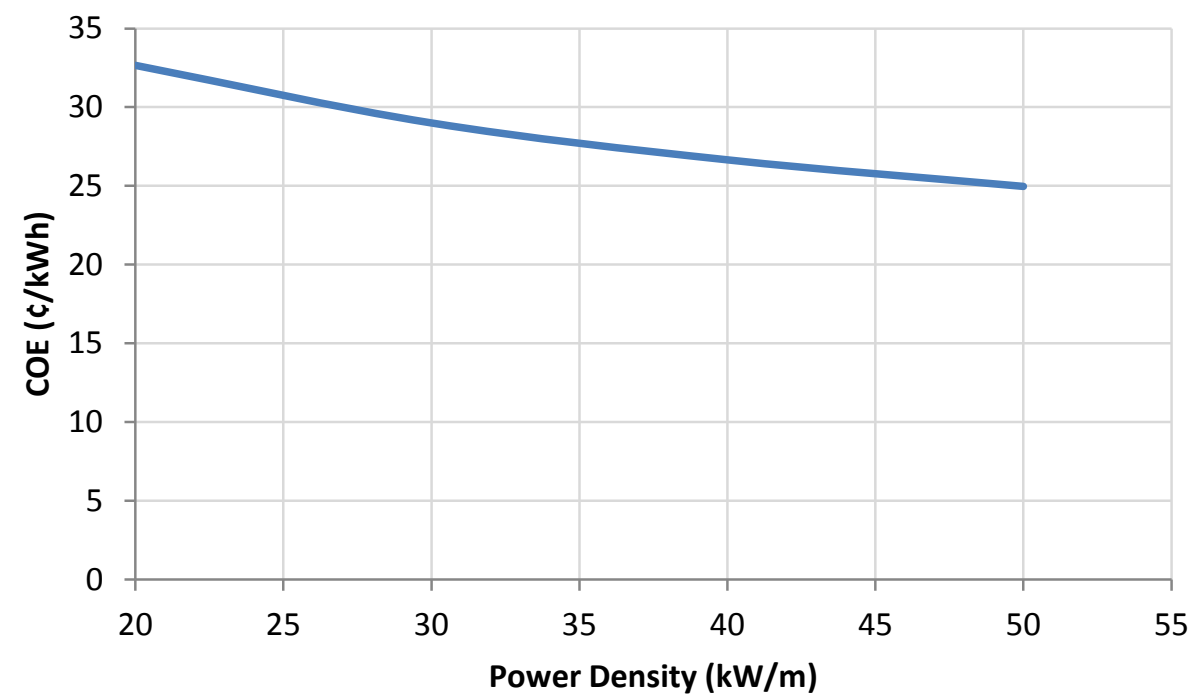

Figure 29 - Cost of electricity as a function of the power density at the deployment site at 50-MW plant scale 


\section{Cost Correlation to Site Data}

To determine the site-specific life-cycle costs of the technologies selected, the team identified cost drivers to develop cost relationships that could be applied to the GIS model. To do so, the technoeconomic cost models developed by RE Vision were applied to different site conditions, and curve-fitted relationships were developed. Although this approach neglects many site-specific parameters that could drive COE projections, it does capture the impact of high-level cost-drivers on the site-specific economics.

The plant scale chosen was assumed to be a commercial-scale plant shown in the cost breakdowns presented in Section 7. Plant capacity at that scale is $50 \mathrm{MW}$, and the team assumed that these types of cost profiles would be attained with a cumulative deployment of $100 \mathrm{MW}$ of capacity. As previously discussed, the machine capacity factor was fixed to $30 \%$. Factors affecting those costs were considered and are described in the following subsections.

\section{Power Density of the Resource}

Power density of the resource showed a strong correlation to the cost of electricity of the plant. In general, sites with higher resource power density will yield more power output per unit of cost, leading to a lower cost of electricity. This analysis neglected site- and region-specific differences in the resource characterization. For wave energy, the frequency distribution and spectrum of the wave resource could make a significant difference in device performance and hence economic profiles, but these factors were not considered in this assessment. Figure 30 and Figure 31 show the correlations used.

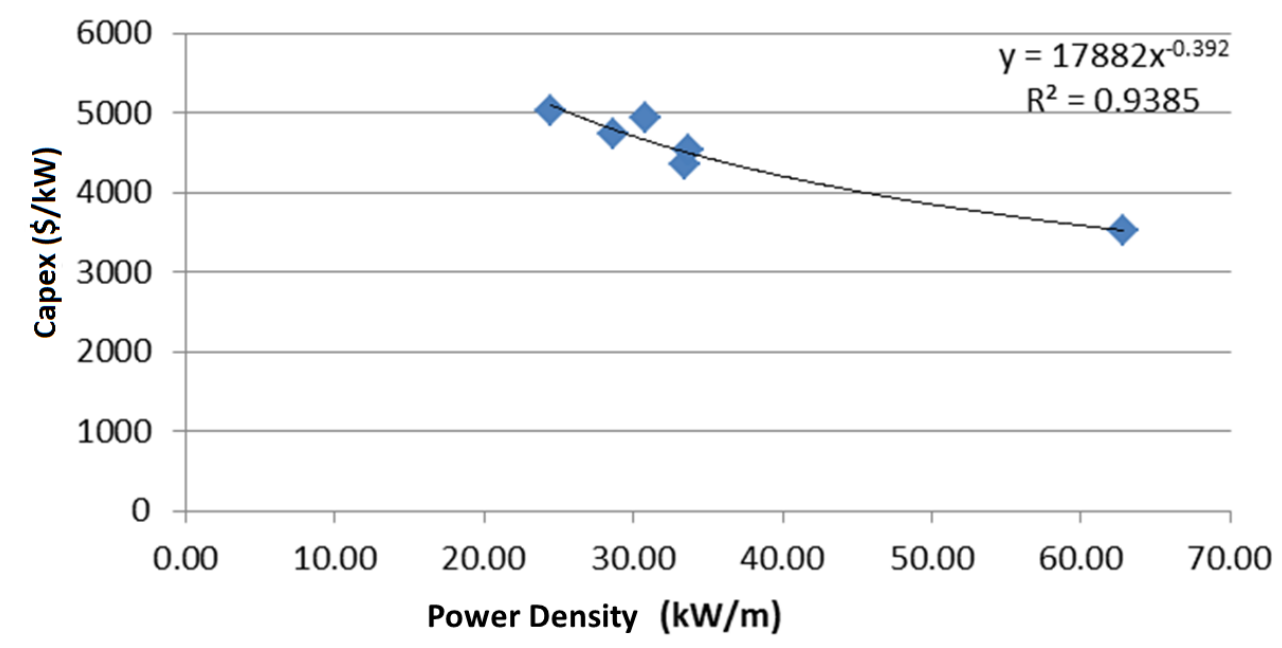

Figure 30 - Wave power density versus Capex 
Each point that is shown is the Capex and Opex of wave technology at six reference sites located in U.S. waters.

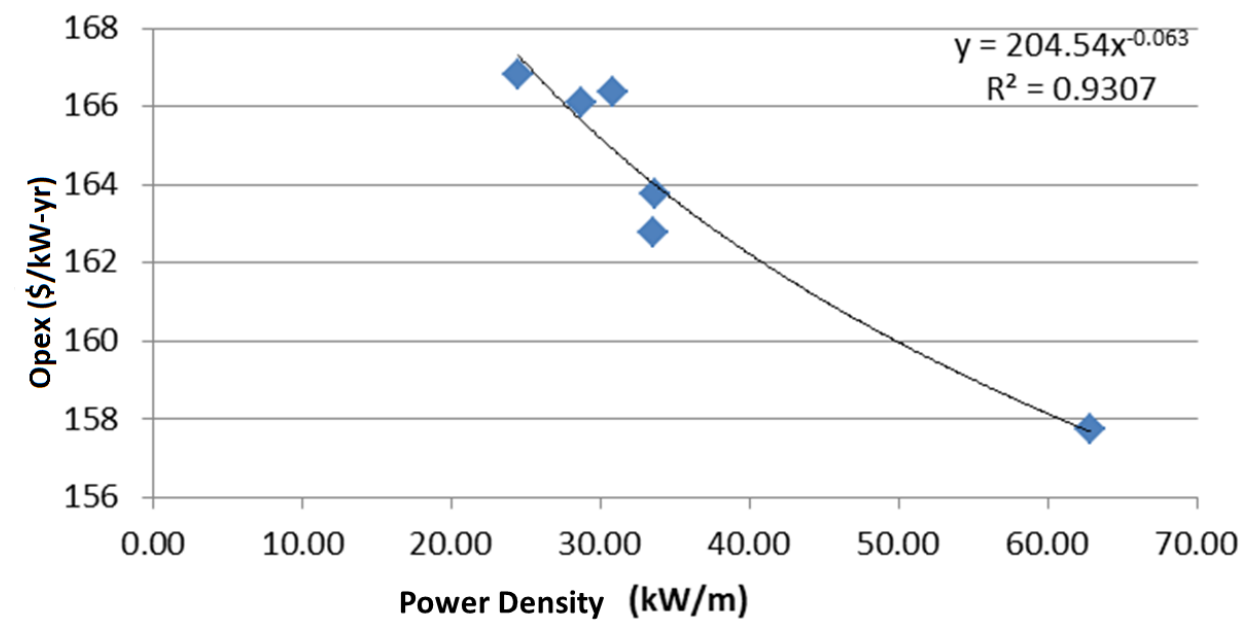

Figure 31 - Wave power density vs. Opex

\section{Transmission Costs}

Because renewable energy generators (e.g., wind, solar, and MHK) are sited according to resource locations, transmission lines are often required to connect the resource centers to the grid/load center substations. For this analysis transmission costs were incorporated into the wave supply curves, assuming a base cost for transmission lines of $2,480 \$ / \mathrm{kW}$-mile. Therefore, larger plants sited farther away from the existing transmission network or load center will incur a higher transmission line cost than a smaller plant located in close proximity. Regional cost multipliers ranging from 1.0 to 3.56 were applied to the base transmission line cost to account for cost increases in regions with higher population densities. The transmission line cost for connecting a resource center to the grid/load center substation was calculated as:

Transmission to Substation $\left(\frac{\$}{\mathrm{MW}}\right)=$ Regional Multiplier $*$ Base Cost $\left(\frac{\$}{\mathrm{MW}-\mathrm{mi}}\right) *$ Distance $(\mathrm{mi})$

Furthermore, each plant incurs a grid connection cost that includes costs for the substation and any other equipment required to connect a plant to the grid/load center. The grid connection cost depends on the size and type of generator supplying power to the grid. The total grid connection cost used for this 
analysis was $117,000 \$ / \mathrm{MW}$ plus either $40,600 \$ / \mathrm{MW}$ for connection to a new substation or 26,400 \$/MW for connection to an existing substation ${ }^{\mathrm{a}}$.

Table 13 - Transmission Cost Summary

\begin{tabular}{|l|r|}
\hline Parameter & Value \\
\hline Regional Transmission Multiplier & $1.0-3.56$ \\
\hline Base Transmission Cost & $2,535 \$ / \mathrm{MW}$-mile \\
\hline Grid Connect Cost & 119,930 \$/MW \\
\hline Additional Grid Connection Costs & \\
\hline Connection to Existing Substations & 27,010 \$/MW \\
\hline Connection to New Substations & $41,560 \$ / \mathrm{MW}$ \\
\hline
\end{tabular}

The documentation for the NREL ReEDS model (Short et al. 2011) discusses the methodology for incorporating transmission line costs for connecting resource to grid/load center substations, along with grid connection costs.

\section{Plant Distance to Shore}

To determine the incremental cost of going farther out to sea (distance to shore), the team analyzed the increase in total plant cost over the baseline case. The incremental cost stems from the cost of additional subsea cables that would be required to bring the power to shore. At $50 \mathrm{MW}$, two cables, each rated $25 \mathrm{MW}$ at $30 \mathrm{kV}$, would connect the plant to shore. The incremental costs increase for adding subsea cable and are expressed by the following function:

Transmission Cost $(\$ / k W)=(D-3.1) * 19.0$, where $D$ is transmission distance to shore in miles.

In reality, the actual topology might change, but this first order approach was considered adequate for this analysis, given that the incremental subsea cable cost is not a cost driver in most areas. Operational cost increases that would result from being farther from shore were not considered in this assessment.

\footnotetext{
${ }^{a}$ Connections to a new substation require double-line termination, a three-phase transformer, and site preparation. Connections to an existing substation require single-line termination and a three-phase transformer. Installed costs for line termination and transformers include engineering costs, material procurement, and construction labor for breakers, switches, bus work, and controls. Site preparation costs include those for a new control building, site preparation, and below-grade features such as foundations, a ground grid, and a conduit/raceway
} 


\section{Cost Reduction Pathways}

The baseline cost assessment represents today's cost from these technologies if they were deployed at a 50-MW farm scale and assuming prior deployment of 100 MW globally. No cost reductions resulting from technology improvements were assumed in this baseline cost. Initial costs for smaller plants reported today are higher, largely because of the compounding factors of small plant deployment scales, high failure rates resulting from limited deployment experience, and high financing costs caused by inherent project and technology risks. The uncertainty band around this cost prediction, given the early stage nature of the technology, is likely on the order of $\pm 30 \%$, which results in a range of $18-34 \varnothing / \mathrm{kWh}$. As a point of comparison, offshore wind is on the order of about $22 \notin / \mathrm{kWh}$, which is comparable, given the uncertainties in this assessment (Tegen et al. 2012).

Learning curves are typically used when predicting longer term cost reductions for an industry. For each doubling of the deployed capacity, a certain percentage cost reduction is attained. Similar renewable energy technologies have historically attained learning rates on the order of $70 \%-90 \%$. Wind technology, for example, which is the most closely related analog, has demonstrated progress ratios on the order of $85 \%$. It is important to understand that these cumulative cost reductions in industries is tied to a wide range of factors, including manufacturing scale, operational efficiencies, improved reliability and availability, and fundamental design changes that drive down cost. When investigating learning curves, one can often observe discontinuities that can be traced back to technology innovations. Globally there have been a limited number of wave energy device deployments with a cumulative installed capacity on the order of $5 \mathrm{MW}$. Furthermore, the wave technology space is characterized by a wide range of different technical approaches, which is typical for a technology space with limited deployments and very similar to wind about 20 years ago. The limited global deployment also means that no technology lock-in has occurred, which is typical for more established technology sectors. This makes transformational technology shifts easier to accommodate in the marketplace and opens up the possibility for rapid cost reduction pathways.

Figure 32 shows two potential cost reduction pathways. The first one (blue lines) shows how the cost would reduce from today's levels to the commercial opening cost level predicted by this study if the technologies stayed the same. Cost reductions in this case are largely based on economies of scale (going from 1-5-MW plants to 50-MW plants) and improvements in device reliability by eliminating high failure rates that are typical in pilot and demonstration projects. From the projected opening cost, the team 
used an $85 \%$ learning curve to predict cost reductions as the cumulative installed capacity base grows. The figure shows that the break-even target, at which no subsidies would be required, occurs at about 50GW cumulative global installed capacity. This point is very similar to the deployed capacity levels at which land-based wind started to become competitive.

The second line (shown in red in Figure 32) shows what would happen if an accelerated research, development, and deployment (RD\&D) strategy were pursued. Such an accelerated program would reduce the cost of electricity to a level of about $15 \phi / \mathrm{kWh}$ within the first $100 \mathrm{MW}$ of cumulative installed capacity. Cost projections extending out from the 100-MW point were assumed to follow a more traditional learning curve with an $85 \%$ progress ratio. The figure shows that the cost of electricity would become competitive in Hawaii at a cumulative deployed capacity of less than $200 \mathrm{MW}$. The learning in this early adopter market would allow costs to be further reduced without any required subsidies. At a cumulative installed capacity of about 3,000 MW, wave power would then reach grid parity with the U.S. mainland (Lower 48 and Alaska).

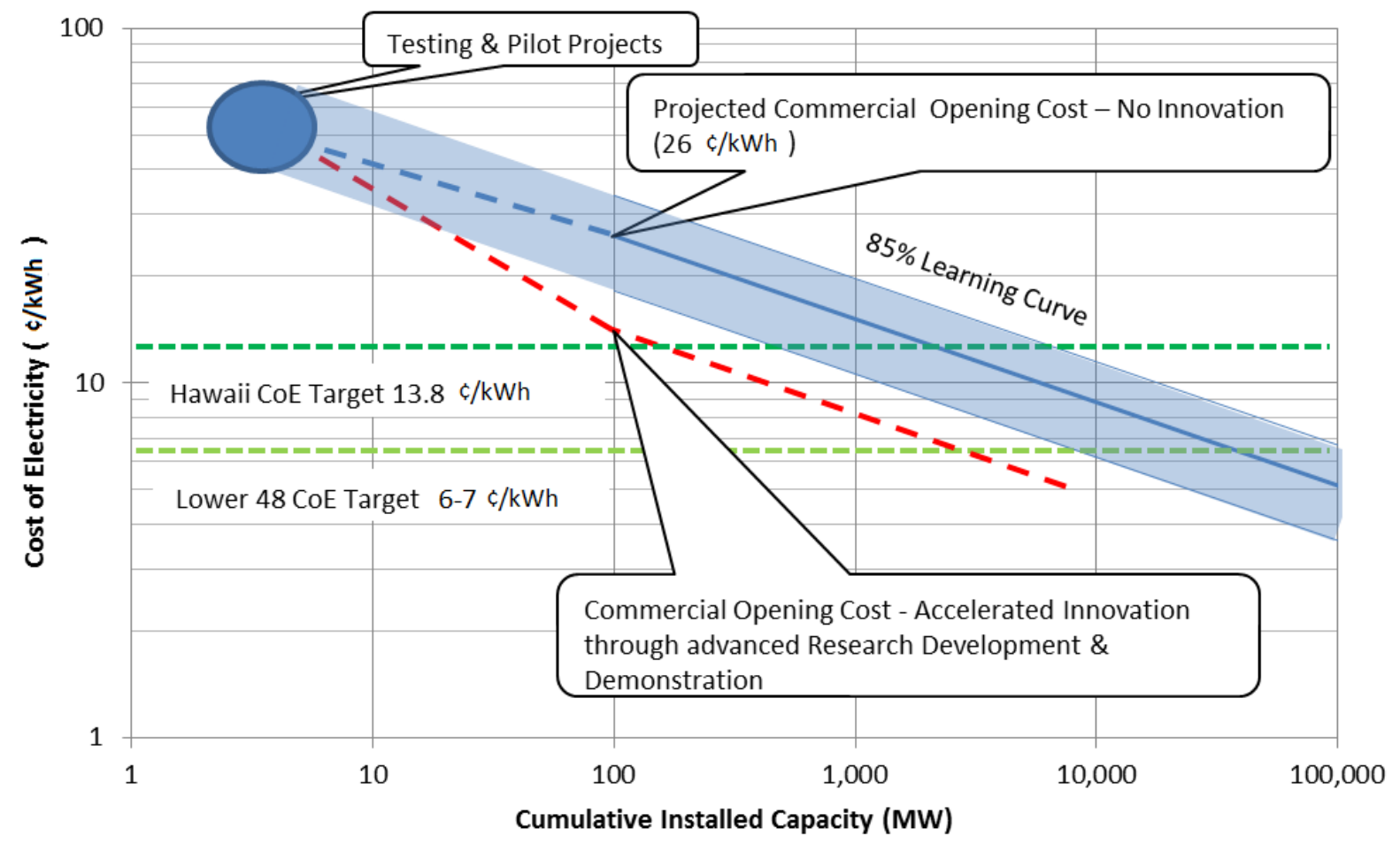

Figure 32 - Potential cost reduction pathways 
This simple example of the potential cost reduction pathways illustrates the need for a strong RD\&D program that nurtures a robust innovation pipeline, while demonstrating technologies in pilot and small array deployments. This will significantly reduce the total costs incurred to develop the technological and commercial capabilities necessary to create a competitive industry.

Significant cost reduction potential exists within the wave energy technologies investigated in this study and are summarized in the following paragraphs.

Development of Efficient Operation and Maintenance Strategies-Although O\&M strategies used in the offshore industry are often adapted for wave energy, they are frequently inefficient and costly. Developing and optimizing O\&M strategies and relying on custom vessels specifically built to carry out wave energy operations could allow for a significant reduction in the O\&M costs of these devices. Furthermore, recent advances in unmanned vehicle technology (both surface and underwater) that could be used to perform routine inspection and maintenance tasks could offer significant opportunities for cost reduction.

Improving Device Power Capture-As discussed in the cost section, the total cost of most wave power machines today is dominated by structural cost. Specifically, these devices show a poor ratio of power output versus the structural cost of the absorber. Many of the device concepts studied show significant potential improvements if optimal tuning strategies are applied to them. As a result, significant cost reductions could come from this area.

Reducing Structural Overdesign Through Improved Load Prediction Tools-Most design standards used in the offshore industry are very conservative, leading to a need to overdesign the structure. This overdesign is a direct result of the limited understanding of the driving load cases to which structures must be designed. A better understanding of these loading conditions could significantly reduce the total material (and cost) of these devices.

Such cost reductions can only be attained if a strong, systematic RD\&D program is in place that nurtures this early industry. Although there are no silver bullets for such a program, there are some guiding principles that should be pursued to ensure success.

Clear Focus on Cost Reduction Pathways-Continued benchmarking of technology innovations in respect to their contributions to reducing the cost of electricity is an important factor in identifying solid cost reduction pathways and measuring program success. 
Demonstration and Validation-Demonstration projects allow the design community to develop a comprehensive understanding of all the elements contributing to the COE of a particular technology. It is important to feed the knowledge gained through these demonstrations back to the development community so that novel design concepts can incorporate those lessons without having to repeat their mistakes. An independent test and validation program can go a long way toward achieving that goal.

Nurturing of Technological Breakthroughs-Systematic studies of novel design concepts should be carried out to keep feeding the innovation pipeline. At this stage of industry development, major breakthroughs are likely to come from radically different design approaches and concepts. Too much focus on established technology could lock out potential breakthroughs that are needed to reduce the cost of electricity.

Development of Strong Theoretical Modeling Capabilities-The key difference between how renewable energy sectors have developed historically and how they develop today are that modern computing capabilities allow rapid simulation and trade-off studies to be performed on devices today. This was not possible a few decades ago. Theoretical modeling reduces the need for validation and testing and holds the key to enabling rapid progress and reducing cost. A shotgun approach to developing these modeling capabilities (using multiple competing teams) could unleash capabilities in private industry, universities, and national laboratories. Traditionally, such code development has been the domain of national laboratories and universities with supercomputing capabilities. Today's desktop computers, though, are often sufficient for these problems, enabling small companies to contribute to this code development more rapidly and at much lower cost. 


\section{Technology Deployment Densities}

Deployment densities are required to establish how many megawatts of capacity can be deployed at a given site. Deployment density represents both the number of physical machines that can be deployed on a given footprint and the extraction efficiency of those machines. In wave power conversion it can be expressed as a percentage of the available wave power (see Table 14). The technology deployment density is largely a function of the technology type chosen. The team used a scenario-based analysis of deployment effects that was carried out by RE Vision Consulting under contract to DOE in 2010 as the baseline for establishing extraction densities (Previsic 2010).

Table 14 - Deployment Densities of Different Technologies Under Development

\begin{tabular}{|l|r|}
\hline Technology & Deployment Density \\
\hline Pelamis Wave Power & $6 \%$ \\
\hline Ocean Power Technologies & $3 \%$ \\
\hline Wave Dragon & $5.5 \%$ \\
\hline Aquamarine Oyster & $36 \%$ \\
\hline
\end{tabular}

With the exception of the Aquamarine Oyster, the devices given in Table 14 are deepwater devices. The relatively low deployment density values achieved by the deepwater technologies can largely be attributed to device spacing requirements and the fact that limited device stacking was used in the deployment scenarios developed by Previsic (2010). Furthermore, it is important to point out that very little attention has been paid in recent years to deployment densities of these devices because manufacturers have been focusing on reducing costs, along with technology survivability in the harsh offshore environment. As the industry starts deploying technologies at the industrial scale, spatial constraints will become a more important driver for technology selection.

Previous estimates from the EPRI ocean energy program used the following assumptions: $15 \%$ deployment density, $80 \%$ mechanical to electrical conversion efficiency and $95 \%$ availability. These values represent a typical average range of values and are used in this report to establish a baseline.

In the early days of wave energy conversion (the 1970s), the University of Edinburgh developed the Salter Duck, a WEC consisting of many absorber floats that extracted power by rotating around a long spine that is arranged perpendicular to the wave direction. Even though this design never progressed beyond the laboratory stage, it proved that high extraction efficiencies and minimal device spacing could 
be attained in a WEC design, resulting in relative deployment densities on the order of $90 \%$ within a certain frequency and wave height range. Figure 33 shows a picture of an array of Salter Ducks.

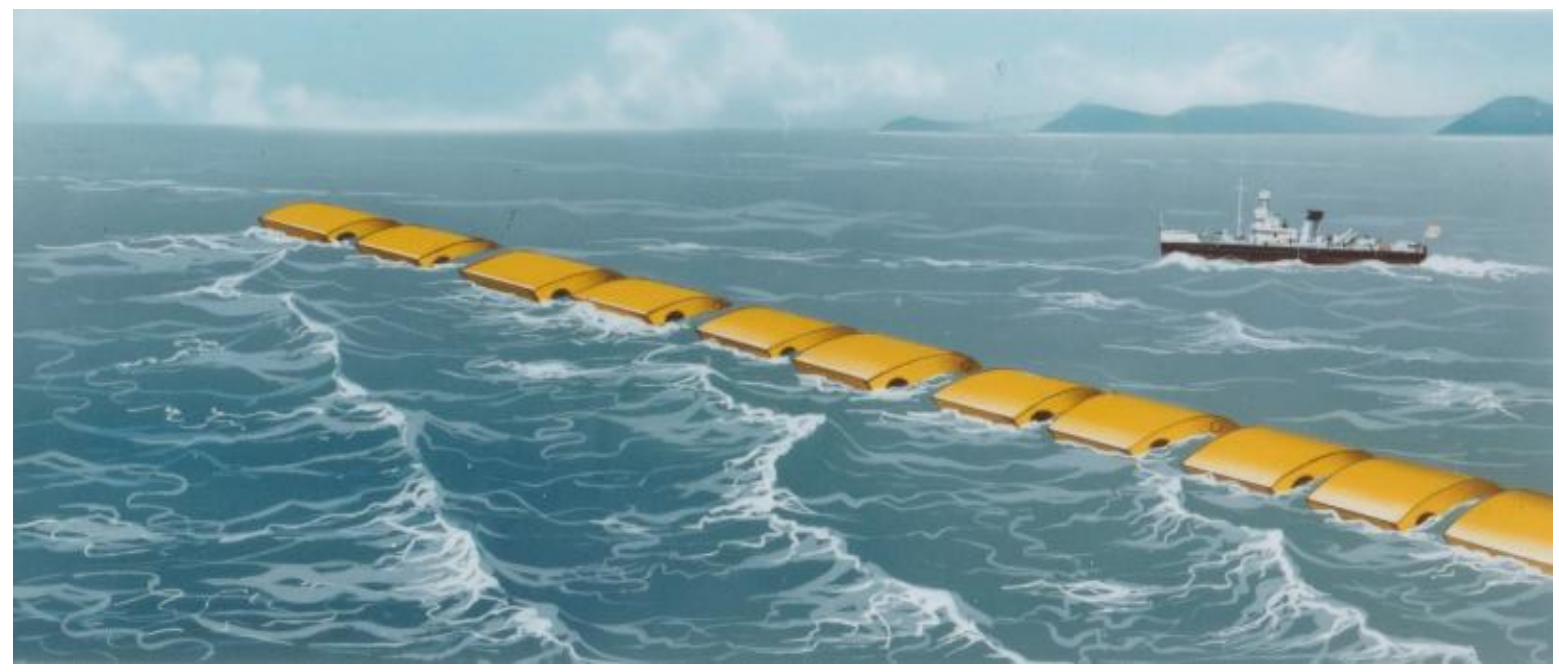

Figure 33 - Artist Illustration of a row of Salter Ducks (Source: www.mech.ed.ac.uk/research/wavepower)

Figure 34 shows a cross section of the device while tank testing.

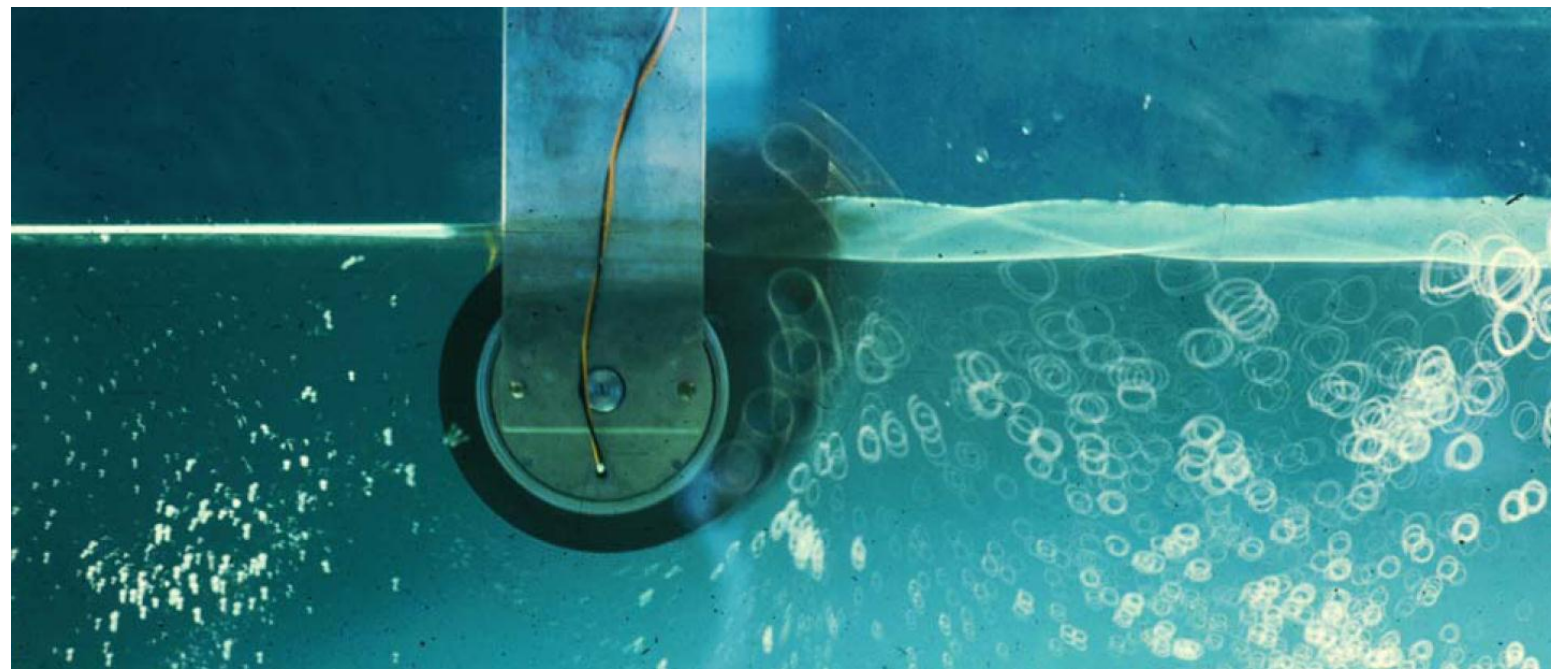

Figure 34 - Tank test of Salter Duck in narrow tank. One-second exposure shows device motion path and wave particle orbits visualized using tracer particles. (Source: www.mech.ed.ac.uk/research/wavepower)

Wave energy extraction efficiencies for most devices are significantly below their theoretical maximums because of a number of technical challenges that will need to be addressed over the coming years. Optimal tuning strategies (if successfully implemented) could improve the extraction efficiency of many WEC designs by a factor of 2 to 3 (Clement and Babarit 2012; Hals et al. 2011; Falnes 2002). The technical challenges to be addressed to move closer to this theoretical optimum are largely related to the 
ability to accurately predict waves on short time horizons ( $<1$ minute), and power conversion system designs that allow advanced tuning strategies to be implemented.

Furthermore, increases in device efficiency and research on tightly spaced arrays will increase deployment densities and allow a higher percentage of the total resource to be recovered. Tightly spaced arrays of devices can be challenging from both the perspective of the mooring system design and the hydrodynamic interactions of multiple bodies.

Given that current limitations on deployment densities are likely to be temporary, and taking the variable nature of the resource into account, it is useful to look at the theoretical deployment density upper limit. To clarify this issue, the team carried out an assessment, assuming no inter-device spacing, a mechanical to electrical conversion efficiency of $90 \%$ and a wave to mechanical conversion efficiency of $100 \%$. This envisioned array would hence span the whole coastline like a fence, and achieve $100 \%$ power extraction from waves that are smaller than or equal to the device rated capacity. If the rated capacity of such a machine is unconstrained, this device would absorb $100 \%$ of incident power, resulting in a deployment density of $100 \%$. Because it is impractical to convert extremely large waves into electricity, however, a rated capacity is superimposed onto the unconstrained machine performance. Figure 35 shows the relationship between the hypothetical plant's capacity factor and the deployment density for this study's reference site.

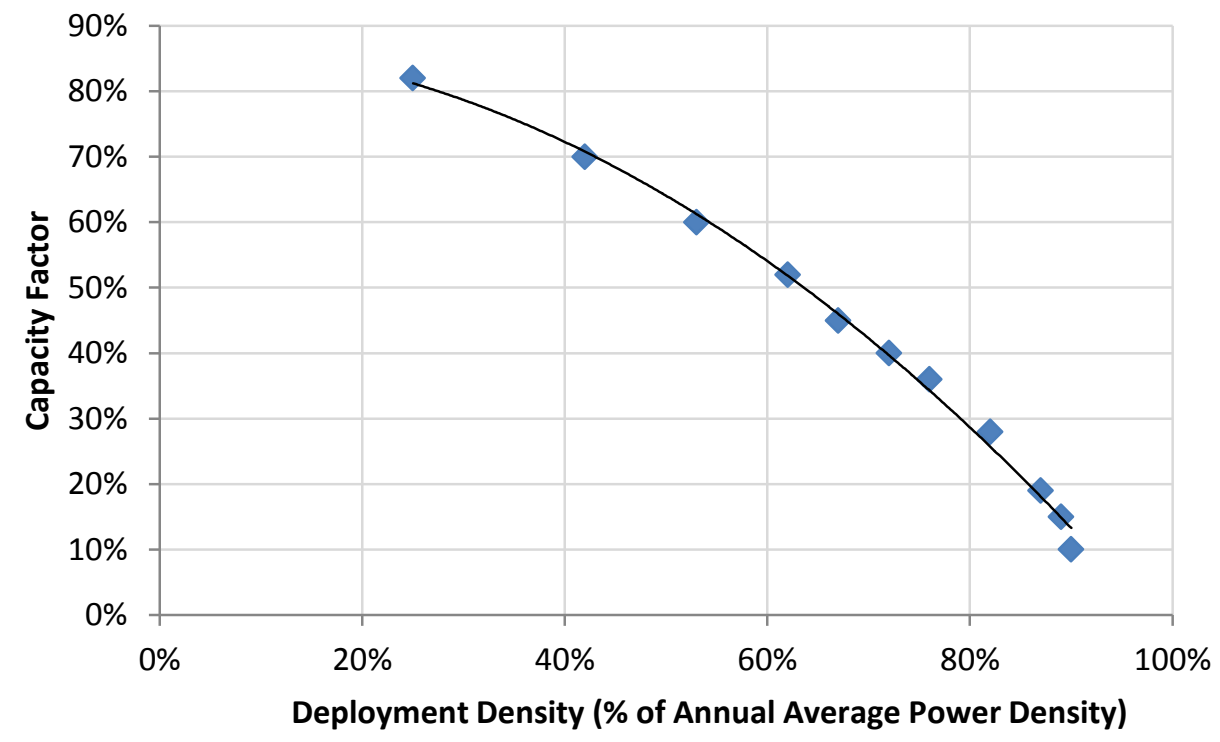

Figure 35 - Capacity factor as a function of the upper limit of deployment density 
It is important to note that the curve shown in Figure 35 is site-specific and depends on how variable the wave resource is at the site of interest. Assuming a target capacity factor of 30\%, Table 15 shows the upper limit deployment density at different sites around the United States and the world.

Table 15 - Upper Limit of Deployment Density at Different Sites Assuming a Capacity Factor of $\mathbf{3 0 \%}$

\begin{tabular}{|l|r|r|}
\hline Deployment Site & $\begin{array}{r}\text { Annual Average } \\
\text { Power Density }\end{array}$ & $\begin{array}{r}\text { Upper Limit Deployment Density for } \\
\mathbf{3 0 \%} \text { Capacity Factor }\end{array}$ \\
\hline Eureka, California, USA & $33.5 \mathrm{~kW} / \mathrm{m}$ & $90 \%$ \\
\hline Reedsport, Oregon, USA & $28.7 \mathrm{~kW} / \mathrm{m}$ & $75 \%$ \\
\hline Yakutat, Alaska, USA & $24.4 \mathrm{~kW} / \mathrm{m}$ & $70 \%$ \\
\hline Waimanalo Bay, Hawaii, USA & $12.5 \mathrm{~kW} / \mathrm{m}$ & $87 \%$ \\
\hline Cape Hatteras, North Carolina, USA & $9.7 \mathrm{~kW} / \mathrm{m}$ & $74 \%$ \\
\hline Galway Bay, Ireland & $62.8 \mathrm{~kW} / \mathrm{m}$ & $74 \%$ \\
\hline Wavehub, SW United Kingdom & $30.8 \mathrm{~kW} / \mathrm{m}$ & $68 \%$ \\
\hline
\end{tabular}

Given the range of values shown in Table 15, an upper limit of $70 \%$ was selected as a reasonable value for our optimistic case. The Salter Duck development clearly demonstrates that high deployment densities are technically achievable. In other words, there is a significant potential to how much energy can be extracted from the U.S. wave energy resource. 


\section{revision}

\section{Resource Data}

In leading a national wave energy resource assessment under contract to DOE, EPRI developed a wave energy resource database for the coastal areas of the United States including Alaska, Hawaii, and Puerto Rico. The data set $^{13}$ includes water depth, monthly and annual wave power density (in kilowatts per meter), significant height, and wave energy period. The full EPRI wave resource assessment report can be downloaded at wwwl.eere.energy.gov/water/pdfs/mappingandassessment.pdf (see also EPRI 2011). As Figure 36 shows, the U.S. West Coast has significantly higher wave power densities that are higher and closer to shore than the U.S East Coast.
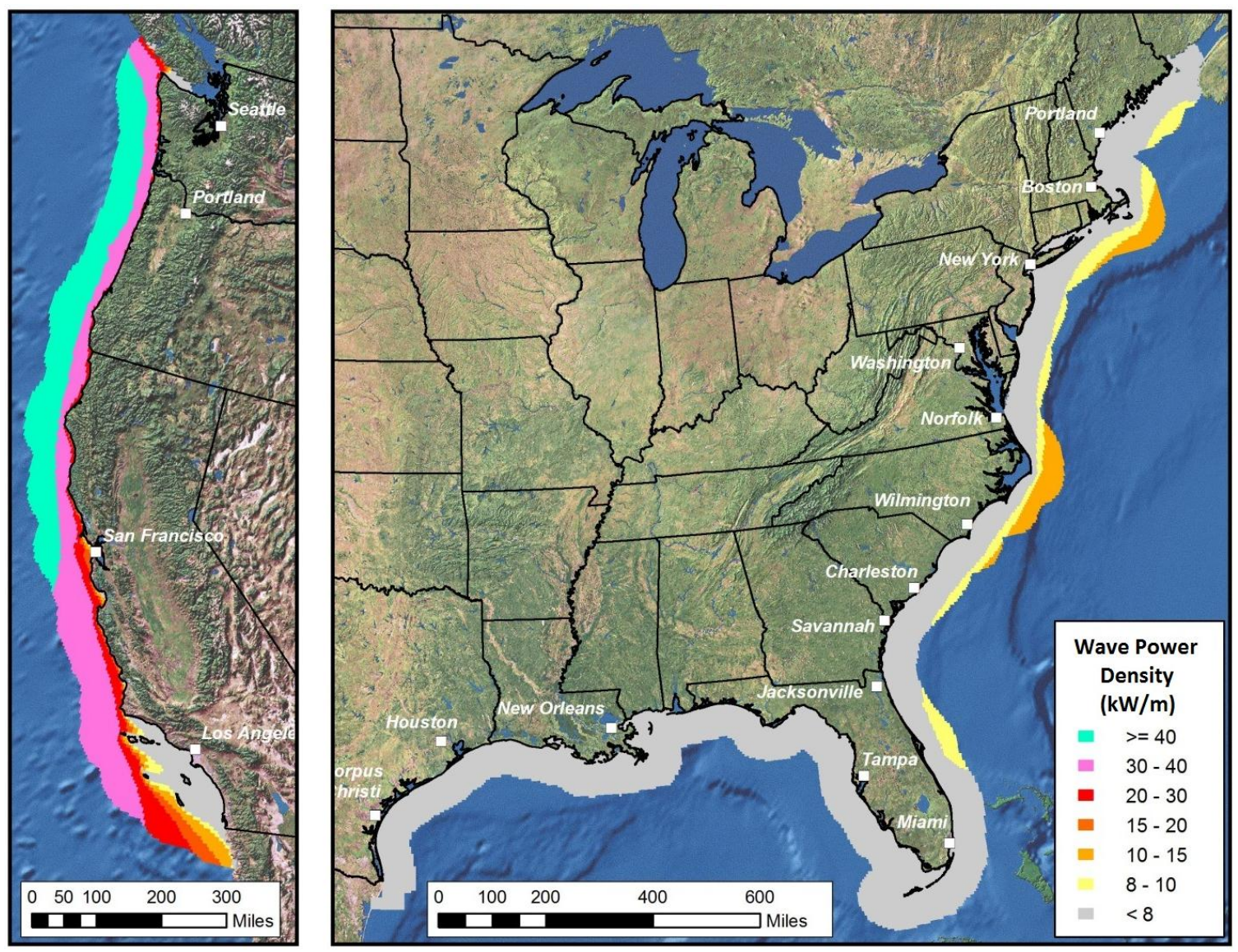

Figure 36 - Annual average wave power density $(\mathrm{kW} / \mathrm{m})$ in the contiguous United States

Alaska contains wave power densities that are very similar in strength to the resource in the Pacific Northwest.

\footnotetext{
${ }^{13}$ Available at /maps.nrel.gov/mhk_atlas
} 


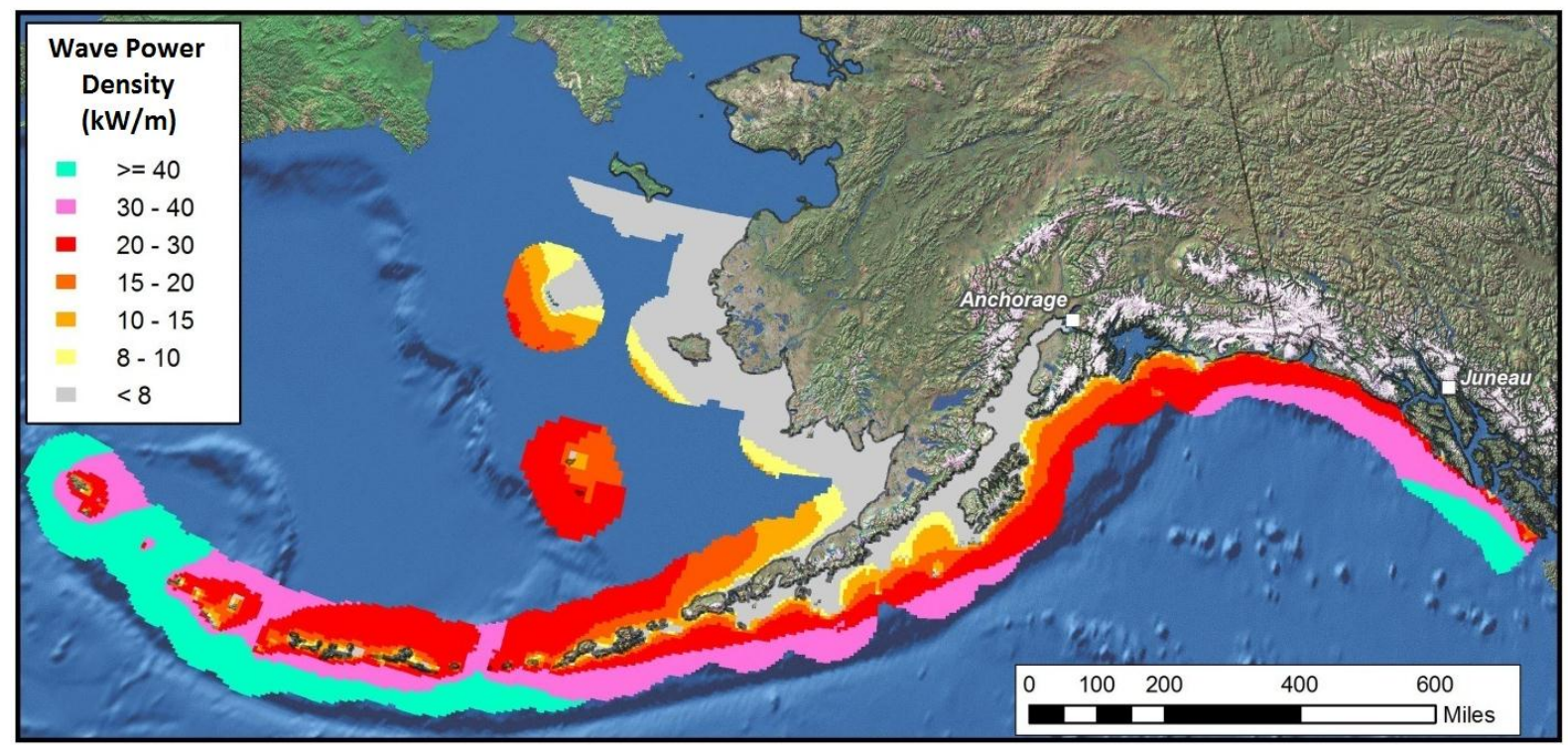

Figure 37 - Annual average wave power density $(\mathrm{kW} / \mathrm{m})$ in Alaska

The northern shores of the Hawaiian Islands contain a moderately strong wave resource. However, the average power density is significantly lower than a majority of the U.S. West Coast wave resource. What makes it a still attractive resource, is the low seasonal power density variations and the high electricity prices in this region.

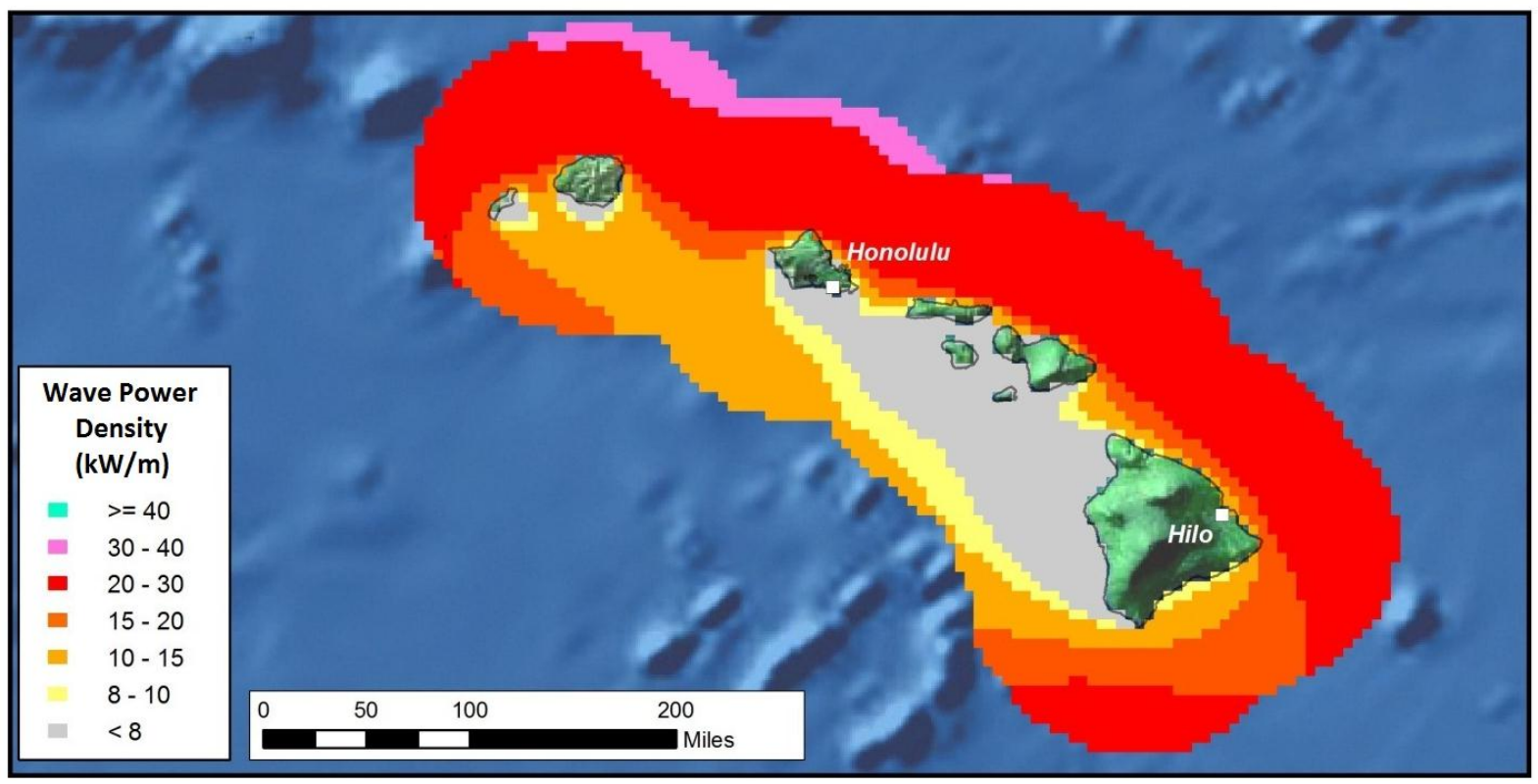

Figure 38 - Annual average wave power density $(\mathrm{kW} / \mathrm{m})$ in Hawaii 


\section{Supply Curves}

The cost of electricity from MHK technology is a direct function of several factors, including deployment site distance to grid, resource power density, and water depth. Initial deployments will occur at sites with favorable attributes that result in the lowest COE. As deployment progresses and the total installed capacity increases, devices will be installed at sites that have lower power densities or other higher cost attributes that will increase the COE. The supply curve captures these trade-offs, providing COE as a function of deployed capacity. In the ReEDS modeling analysis, the less expensive resources are developed first. Requiring additional, more expensive generation increases the per-unit cost of power as reflected in the supply curves.

The team's general approach to establishing these supply curves follows:

1. Determine the available wave resource at 100-m water depths from the resource.

2. Exclude sites where

a. The power density is below an economic threshold of $8 \mathrm{~kW} / \mathrm{m}$.

b. The area is a marine sanctuary.

c. The location is more than 600 miles from an electrical grid interconnection point.

3. Determine each site's rated capacity and apply the life-cycle cost profiles derived from site-specific cost-driving parameters.

4. Determine the available electrical grid capacity and transmission costs, and allocate the site to the electrical grid.

5. Generate the supply curve using the cost profiles to rank each site by the COE.

\section{Processing the Resource Data}

The team used the geospatial wave resource database by the following method:

1. Along the coastlines of the United States, Alaska, and Hawaii a 100-m water depth contour was mapped as a guide for the resource selection. Where bathymetry made the selection difficult, contours were selected to keep the depth between 90 and $120 \mathrm{~m}$. Bathymetric data were imported from the National Oceanic and Atmospheric Administration's (NOAA's) Coastal Relief Model, a highresolution bathymetric database. The 100-m depth contour was chosen because (1) the wave energy resource data used in this study were derived from a deepwater model and shallower sites are unlikely to be accurate, and (2) this water depth still is within the upper range of deployment depths for which technologies under development are designed. 
2. Using the wave resource database, each database grid point (surrounding area referred to as a site) that was crossed by the depth contour was selected for the supply curve. Database grid points and the depth contour are shown below for the a small segment of coastline in the Pacific Northwest.

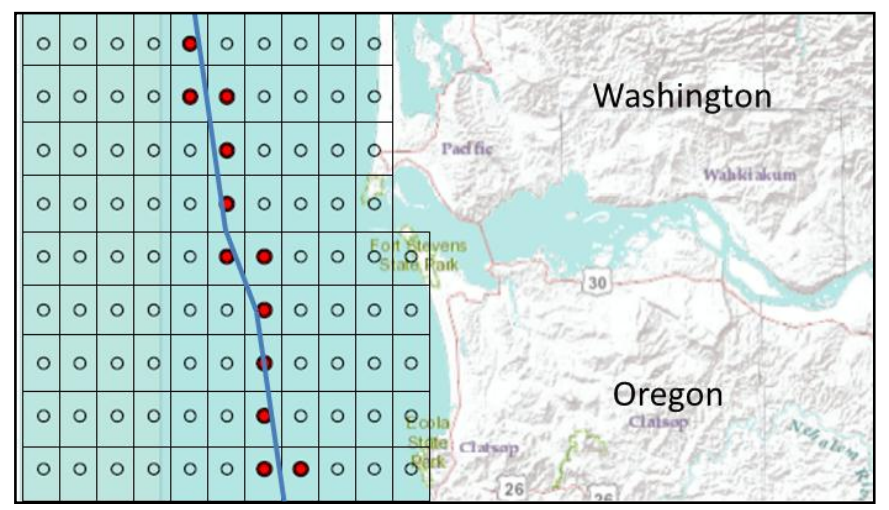

Figure 39 - Washington \& Oregon 100-m depth contour (blue), grid points (black circles) and site areas

3. For each site the total wave resource was determined based on the annual average power flux of the site and the wave front length of the site. Wave front length of each site was taken to be the depth contour length that passed through each site.

4. Additional parameters such as distance from shore, distance to the electrical grid, and exclusion information, were used to determine the complete cost profile.

5. The $\mathrm{COE}$ and installed capacity were generated for each site using the characteristics and correlations described in Sections 6 through 8.

\section{Wave Resource Exclusions}

Exclusions to the deployable areas considered for the supply curve process include power flux exclusions, marine sanctuary exclusions, and transmission distance exclusions. A 600-mile transmission to grid connection limit was imposed to eliminate sites where the costs were likely to be prohibitively high such as the wave resource of Northwest Alaska.

The power density exclusion was a simple implementation that excluded sites where the annual average power density was below $8 \mathrm{~kW} / \mathrm{m}$ from the supply curve. As seen in Figure 36 this exclusion primarily affects the supply curve capacity of the Gulf of Mexico and the U.S. East Coast.

Marine sanctuaries included all federal marine sanctuaries, wildlife refuges, state designated marine protected areas, or any other designated environmentally protected area. The largest marine protected 
areas in the contiguous United States are off the coasts of Florida, California, and Washington. On the West Coast, these large areas extend far offshore and affect the available wave energy resource used for the supply curves. In Alaska, the Aleutian Islands contain a vast number of marine protected areas. Despite the quality of the wave resource, there is limited demand for power in these areas and the transmission distances to any grid would be cost prohibitive.

Other exclusions that might affect development include the type of seafloor substrate; the presence of debris; and any existing commercial, recreational, or military use of an area. When a national representation of this information is available, future studies would benefit from assessing the potential impact of the exclusions to the resource total or site development costs.

\section{Determining Available Grid Capacity}

The electricity grid components used to develop the supply curve include transmission lines, substations, cities, and center points for the ReEDS balancing areas (BAs). Each grid component has an open capacity for wave power generation set at $10 \%$ of its total estimated capacity. ${ }^{a}$ The capacity for each transmission line is estimated based on its length and nominal voltage (Weiss and Spiesak 1998). Substations are linked to the transmission lines marking their endpoints and have capacity equal to half the cumulative connected transmission line capacity. ${ }^{\mathrm{b}}$ When developable sites are assigned to a transmission line or substation, their linked component capacities are reduced accordingly. A city component has at least 10,000 people with the remaining population represented by the county at its spatial center. The city's capacity is represented using annual peak load, ${ }^{\mathrm{c}}$ apportioned to each city by population. The ReEDS BA components represent locations where large transmission lines are built from the center of one balancing region to another. For this study, the team considered the inter-regional transmission capacity to be unlimited. All wave points will be assigned to a grid component, and when available transmission, substation, and city capacities are exhausted, the resource points will by default be assigned to the closest BA center.

\footnotetext{
${ }^{a}$ Individual line availability varies based on a variety of factors including ownership, contractual agreements with individual generation plants, and rules and regulations of particular transmission system operation entities. Precise estimates of individual transmission line capacity as a function of time are not publicly available. In lieu of linespecific data, the team assumed $10 \%$ existing capacity available for new generation for simplicity.

${ }^{\mathrm{b}}$ Transmission line data were extracted from Platts POWERmap product for the contiguous United States, and from the Homeland Security Infrastructure Program 2011 for Alaska and Hawaii.

${ }^{\mathrm{c}}$ The team extracted regional peak load data we from Platts POWERmap and POWERdat products for the contiguous United States.
} 
The resource supply curves developed here are the result of iteratively selecting the lowest cost site and allocating the site to grid components based on their available capacity. The process begins by calculating an initial development cost for each site to build to the lowest cost grid component. The sites were sorted by cost, and the lowest cost site was selected. The grid component to which it is tied is then identified, and its remaining available capacity queried. If the grid component capacity can accept the site capacity, the site was assigned to it and the grid component's available capacity was decremented accordingly. The next lowest cost developable site was then evaluated. If the grid component's available capacity is not sufficient to fully utilize the site, however, the next lowest cost grid component with enough capacity was identified and development costs were recalculated. The developable site was then re-sorted into the remaining pool of unassigned sites, and the next lowest cost site was evaluated. This process is described in more detail in Appendix IV.

\section{Selected Wave Resource and Exclusions}

Figure 40 shows the selected wave resource data, the marine sanctuary exclusions, and transmission lines within 100 miles of the U.S. coastline. It shows the annual average wave power density (in kilowatts per meter) along the $100 \mathrm{~m}$ water depth contour lines.
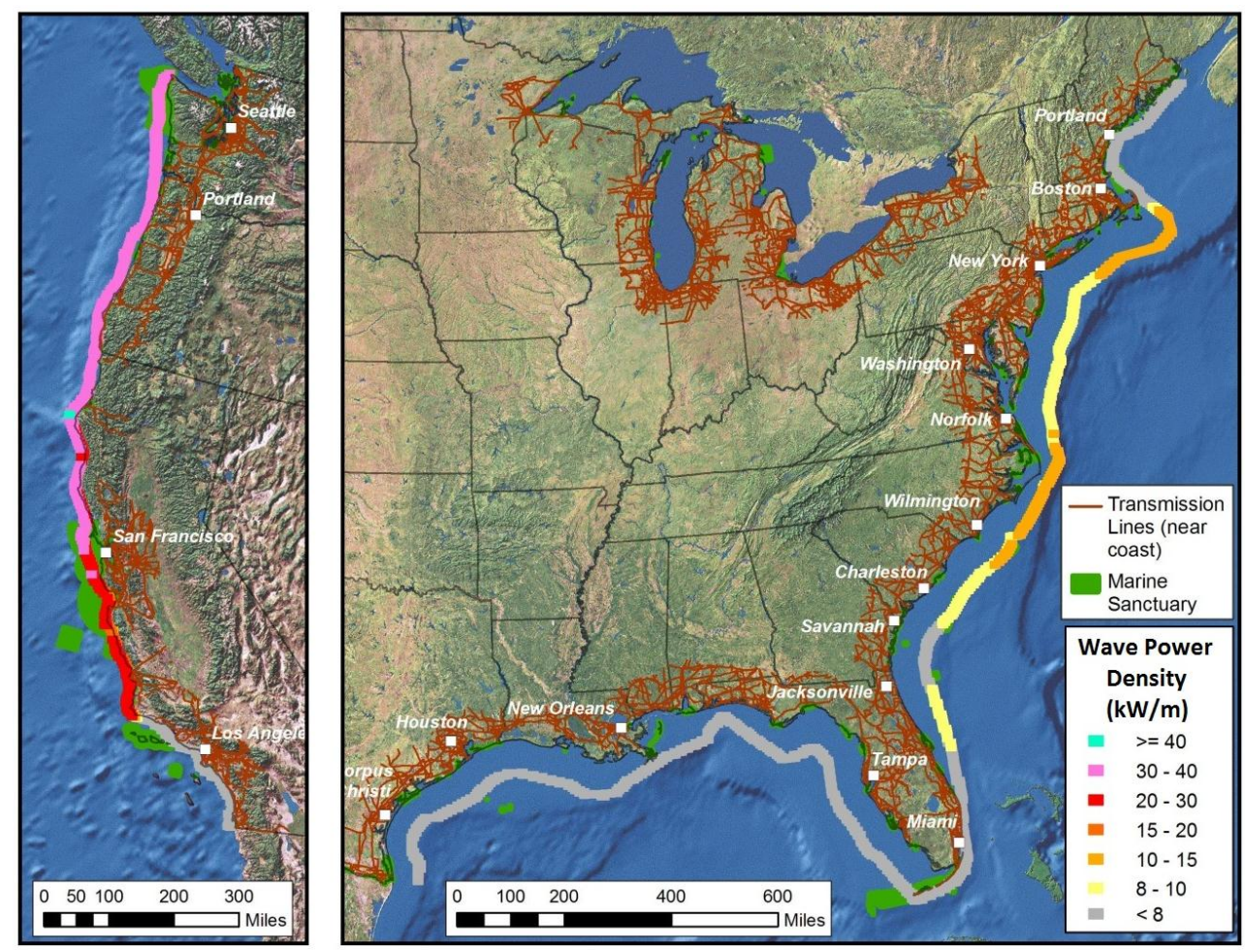

Figure 40 - Wave energy developable sites in the contiguous U.S. at 100-m depth 
The gray sites have annual average power densities of less than $8 \mathrm{~kW} / \mathrm{m}$ and were not included in the supply curves because they would be very costly to develop. For completeness those sites are shown both here and later in the COE maps to present a complete summary of the U.S. wave resource. In Figure 41, Alaska also has the 600-mile transmission distance exclusion that limits the wave resource further.

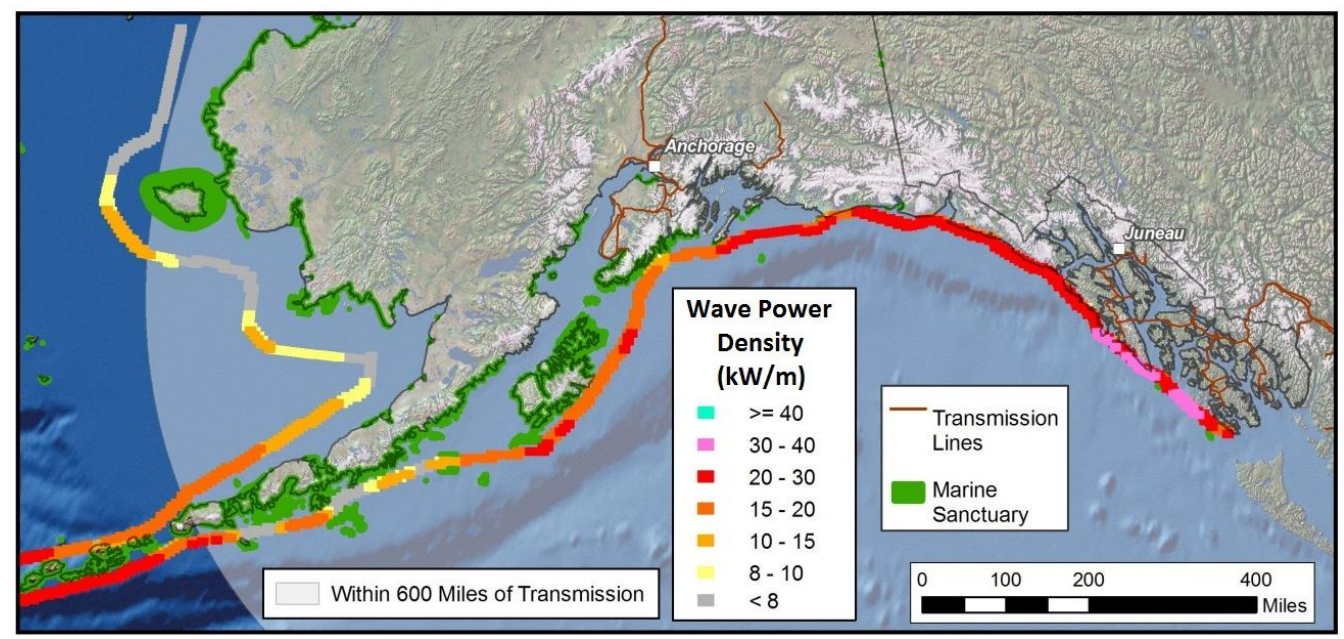

Figure 41 - Wave energy developable sites in Alaska at 100-m depth

The Hawaiian wave resource is closer to shore than elsewhere in the United States because the 100-m depth contours are close to shore. High power density resource areas are located on the north-facing coastlines. Figure 42 shows the deployment locations of interest.

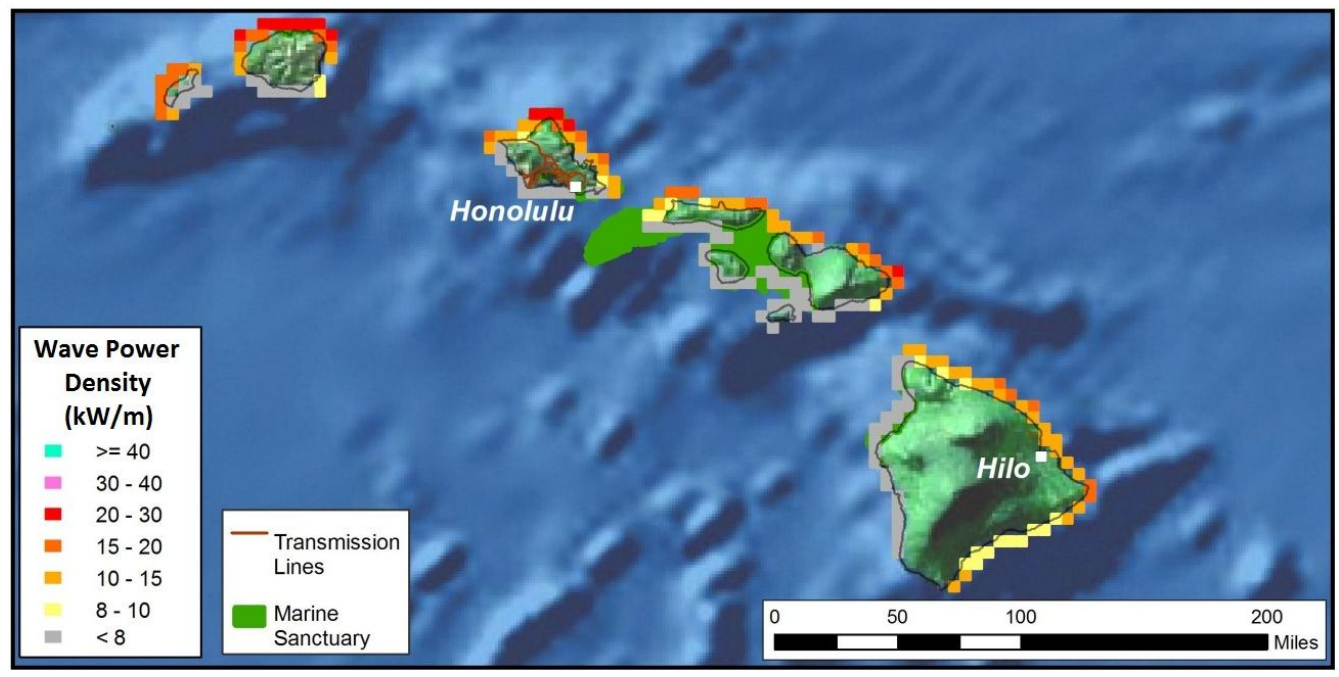

Figure 42 - Wave energy developable sites in Hawaii at 100-m depth 
Using the wave power density contours, the total average resource potential was calculated from the power flux and the wave front length (see Table 16).

Table 16 - Annual Average Wave Power

\begin{tabular}{|l|r|}
\hline Region & Resource Total (MW) \\
\hline Contiguous United States & 88,940 \\
\hline Alaska & 111,030 \\
\hline Hawaii & 11,160 \\
\hline Total & 211,130 \\
\hline
\end{tabular}

\section{Site-Specific Cost of Electricity}

To understand the COE as a function of deployment site conditions, relevant site parameters such as water, depth and resource strength must be considered. The team calculated site-specific COE using the parametric relationships described in Chapter 8.
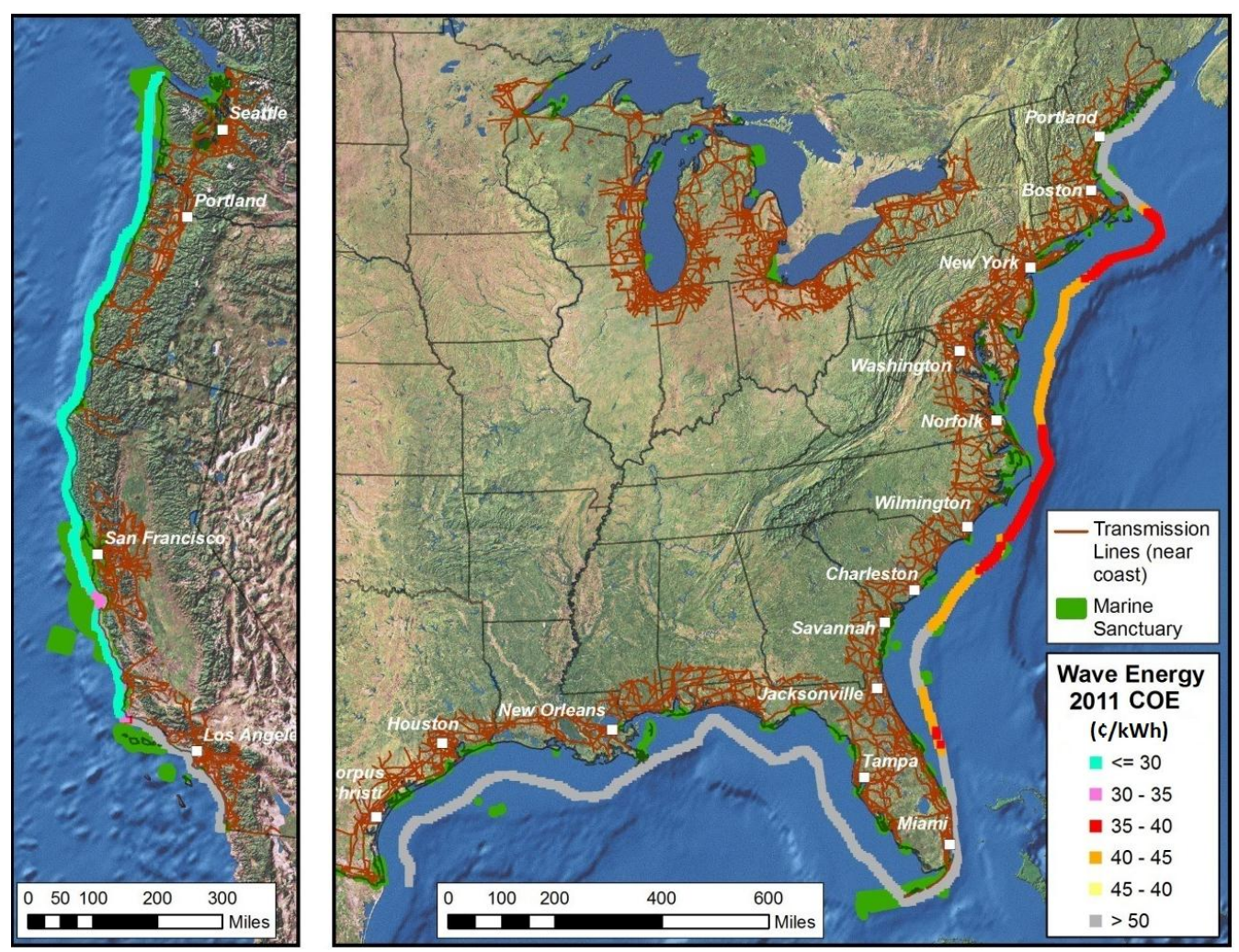

\section{Figure $43-$ COE for the contiguous U.S. wave resource at 100-m depth}

The developable sites with the lowest COE are located off the West Coast of the contiguous United States. These sites have high resource intensity while still being close to shore and existing grid 


\section{revision}

infrastructure, and the resulting cost of electricity ranges from $25-42 \phi / \mathrm{kWh}$. The East Coast wave resource has lower energy fluxes and is much farther offshore, leading to a higher COE. The East Coast assigned costs range from $38-47 \phi / \mathrm{kWh}$.

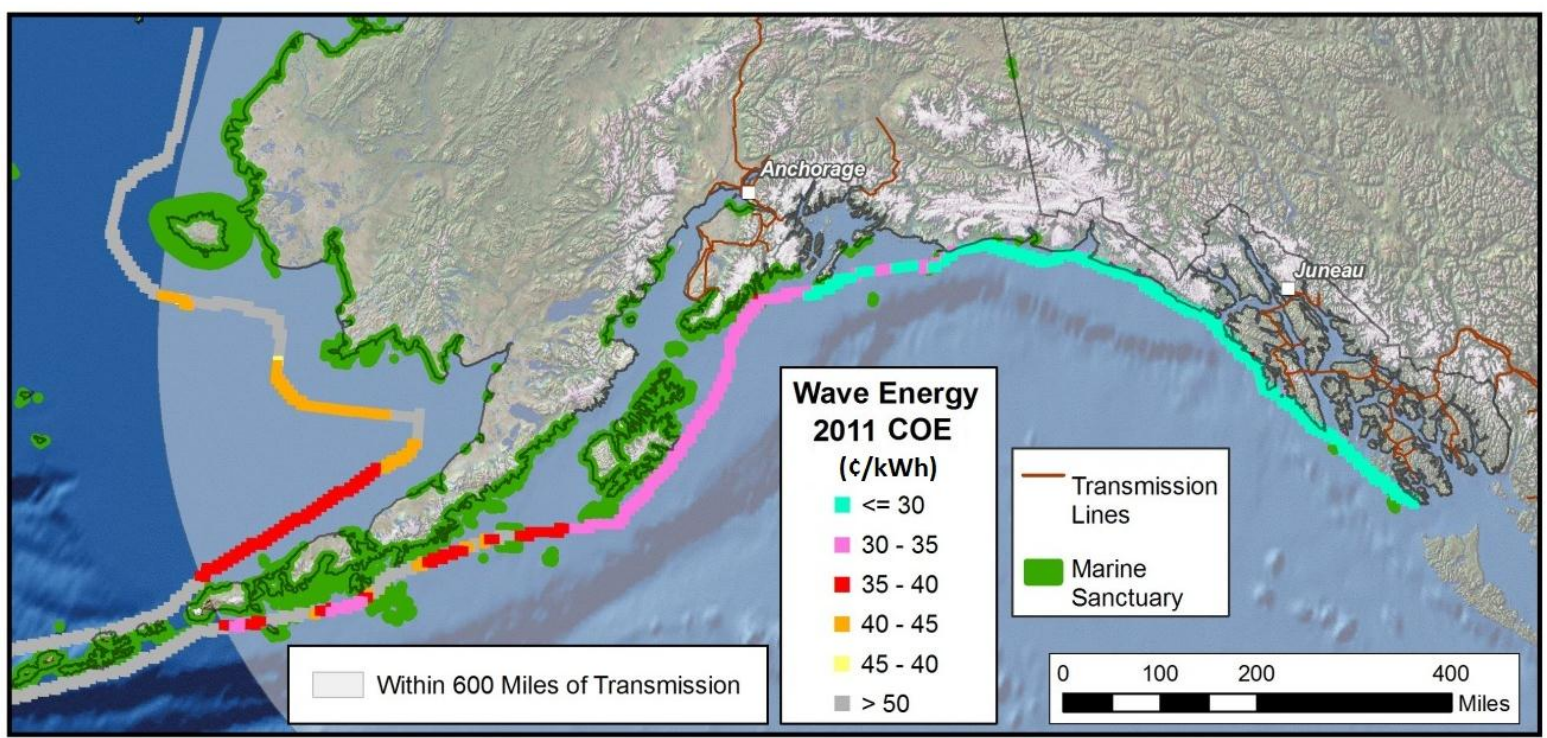

\section{Figure $44-$ COE for Alaskan wave resource at 100-m depth}

As shown in the figure beforehand, Alaska has many areas of high resource intensity, but most of the resource is located far from the existing infrastructure, resulting in a large range of COE spanning 26-49 $\phi / \mathrm{kWh}$.

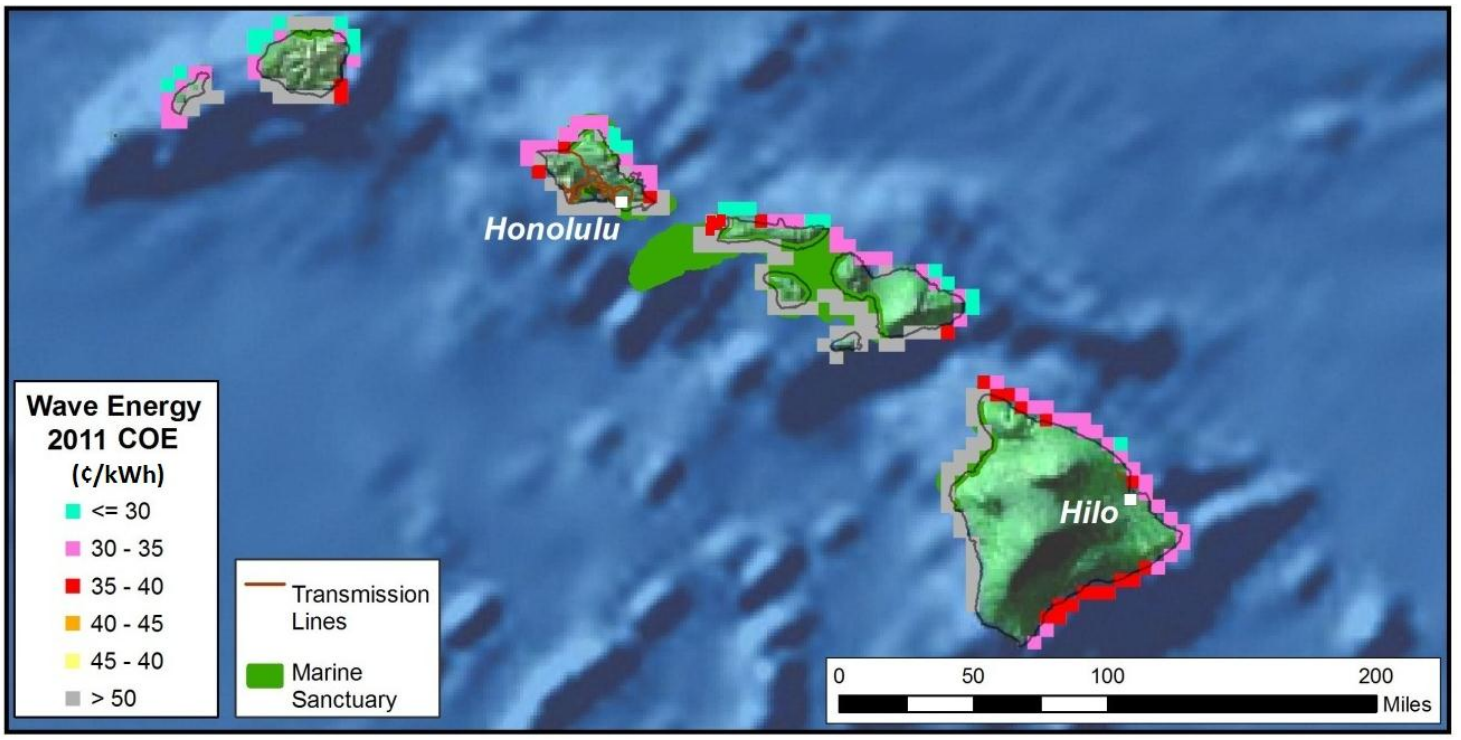

Figure 45 - COE for Hawaiian wave resource at 100-m depth 
Hawaii has a smaller pool of relatively good resource areas near shore, with total assigned costs ranging from 28 to $41 \notin / \mathrm{kWh}$.

\section{Supply Curve Scenarios}

Using the wave energy resource database, the exclusion information, Capex and Opex cost profiles, and the site and grid capacities, the team developed supply curves for two different scenarios, a baseline scenario (15\% deployment density with all exclusions) and an optimal scenario (70\% deployment density without any marine sanctuary exclusions). This was done largely to identify the likely range of potential generation given the inherent uncertainties in technology attributes.

These scenarios were chosen to represent where the technology is today (15\%) and where the upper limit for the technology could be $(70 \%)$. Sites with marine sanctuaries were excluded from the $15 \%$ scenario but included in the $70 \%$ scenario to identify the likely upper limits to extraction. Figure 46 shows the supply curves resulting from the resource and grid component assignments for Alaska, Hawaii, and the contiguous United States, along with a total aggregate supply.

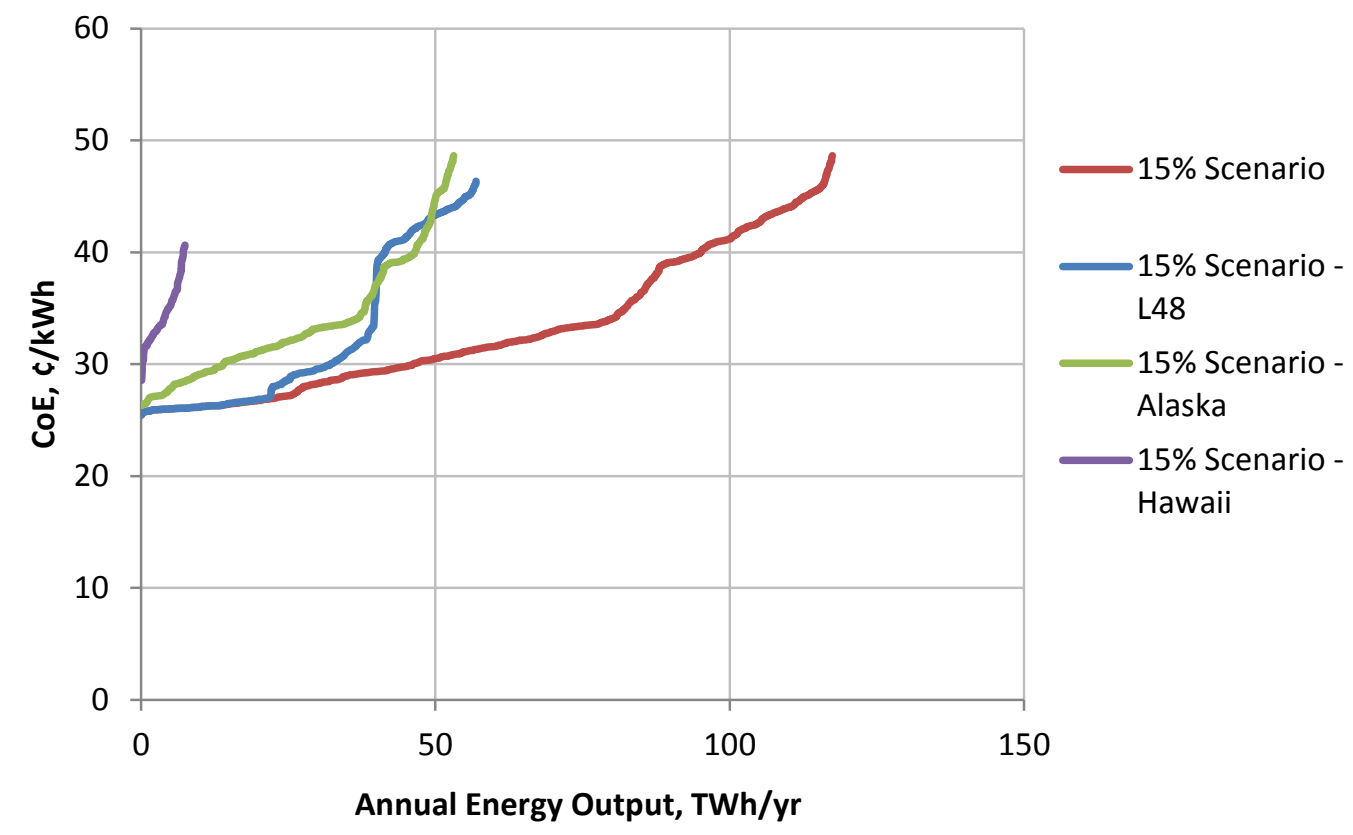

Figure 46 - Wave energy supply curve, $15 \%$ scenario results by region

It is illustrative to understand how the theoretical resource is reduced to a technically extractable resource as filters are applied to the overall model. Table 17 details how the resource reduces from the theoretical to the practical resource for the $15 \%$ scenario. 
Table 17 - 15\% Scenario Wave Energy Extractable Potential (TWh/yr Annual Energy Output)

\begin{tabular}{|l|r|r|r|r|r|}
\hline & Hawaii & Alaska & Lower $\mathbf{4 8}$ & Total & $\%$ \\
\hline Theoretical Resource & 98 & 973 & 779 & 1,849 & $100 \%$ \\
\hline Technical Resource Filters & 15 & 146 & 117 & 277 & $15 \%$ \\
\hline Deployment Density Filter (15\%) & 11 & 109 & 87 & 207 & $11 \%$ \\
\hline Power Conversion Efficiency and Availability & \multicolumn{5}{|c|}{} \\
\hline Practical Resource Filters & 9 & 105 & 72 & 186 & $10 \%$ \\
\hline Economic Power Density Filter $>8 \mathrm{~kW} / \mathrm{m}$ & 9 & 53 & 72 & 135 & $7 \%$ \\
\hline 600-Mile Distance to Grid Filter & 7 & 53 & 57 & 117 & $6 \%$ \\
\hline Marine Protected Area Filter & $\mathbf{7}$ & $\mathbf{5 3}$ & $\mathbf{5 7}$ & $\mathbf{1 1 7}$ & $\mathbf{6 \%}$ \\
\hline Practical Annual Energy Output &
\end{tabular}

Figure 47 shows the supply curve for Alaska, Hawaii, the contiguous United States, and the total supply curve which combines each region.

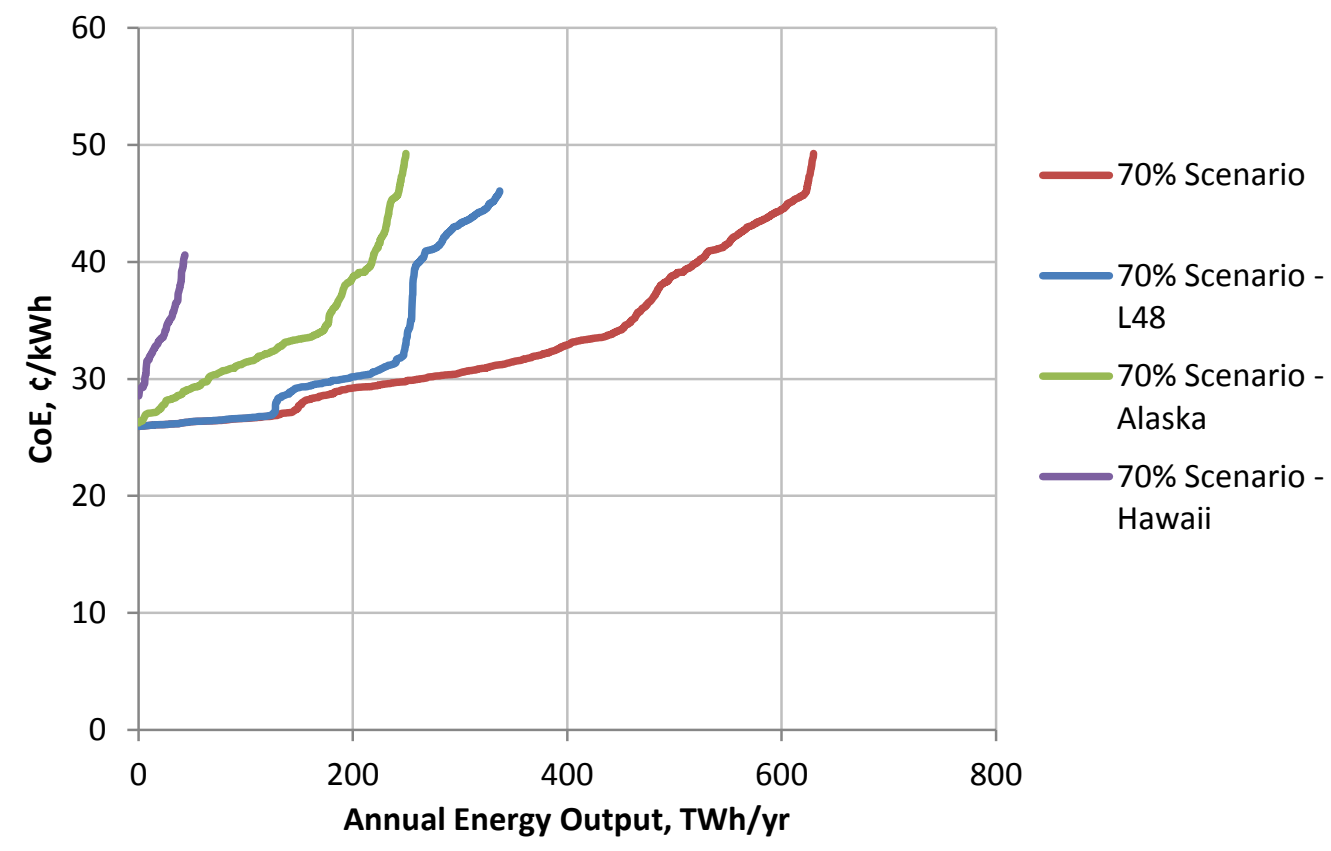

Figure 47 - Wave energy supply curve, $70 \%$ scenario results by region

As shown in Table 18 the $70 \%$ scenario provides over five times the energy output in the supply curve when compared to the $15 \%$ scenario. 
Table 18 - 70\% Scenario Upper Limits to Wave Energy Extraction Potential (TWh/yr Annual Energy Output)

\begin{tabular}{|l|r|r|r|r|r|}
\hline & Hawaii & Alaska & Lower $\mathbf{4 8}$ & Total & $\%$ \\
\hline Theoretical Resource & 98 & 973 & 779 & 1,849 & $100 \%$ \\
\hline Technical Resource Filters \\
\hline Deployment Density Filter (70\%) & 68 & 681 & 545 & 1,295 & $70 \%$ \\
\hline Power Conversion Efficiency and Availability & 51 & 507 & 406 & 964 & $52 \%$ \\
\hline Practical Resource Filters & 43 & 488 & 337 & 868 & $47 \%$ \\
\hline Economic Power Density Filter $>8 \mathrm{~kW} / \mathrm{m}$ & 43 & 249 & 337 & 630 & $34 \%$ \\
\hline 600-Mile Distance to Grid Filter & $\mathbf{4 3}$ & $\mathbf{2 4 9}$ & $\mathbf{3 3 7}$ & $\mathbf{6 3 0}$ & $\mathbf{3 4 \%}$ \\
\hline Practical Annual Energy Output &
\end{tabular}

Because the filters are applied in sequential order, some of the filters applied near the end of the process appear to have a smaller impact than the ones that were applied first. To weigh the relevance of each one of the practical resource filters on annual energy output, each filter was applied to the technical resource individually to measure their relative impact. Table 19 summarizes the relative reduction in total resource potential for each filter. As expected, the distance to grid filter has the most dominant affect because it excludes a significant portion of Alaska's wave energy resource.

Table 19 - Independent Effect of Applying Practical Resource Filters for $70 \%$ Scenario (TWh/yr)

\begin{tabular}{|l|r|r|r|r|r|}
\hline Limiting Factor & Hawaii & Alaska & Lower 48 & Total & \% of Total \\
\hline Technical Resource & 51 & 507 & 406 & 964 & \\
\hline Economic Power Flux Filter & -8 & -19 & -69 & -96 & $-10 \%$ \\
\hline Distance to Grid Filter & 0 & -245 & 0 & -245 & $-25 \%$ \\
\hline Marine Protected Area Filter & -11 & -2 & -73 & -86 & $-9 \%$ \\
\hline
\end{tabular}




\section{revision}

\section{ReEDS Analysis for the Contiguous United States}

The U.S. electricity sector is a complex system, and understanding the potential impacts of introducing new power generation technologies into this system is not trivial. Technology costs and performance characteristics, load requirements, system reliability, and transmission infrastructure are all important factors in making capacity expansion and dispatch decisions for the electric sector.

NREL's ReEDS model takes these factors into consideration in great detail for the contiguous United States. ReEDS is an electric sector capacity expansion model that optimizes investment and dispatch decisions for power generation technologies in the contiguous United States through 2050. ReEDS chooses the optimal mix of technologies that meet all regional and temporal electric power demand requirements, grid reliability reserve requirements, technology resource constraints, and policy constraints. As such it is uniquely suited to assess the economic potential of the WEC technologies examined in this report. As with most capacity expansion models of the United States, ReEDS not only considers the cost competitiveness of wave power relative to other electricity generation technologies, but it also directly addresses major integration issues associated with the variability of the wave resources, the transmission requirements for these technologies, and the balance of generation technologies available in a particular region.

In this analysis, the team used ReEDS to determine what percentage of the total available wave resource in the contiguous United States might be used to produce electricity given various reductions in today's wave technology cost by 2022. During the analysis, the team took resource variability and transmission issues in account, and assumed BAU electricity system operation and expansion policies. Appendix III expands on the background to the ReEDS modeling assumptions.

\section{Scenarios Considered}

In general, this ReEDS model analysis examined the potential of wave technology in a BAU electric system operation case assuming some reduction in today's cost of wave energy by 2022 . The figures and tables in the following sections include data labels for each ReEDS model run in the form of a percent cost reduction by 2022 followed by the supply curve deployment density assumption for that scenario. For instance, a scenario with an $80 \%$ reduction in today's COE by 2022 - using the $15 \%$ scenario supply curve assumption - is labeled as $80 \% \mathrm{CR}-15 \%$. Table 20 shows the names for all scenarios run with ReEDS. 
Table 20 - List of Scenario Names for the ReEDS Analysis

\begin{tabular}{|c|c|c|c|}
\hline Scenario & $\begin{array}{r}70 \% \text { Cost Reduction by } \\
2022 \\
\end{array}$ & $\begin{array}{r}75 \% \text { Cost Reduction by } \\
2022 \\
\end{array}$ & $\begin{array}{r}80 \% \text { Cost Reduction by } \\
2022 \\
\end{array}$ \\
\hline 15\% Deployment Density & $70 \%$ CR $-15 \%$ & $75 \% \mathrm{CR}-15 \%$ & $80 \% C R-15 \%$ \\
\hline 70\% Deployment Density & $70 \% \mathrm{CR}-70 \%$ & $75 \% \mathrm{CR}-70 \%$ & $80 \% \mathrm{CR}-70 \%$ \\
\hline
\end{tabular}

The reductions in wave technology costs are assumed to occur through learning benefits from installing commercial wave plants throughout the world. As a learning curve reference point, $100 \mathrm{MW}$ of global wave capacity was assumed to be installed by 2016 . Using an $85 \%$ progress ratio, the assumed global installed wave capacity to achieve the desired cost reduction levels by 2022 was calculated using the following equation:

$Q_{2022}=Q_{2016} * 2^{\left(\frac{\ln (1-r)}{\ln (0.85)}\right)}$

where

$Q_{2016}$ - global installed wave capacity by 2016

$Q_{2022}$ - global installed wave capacity by 2022

$r$ - percent cost reduction to be achieved by 2022

These assumed global wave installations by 2022 to achieve the desired cost reductions are shown in brackets in Table 21, along with supply curve cost ranges and supply curve capacities. Note that any estimated U.S. capacity installations by 2022 from the ReEDS results are implicit in the assumed global capacities in 2022.

Table 21 - Cost Reduction Scenarios Considered for Each Wave Resource Supply Curve

\begin{tabular}{|l|r|r|r|r|r|}
\hline Supply Curve & $\begin{array}{r}\text { Today's COE } \\
\text { Range } \\
(\mathbf{c} / \mathbf{k W h})\end{array}$ & $\begin{array}{r}\text { Contiguous U.S. } \\
\text { Supply Curve } \\
\text { Capacity (GW) }\end{array}$ & \multicolumn{3}{|r|}{$\begin{array}{r}\text { Assumed Cost Reduction in Today's COE by 2022 } \\
\text { [Assumed Global Capacity by 2022] }\end{array}$} \\
\cline { 1 - 2 } $15 \%$ & $25.4-48.6$ & 23.3 & $70 \%$ & $75 \%$ & $80 \%$ \\
\cline { 1 - 2 } & $25.9-49.2$ & 137.7 & [17-GW Global] & [37-GW Global] & [95.7-GW Global] \\
\hline
\end{tabular}

Figure 48 shows all supply curves, $15 \%$ and $70 \%$ deployment densities, at each cost reduction level by $2022(70 \%, 75 \%$, and $80 \%)$ assuming no resource is used. Even though the COE range is approximately the same between the supply curves, the total available wave resource varies. 


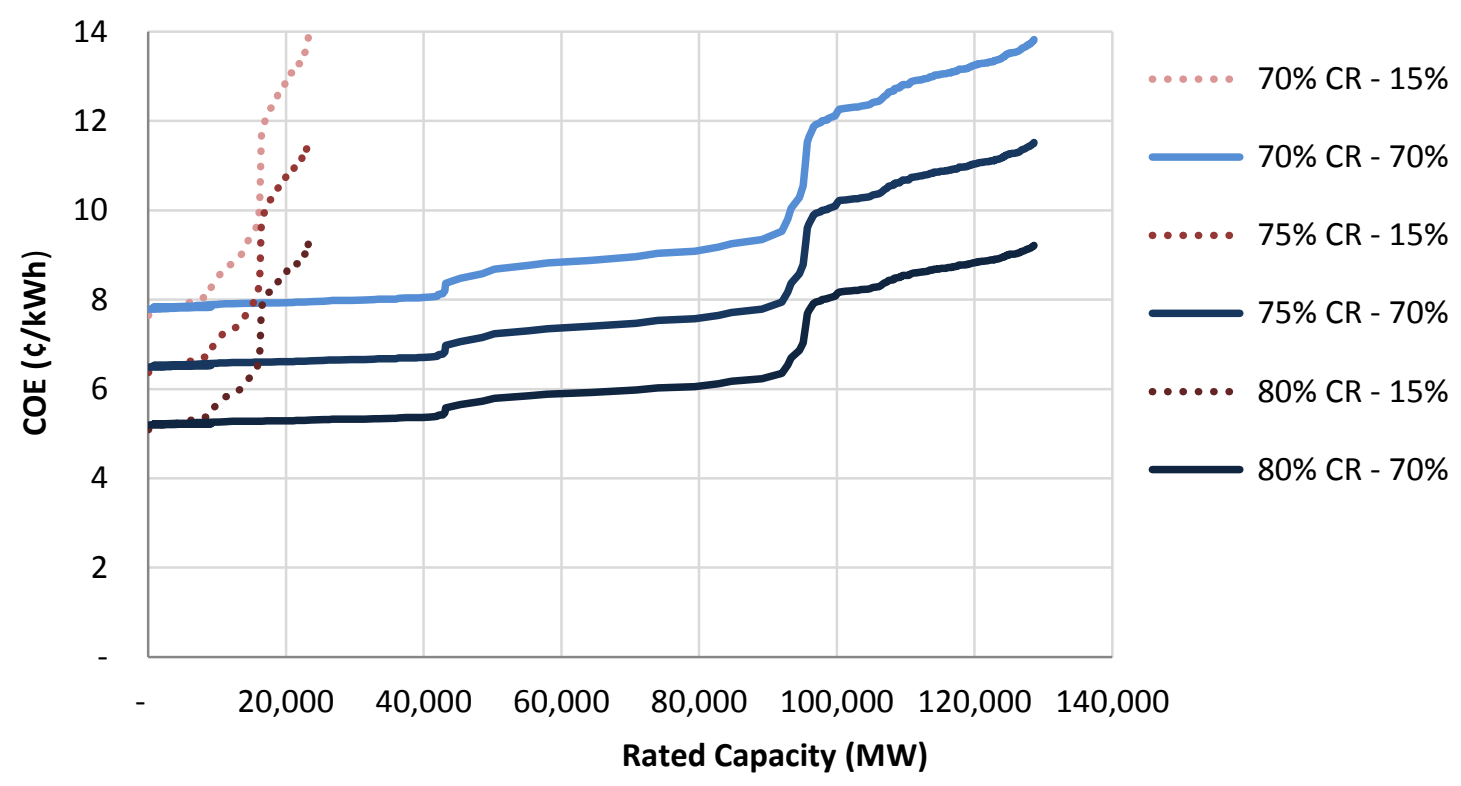

Figure 48 - L48 supply curves at various cost reduction levels by 2022

\section{Results from ReEDS}

Figure 49 shows the ReEDS estimations for deployment levels of WEC technologies through 2050 for the three different supply curves as a function of the COE reduction by 2022 . At a $75 \%-80 \%$ reduction in today's wave energy cost by 2022, significant fractions of the total supply curve capacity could be utilized.

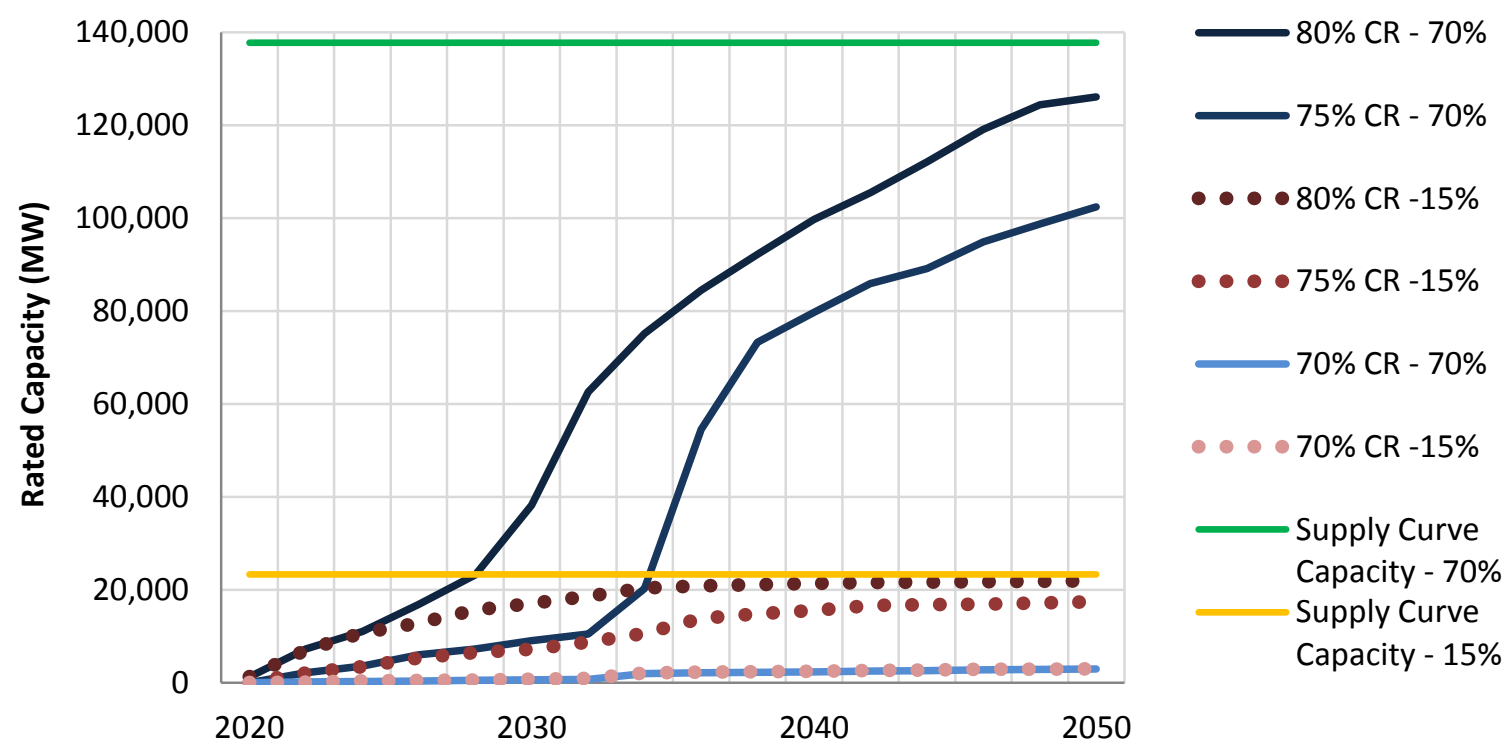

Figure 49 - L48 estimated cumulative wave capacity deployment through 2050 
Table 22 shows the wave capacity deployment and percent of total resource deployed by 2030 and 2050 for the various cost reduction scenarios and supply curves. For the optimal scenario $70 \%$ supply curve, ReEDS estimates that by $2050,92 \%(126 \mathrm{GW})$ of the $138 \mathrm{GW}$ in the supply curve is economical (practical resource) if an $80 \%$ cost reduction is achieved by $2022 ; 74 \%(102 \mathrm{GW})$ is economical at a $75 \%$ cost reduction; and $2 \%(2.91 \mathrm{GW})$ is economical at a $70 \%$ cost reduction.

Table 22 - Estimated Wave Capacity Deployment (GW) by 2030 and 2050 for the Various Cost Reduction Scenarios and Supply Curves

\begin{tabular}{|l|r|r|r|r|}
\hline $\begin{array}{l}\text { Cost Reduction } \\
\text { by 2022 }\end{array}$ & $\begin{array}{r}\text { 2030 Capacity (GW) } \\
\text { [\% of Supply Curve Capacity] }\end{array}$ & $\begin{array}{r}\text { 2050 Capacity (GW) } \\
\text { [\% of Supply Curve Capacity] }\end{array}$ \\
\hline $70 \%$ CR & $15 \%$ Scenario & $70 \%$ Scenario & $15 \%$ Scenario & $70 \%$ Scenario \\
\hline $75 \%$ CR & $0.74[3 \%]$ & $0.58[0.4 \%]$ & $3.01[13 \%]$ & $2.91[2 \%]$ \\
\hline $80 \%$ CR & $7.18[31 \%]$ & $9.04[7 \%]$ & $17.4[75 \%]$ & $102[74 \%]$ \\
\hline $\begin{array}{l}\text { Rated Capacity } \\
\text { (GW) }\end{array}$ & $17.0[73 \%]$ & $38.2[28 \%]$ & $21.9[94 \%]$ & $126[92 \%]$ \\
\hline
\end{tabular}

Figure 50 and Figure 51 show estimations for capacity and generation, respectively, in 2030 and 2050 for the various scenarios. These figures illustrate that large cost reductions in wave technologies will be needed before a significant fraction of the resources can be accessed for electric power production, at which point wave power might provide $2 \%$ and $5.8 \%$ of the national generation by 2030 and 2050, respectively.

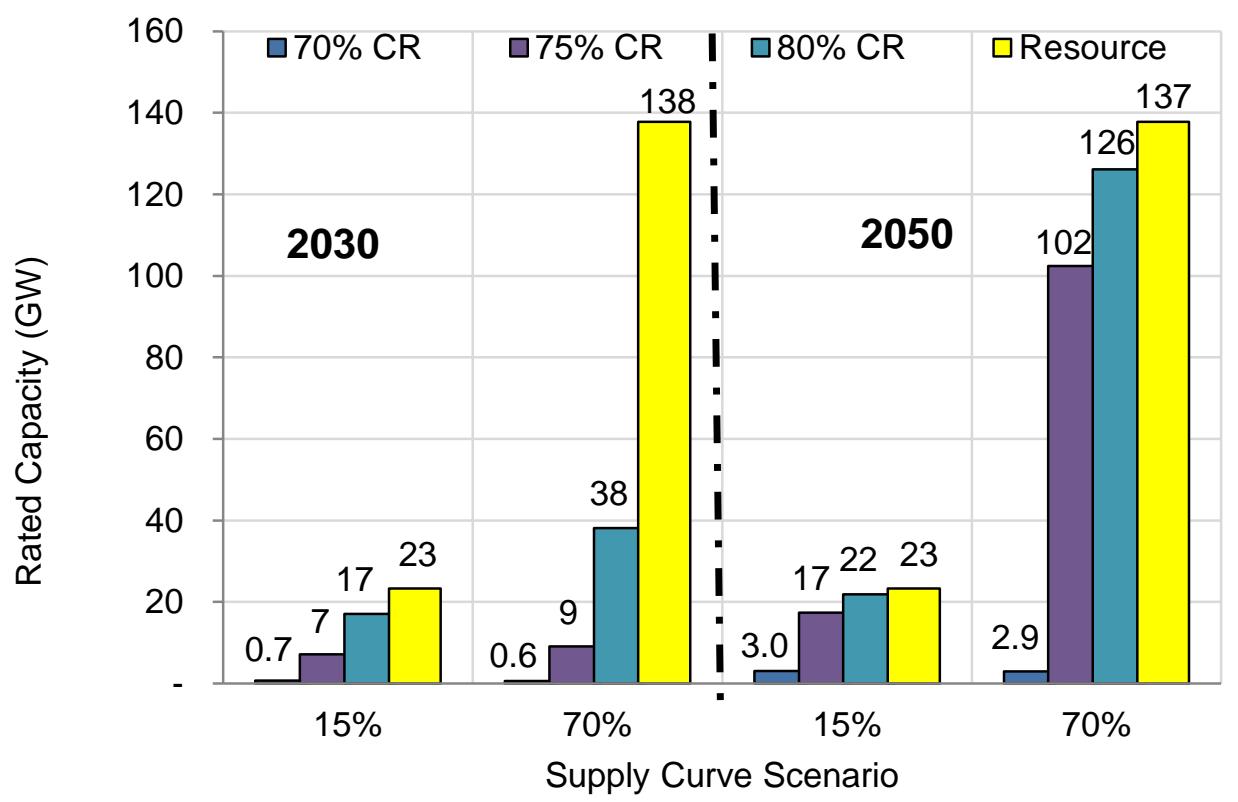

Figure 50 - L48 estimated cumulative wave capacity installation in 2030 and 2050. 


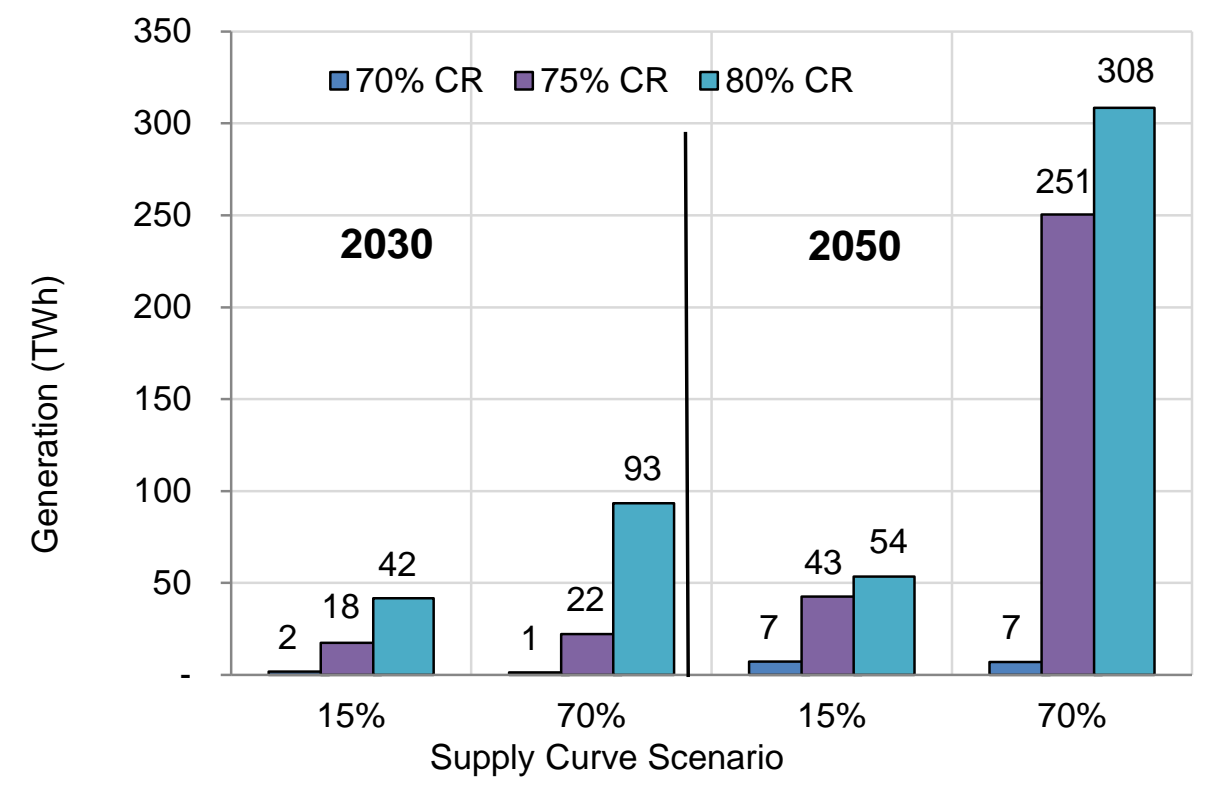

Figure 51 - L48 estimated annual wave energy generation in 2030 and 2050

Figure 52 and Figure 53 show a geographical representation of the estimated WEC technology deployment by 2030 and 2050 for the $80 \%$ CR $-15 \%$ and the $80 \%$ CR $-70 \%$ scenarios. Wave technology deployment is heavily concentrated on the Pacific Coast where the wave resource has higher power densities.

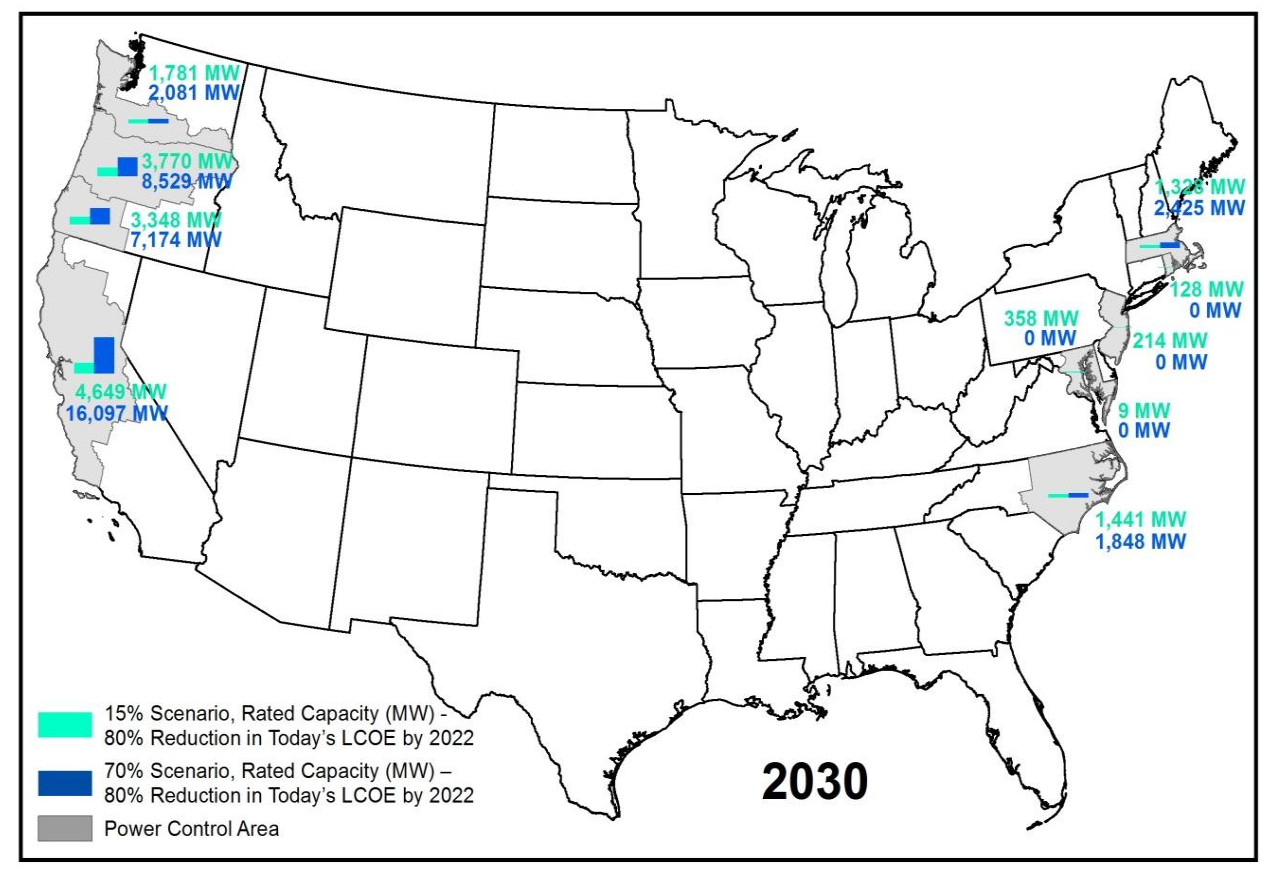

Figure 52 - Estimated geographical deployment of wave technology by 2030 


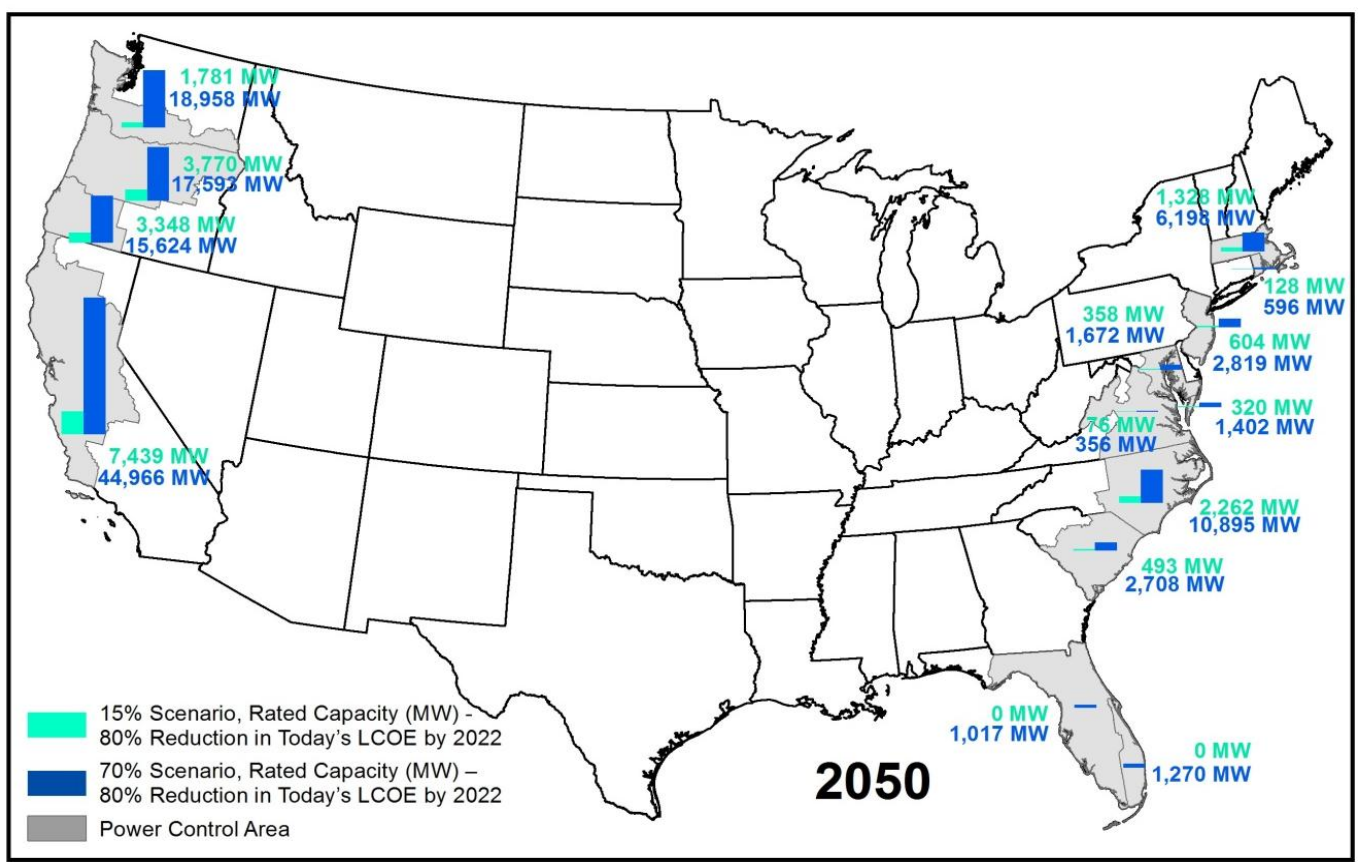

Figure 53 - Estimated geographical deployment of wave technology by 2050

In general, electrical energy generated from ocean waves will likely contribute to greater percentages of electrical loads for states in the western United States because of the heavy wave resource concentration on the Pacific Coast versus the Atlantic Coast. Although the energy contribution from wave power to the national load might be relatively small, wave technologies could provide noticeable quantities of energy to individual states. By 2050, energy from waves could contribute to a significant percentage of electricity demand in diversified mixture of coastal and inland locations.

Table 23 displays the source data for Figure 52 and Figure 53, respectively, as well as state RPS that are taken from the Database of State Incentives for Renewable Energy (DSIRE). ${ }^{\text {a }}$ The state RPS requires a utility to install or generate a certain fixed amount of renewable capacity or energy. Unless prohibited by law, a state might also meet the requirement by importing electricity. These tables show that a RPS policy is enacted for the majority of the states where wave power might contribute to load, suggesting that this particular policy will likely aid in future deployment.

\footnotetext{
${ }^{a}$ Database of State Incentives for Renewable Energy (DSIRE). http://www.dsireusa.org/. Accessed January 2010.
} 
Table 23 - Percentage of Annual Load Met by Wave Energy for States in the L48 Where Wave Energy is Delivered in 2030 and 2050

\begin{tabular}{|c|c|c|c|c|c|}
\hline \multirow{2}{*}{ State } & \multicolumn{2}{|c|}{2030} & \multicolumn{2}{|c|}{2050} & \multirow{2}{*}{ RPS } \\
\hline & $80 \%$ CR - $15 \%$ & $80 \%$ CR - $70 \%$ & $80 \%$ CR - $15 \%$ & $80 \%$ CR - $70 \%$ & \\
\hline Oregon & $3.13 \%$ & $29.7 \%$ & $2.62 \%$ & $74.5 \%$ & $20.4 \%$ \\
\hline Washington & $7.49 \%$ & $7.47 \%$ & $6.27 \%$ & $36.3 \%$ & $12.7 \%$ \\
\hline California & $3.76 \%$ & $13.7 \%$ & $4.50 \%$ & $30.4 \%$ & $32.4 \%$ \\
\hline Nevada & $7.15 \%$ & $7.53 \%$ & $7.21 \%$ & $8.43 \%$ & $22.1 \%$ \\
\hline Colorado & $5.99 \%$ & $5.99 \%$ & $5.16 \%$ & $5.64 \%$ & $19.4 \%$ \\
\hline Utah & - & - & - & $4.93 \%$ & - \\
\hline Montana & $1.34 \%$ & $1.28 \%$ & $1.13 \%$ & $3.61 \%$ & $10.0 \%$ \\
\hline New Mexico & $2.74 \%$ & $2.74 \%$ & $2.59 \%$ & $2.79 \%$ & $15.2 \%$ \\
\hline Arizona & $2.58 \%$ & $2.52 \%$ & $2.29 \%$ & $2.67 \%$ & $6.17 \%$ \\
\hline Vermont & - & - & - & $58.6 \%$ & - \\
\hline North Carolina & - & $1.04 \%$ & $1.21 \%$ & $6.52 \%$ & $11.1 \%$ \\
\hline Pennsylvania & $1.65 \%$ & $1.85 \%$ & $1.49 \%$ & $6.34 \%$ & $17.5 \%$ \\
\hline Maryland & $2.83 \%$ & $2.94 \%$ & $3.03 \%$ & $5.05 \%$ & $19.3 \%$ \\
\hline South Carolina & - & - & - & $4.39 \%$ & - \\
\hline Illinois & - & - & - & $4.33 \%$ & $22.1 \%$ \\
\hline New Hampshire & $2.10 \%$ & $2.30 \%$ & $3.41 \%$ & $4.22 \%$ & $23.4 \%$ \\
\hline Connecticut & $1.62 \%$ & $1.61 \%$ & $2.92 \%$ & $3.60 \%$ & $21.5 \%$ \\
\hline Delaware & $1.65 \%$ & $1.65 \%$ & $2.15 \%$ & $3.58 \%$ & $13.9 \%$ \\
\hline New Jersey & $1.17 \%$ & $1.19 \%$ & $2.19 \%$ & $3.35 \%$ & $24.9 \%$ \\
\hline Massachusetts & $1.46 \%$ & $1.45 \%$ & $2.05 \%$ & $3.23 \%$ & $19.5 \%$ \\
\hline Rhode Island & $1.20 \%$ & $1.19 \%$ & $2.18 \%$ & $2.64 \%$ & $15.9 \%$ \\
\hline New York & - & - & - & $2.16 \%$ & $20.9 \%$ \\
\hline Ohio & - & - & - & $1.89 \%$ & $11.1 \%$ \\
\hline Florida & - & - & - & $1.40 \%$ & - \\
\hline Georgia & - & - & - & $0.78 \%$ & - \\
\hline Michigan & - & - & - & $0.47 \%$ & $10.0 \%$ \\
\hline
\end{tabular}

Figure 54 shows the stacked capacity expansion for all ReEDS technologies over time for the $80 \% \mathrm{CR}-$ $70 \%$ scenario. For this particular scenario, wave capacity deployment reaches about 38.2 and $126 \mathrm{GW}$ by 2030 and 2050, respectively. Gas-CC plants contribute the highest percentage of capacity compared to any other technology because of low natural gas prices, high heat rates, and dispatchability. Combined 
cycle plants can provide both energy and firm capacity, which gives this thermal power generator an advantage over variable-resource renewables.

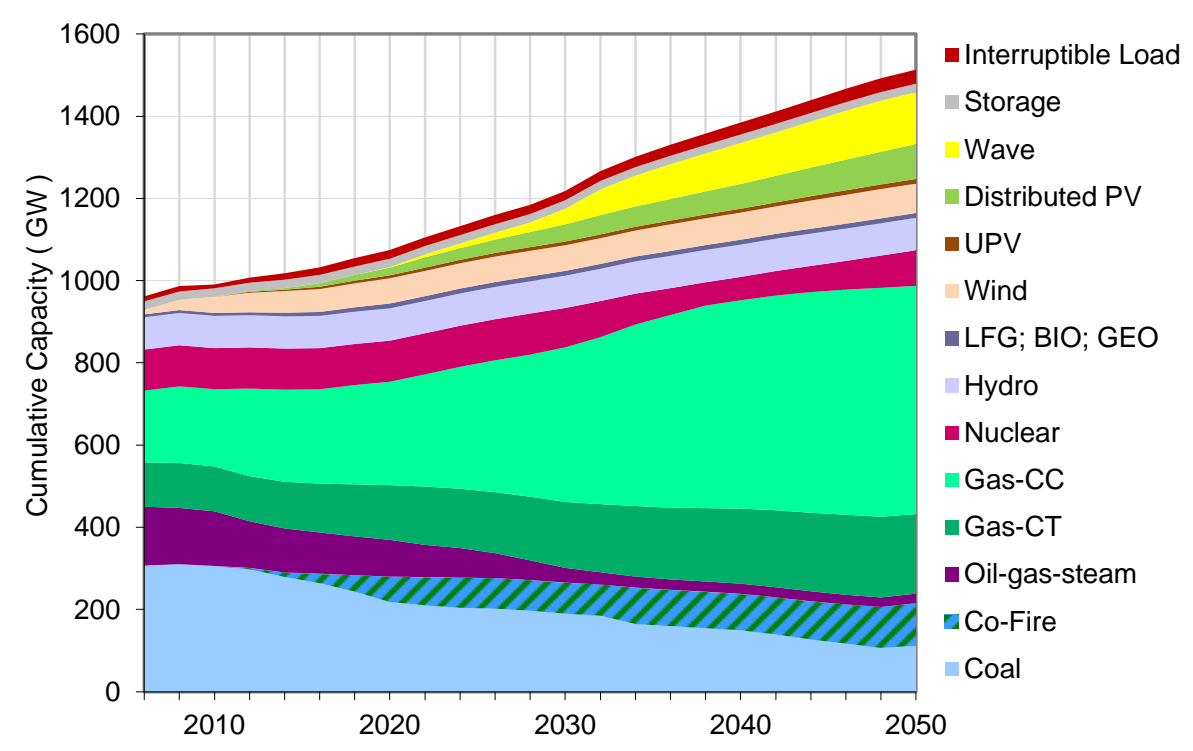

Figure 54 - Estimated capacity expansion over time for all generating technologies - $80 \%$ CR - $70 \%$ Scenario

Figure 55 shows the estimates for annual and cumulative installed wave capacity through 2050 for the $80 \%$ CR $-70 \%$ scenario. Annual wave capacity additions start at about $0.63 \mathrm{GW}$ in 2019 and peak by 2031 at about $12.2 \mathrm{GW}$, which corresponds to a $28 \%$ compound annual growth rate. Recall that for this particular scenario, wave capacity deployment reaches about $28 \%$ and $92 \%$ of the total $136 \mathrm{GW}$ available supply curve capacity by 2030 and 2050, respectively.

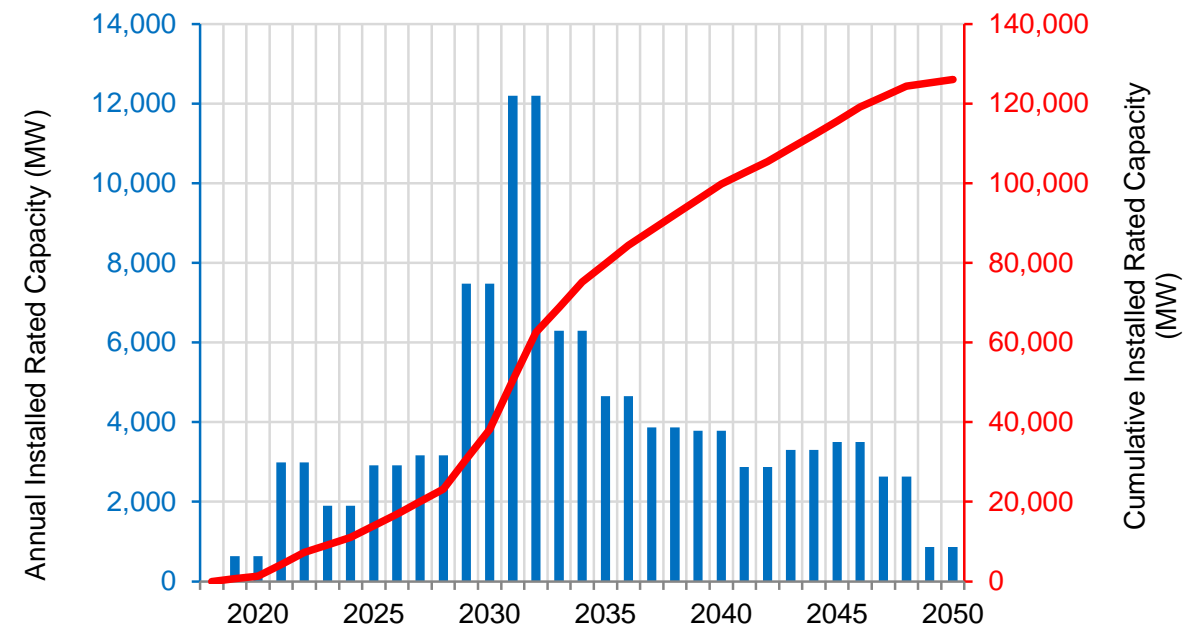

Figure 55 - Estimates for annual and cumulative installed wave capacity through $2050-80 \%$ CR - $70 \%$ 


\section{Policy Scenarios}

The ReEDS BAU scenario gives a more conservative approach for modeling the potential market penetration of renewable technologies. Although not considered in this analysis, wave technologies could also be modeled in a policy scenario such as a clean energy standard (CES), which incentivizes generation from clean energy technologies including renewables, nuclear, natural gas, and plants equipped with carbon capture and sequestration. Technologies that are credited toward achieving a CES can become competitive at a higher cost of energy. Therefore, typical ReEDS model results with a CES policy show renewable technology deployment levels that are greater (baring any resource limitations) and occur sooner than in a BAU scenario. Modeling a CES policy would provide a liberal estimation of potential wave deployment. Because the BAU and CES scenarios can be considered as two extremes for wave deployment, these combined scenario results would provide the bounds for a range of potential outcomes from any variety of policies. 


\section{High-Level Analysis for Hawaii and Alaska}

Alaska and Hawaii have significant wave and tidal resources. In fact, Alaska's wave resources exceed the MHK resources in the contiguous United States. Integration of wave and tidal systems into the electric grids in these two states must address many of the same issues discussed in the preceding sections for the contiguous United States (e.g., cost competitiveness, transmission access, variability issues, etc.). Unfortunately, the team was unable to use the ReEDS model for these two states because ReEDS addresses only the contiguous states and does not include Alaska and Hawaii. Because building a model for these two states was beyond the scope of this analysis, this section presents a simple qualitative assessment of the potential of MHK technologies in these two states. The assessment is based on the data available and the translation of any insights gained from the ReEDS modeling of the contiguous United States

Analyzing the potential of MHK in Alaska and Hawaii is complex because of several unique factors in these two states: significant possible contributions from variables resources, the lack of an interconnected grid, one dominant subgrid in each state, a lack of seasonal load variability, and imported fuels for power.

Both Alaska and Hawaii have other highly variable renewable resources in the form of wind and solar that could further increase the need for reserves. The existence of a state RPS in Hawaii will increase the adoption of these variable renewables, the need for reserves, and the possibility of curtailments of surplus generation during times of low loads and high renewable energy availability. A detailed analysis of these variability issues requires a considerable effort; here the team considers them with some simple bounding concepts. Another factor that affects the market potential of MHK in these two states is the lack of an interconnected grid in each state. As shown in Figure 56 and Figure 57, both states have several small transmission grids serving a major load center and its surrounding area. In Alaska there are two major grids, the Railbelt connecting Anchorage, Fairbanks, and surrounding areas, and the grid around Juneau. In Hawaii, each island has an isolated grid with no interconnection between the islands. These islanded networks are problematic in any scenario because they each have to provide their own reserves; reserves are generally proportionately larger in small balancing areas like these than in the larger areas common in the contiguous United States. The need for additional reserves in such minigrids would be further exacerbated if variable generation from MHK technologies were introduced. 


\section{revision}

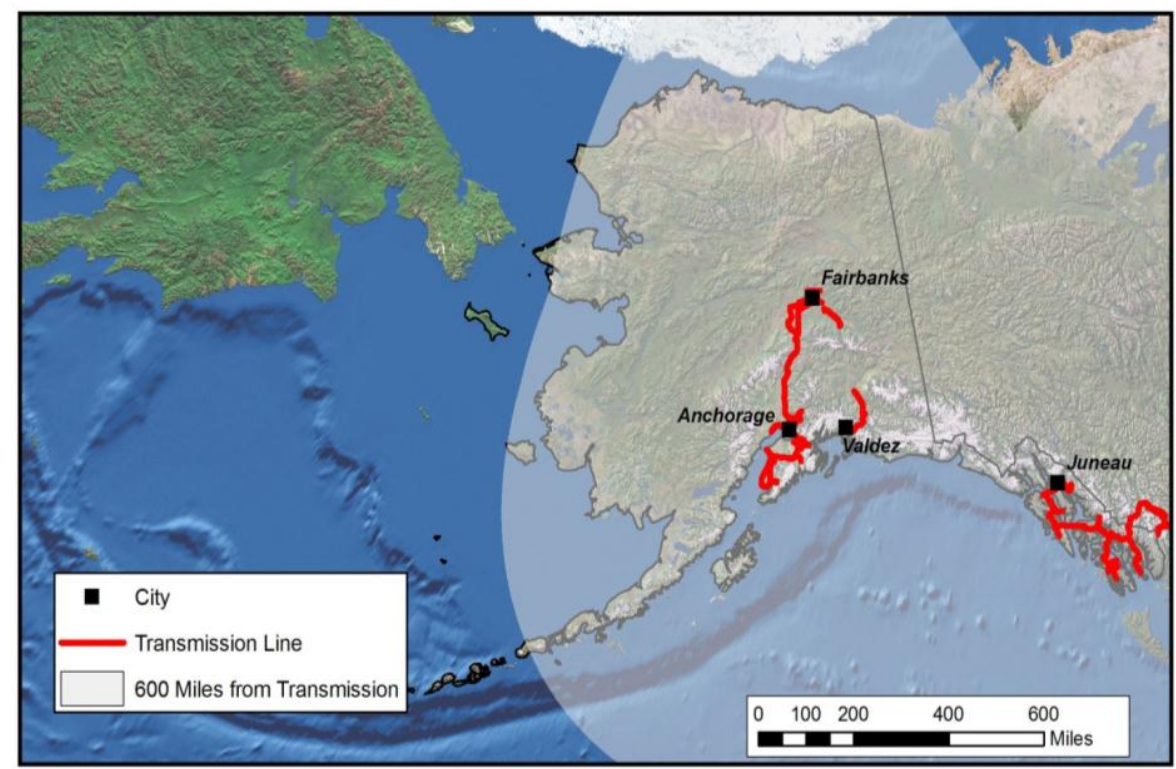

Figure 56 - Alaskan grids and wave resource

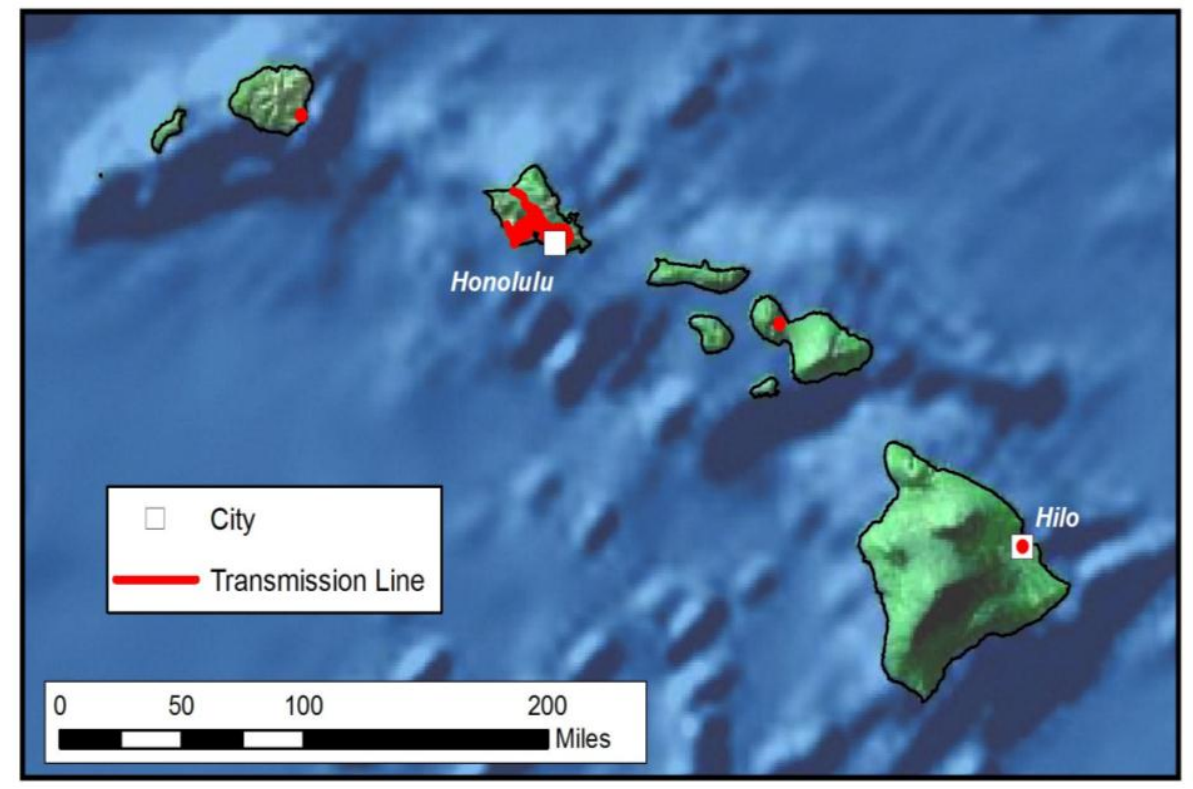

\section{Figure 57 - Hawaiian grids and wave resource}

These two state markets are also similar in that one of the minigrids far outweighs all the other grids in each state. Figure 58 shows that the Railbelt grid in Alaska that serves Anchorage and Fairbanks comprises about two-thirds of the generation in that state. In total, just over 1,400 MW of installed power generation capacity exists along the Railbelt to serve an average load of approximately $600 \mathrm{MW}$ and a peak load of over $800 \mathrm{MW}$. 


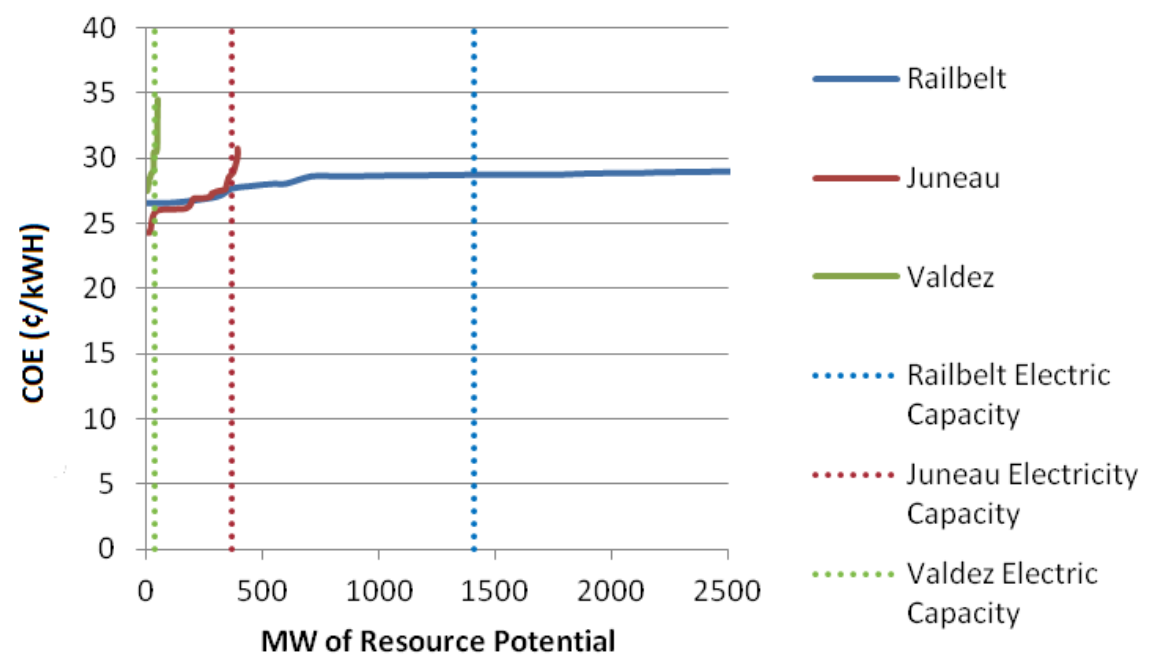

Figure 58 - Alaska wave energy supply curves

The team carried out a simplified electric market assessment to characterize the Alaska and Hawaii electricity markets, which is included in the Appendix I. Table 24 shows some critical characteristics of these markets and put them into context with the contiguous United States.

Table 24 - Regional Comparison Table

\begin{tabular}{|c|c|c|c|}
\hline & Hawaii & Alaska & L48 \\
\hline \multicolumn{4}{|l|}{ Theoretical Wave Resource Potential by Region } \\
\hline Average Wave Resource Potential (GW) & 11 & 111 & 89 \\
\hline Resource Potential (TWh/year) & 98 & 973 & 779 \\
\hline \multicolumn{4}{|c|}{ Practical Wave Resource Potential for $15 \%$ and $70 \%$ Scenarios } \\
\hline Upper Limit Installed Capacity - 70\% Scenario (GW) & 19 & 101 & 138 \\
\hline Upper Limit Installed Capacity - 15\% Scenario (GW) & 3 & 22 & 23 \\
\hline Upper Limit Energy Output - 70\% Scenario (TWh/year) & 35 & 247 & 266 \\
\hline Upper Limit Energy Output - 15\% Scenario (TWh/year) & 7 & 53 & 57 \\
\hline \multicolumn{4}{|l|}{ Electrical Generation Figures $2011^{a}$} \\
\hline Regional Installed Generation Capacity (GW) & 2.6 & 2.5 & 1,160 \\
\hline Regional Electric Energy Generated (TWh/year) & 1.6 & 1.2 & 4,106 \\
\hline \multicolumn{4}{|l|}{ Economic Comparison } \\
\hline Market Cost of Electricity Hurdle Rate ( $\$ / k W h)$ & $13.8^{\mathrm{b}}$ & 7 & $6-7^{c}$ \\
\hline Starting COE of Wave Energy within Region ( $\mathrm{c} / \mathrm{kWh})$ & 28.5 & 26.3 & 25.5 \\
\hline Required Cost Reduction (\%) & $52 \%$ & $73 \%$ & $75 \%$ \\
\hline
\end{tabular}

${ }^{\mathrm{a}}$ EIA (2011a), EIA (2012)

${ }^{\mathrm{b}}$ Based on base FIT; can be significantly higher depending on island and season.

${ }^{c}$ Strongly dependent on region, but $6-7 \mathrm{c} / \mathrm{kWh}$ is indicative for regions with good wave energy resources (i.e., California, Oregon, and Washington) 


\section{revision}

\section{Wave Power in Alaska}

Figure 58 shows the wave power potential in Alaska. The horizontal axis of this figure extends to only 2,500 MW so that the resources in Juneau and Valdez can be emphasized. The Railbelt potential actually includes up to $120 \mathrm{GW}$ of potential, far exceeding the generation capacity owned by Railbelt utilities. Figure 58 also shows, though, that the cost of wave power would have to decrease by $75 \%$ to be competitive.

If such cost reductions were achieved, the strong seasonal variability of wave power shown in Figure 59 would limit the ultimate deployment of wave power. Figure 59 shows that, if one were to build enough wave power capacity to meet the bulk of summer loads in Alaska, there would be surplus wave generation in the winter months. These curtailments would reduce the cost effectiveness of these wave power installations. On the other hand, if the wave capacity was limited to meet the winter loads, much of the summer load would not be met by wave generation.

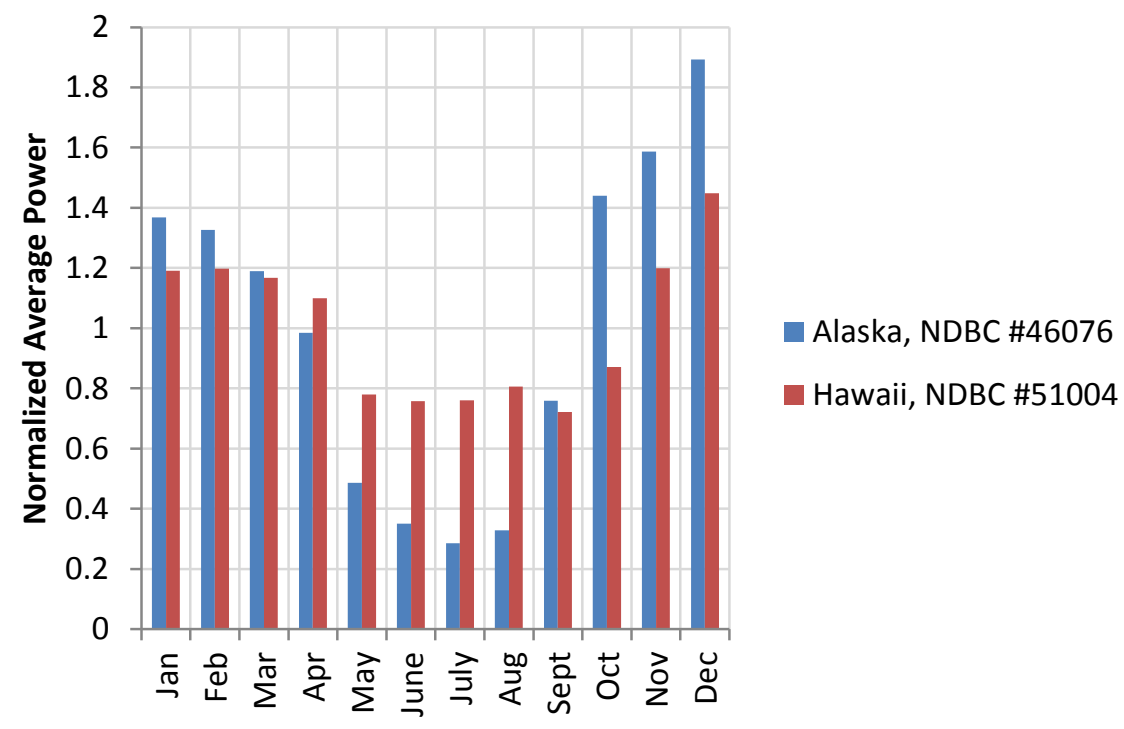

Figure 59 - Monthly wave power variations in Alaska and Hawaii (NDBC) 
Wave Power in Hawaii

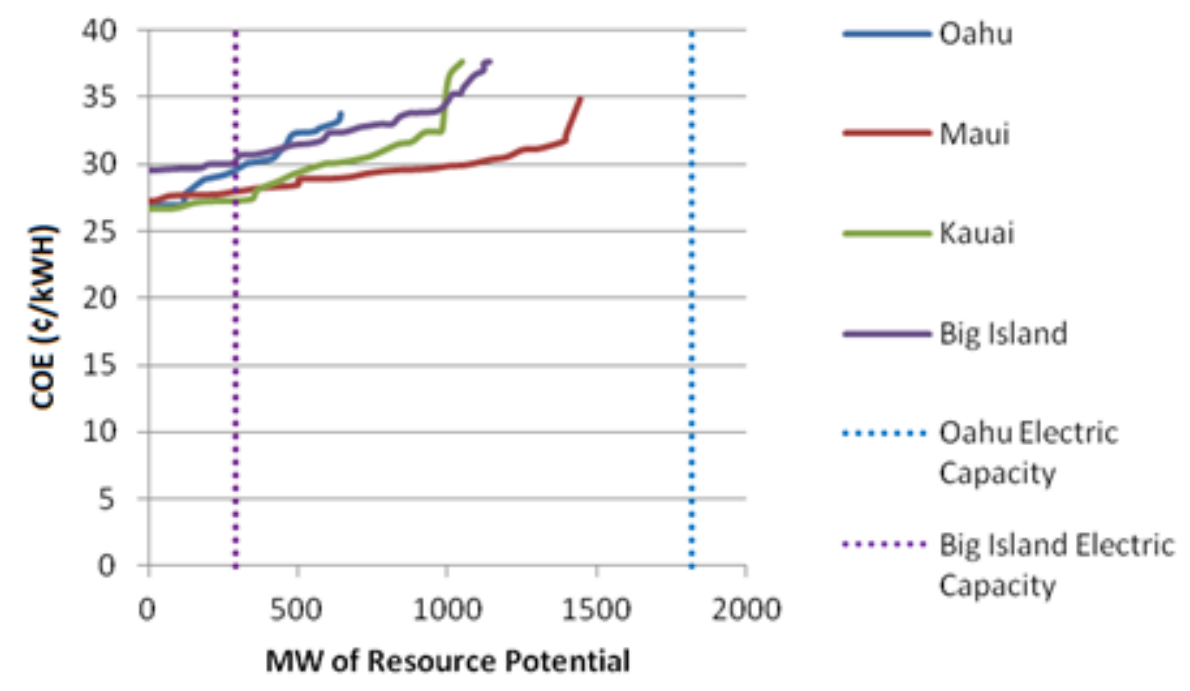

Figure 60 shows that, as with wave power in Alaska, wave power resources in Hawaii exceed installed generation capacity on Maui and the Big Island. The resource available to the largest load center, Oahu, though, is significantly less than today's power capacity on that island. Wave power costs in Hawaii are similar to those in Alaska. To be competitive, however, they would not have to be reduced as much as in Alaska, because the costs of other sources of generation are higher in Hawaii as indicated by avoided costs and FITs (see tables in Appendix I).

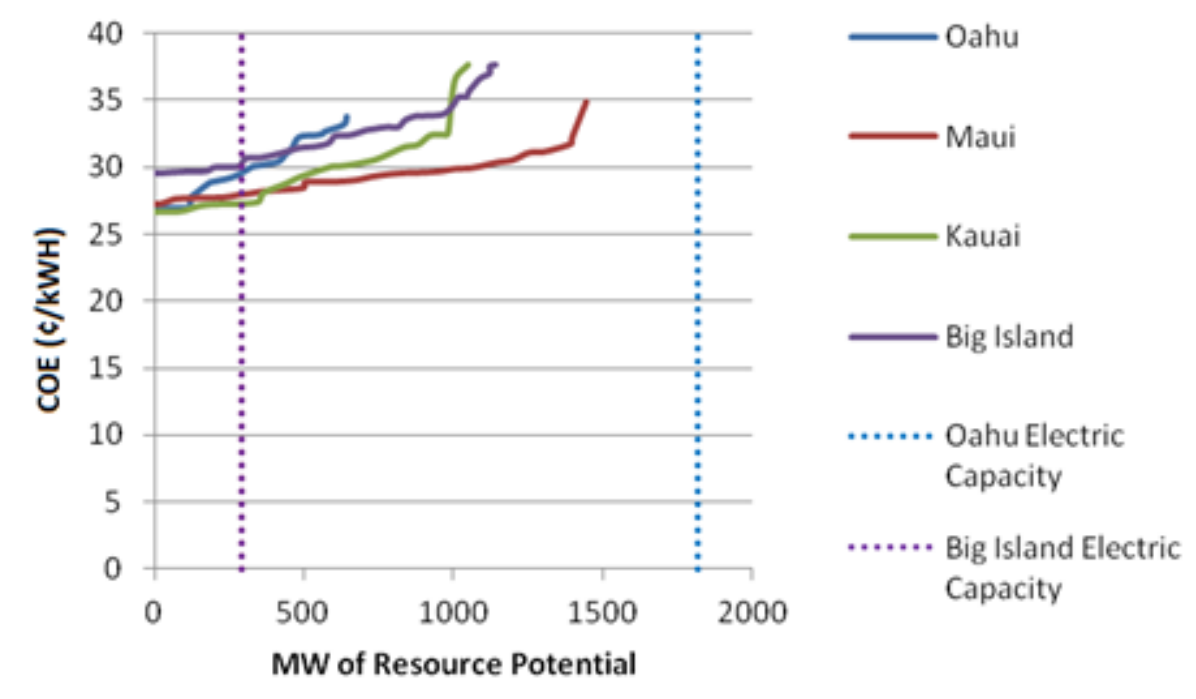

Figure 60 - Hawaii wave resource supply curves 


\section{Conclusions}

Ocean wave energy could potentially meet a substantial portion of U.S. electricity needs, is located close to coastal population centers, and, although variable in nature, may be more consistent and predictable than some other renewable generation resources. As a renewable electricity generation technology, ocean wave energy offers a way to diversify the U.S. electricity generation portfolio with a low air pollutant option. In addition, the output characteristics of these technologies may complement those of other renewable technologies.

This study addresses the following:

(1) The theoretical, technical and practical potential for electricity generation from wave energy

(2) The present lifecycle cost profile (Capex, Opex, and Cost of Electricity) of wave energy conversion technology at a reference site in Northern California at different plant scales

(3) Cost of electricity variations as a function of deployment site, considering technical, geo-spatial and electric grid constraints

(4) Technology cost reduction pathways

(5) Cost reduction targets at which the technology will see significant deployment within US markets, explored through a series of deployment scenarios

RE Vision Consulting, LLC (RE Vision), engaged in various analyses to establish current and future cost profiles for marine hydrokinetic (MHK) technologies, quantified the theoretical, technical and practical resource potential, performed electricity market assessments and developed deployment scenarios. RE Vision was supported in this effort by NREL analysts, who compiled resource information, performed analysis using the $\operatorname{ReEDS}^{\mathrm{a}}$ model to develop deployment scenarios, and developed a simplified assessment of the Alaska and Hawaii electricity markets.

Wave energy is an emerging renewable technology sector with a wide range of different technologies being pursued by industry. To represent the wide range of technologies under development, RE Vision developed two scenarios that represent the likely range of potential outcomes if wave technology is being pursued commercially. The following table provides a summary of high-level results.

\footnotetext{
${ }^{\mathrm{a}}$ See http://www.nrel.gov/analysis/reeds/ for more information.
} 
Table 25 - Summary Table of Results

\begin{tabular}{|c|c|c|c|c|}
\hline & Hawaii & Alaska & Lower 48 & Total \\
\hline Theoretical Wave Resource Potential by Region & 98 & 973 & 779 & 1,849 \\
\hline \multicolumn{5}{|l|}{ Technical Wave Resource Potential by Region } \\
\hline $70 \%$ Scenario (TWh/year) & 51 & 507 & 406 & 964 \\
\hline $15 \%$ Scenario (TWh/year) & 11 & 109 & 87 & 207 \\
\hline \multicolumn{5}{|l|}{ Practical Wave Resource Potential by Region } \\
\hline $70 \%$ Scenario (TWh/year) & 35 & 247 & 266 & 630 \\
\hline 15\% Scenario (TWh/year) & 7 & 53 & 57 & 117 \\
\hline \multicolumn{5}{|l|}{ Regional Electrical Generation Figures for $2011^{a}$} \\
\hline Regional Installed Generation Capacity (GW) & 2.6 & 2.5 & 1,160 & 1,164 \\
\hline Regional Electric Energy Generated (TWh/year) & 1.6 & 1.2 & 4,106 & 4,109 \\
\hline \multicolumn{5}{|l|}{ Economic Comparison } \\
\hline Market Cost of Electricity Hurdle Rate $(\$ / \mathrm{kWh})$ & $13.8^{b}$ & 7 & $6-7^{c}$ & \\
\hline Starting COE within Region ( $\$ / k W h)$ & 28.5 & 26.3 & 25.5 & \\
\hline Required Cost Reduction (\%) & $52 \%$ & $73 \%$ & $75 \%$ & \\
\hline
\end{tabular}

The total electrical energy generated in the United States in 2011 was 4,106 TWh/year (EIA 2012), with a total installed generation capacity of 1,164 GW (EIA 2011a). Under the optimal (70\%) scenario the team examined, wave energy could supply up to $630 \mathrm{TWh} / \mathrm{year}$, which corresponds to $15 \%$ of the U.S. electric demand in 2011. This is a significant potential contribution, and could more than double the current renewable installed capacity, which is at about $12 \%$ of U.S. electric demand. Note that the $70 \%$ scenario was developed as an upper limit to the large range of deployment densities possible with wave power technologies. For this reason, that scenario should not be used as a policy goal.

The deployment density of the technology, measured as the fraction of energy incident upon a wave energy array that can be converted to mechanical energy, is dependent on device spacing and device extraction efficiency. Deployment density can be expressed as the ratio of energy incident upon a wave energy array and the amount of mechanical power the array produces. A survey of different device technologies showed that such deployment densities are on the order of 4\%-30\% and are highly dependent on the technology type. The baseline in this study used a $15 \%$ limit, which is a median value of technologies under development today. Much higher deployment densities are technically achievable, though, likely on the order of $70 \%-80 \%$. This study demonstrates that the technology deployment density

\footnotetext{
${ }^{\mathrm{a}}$ EIA (2011a), EIA (2012)

${ }^{a}$ Based on base feed-in tariff (FIT); can be significantly higher depending on island and season.

${ }^{\mathrm{c}}$ Strongly dependent on region, but $6-7 \phi / \mathrm{kWh}$ is indicative for regions with good wave energy resources (i.e., California, Oregon, and Washington)
} 


\section{Conclusions}

is an important driver that will ultimately affect how much energy can be extracted from this resource in the United States and the contribution it can make to meet electricity needs. Deployment density improvements can come from a number of factors, but most notably from minimizing spacing between individual devices through compact mooring arrangements or mounting multiple single-absorber systems onto a common platform.

In the best deployment locations, the predicted COE from this resource is on the order of $26 \phi / \mathrm{kWh}$. The baseline cost assessment in this report represents today's cost from these technologies if they were deployed at a 50-MW farm scale and assuming a deployment of about $100 \mathrm{MW}$ globally. No cost reductions resulting from technology improvements were assumed in this baseline cost. Initial costs for smaller plants reported today are higher, largely because of the compounding factors of small plant deployment scales, high failure rates arising from limited deployment experience, and the high financing costs that accompany inherent project and technology risks. The uncertainty band around this cost prediction, given that the technology is in its infancy, is likely on the order of $\pm 30 \%$. This results in a range of 18-34 $\phi / \mathrm{kWh}$. As a point of comparison, offshore wind is on the order of $22 \phi / \mathrm{kWh}$, which is within the uncertainty range of this assessment (Tegen et al. 2012).

Learning curves are typically used when predicting longer term cost reductions for an industry. For each doubling of the deployed capacity, a certain percentage cost reduction is attained. Similar renewable energy technologies have historically attained learning rates on the order of $70 \%-90 \%$. Wind technology, for example, which is the most closely related analog, has demonstrated learning rates on the order of $85 \%$. These cumulative cost reductions in industries are tied to diverse factors that drive down costs, such as manufacturing scale, operational efficiencies, improved reliability and availability, and fundamental design changes. When investigating learning curves, discontinuities can be observed that can be traced back to technology innovations. There have been a limited number of wave energy device deployments around the world with a cumulative installed capacity on the order of 5MW. In addition, the wave technology space is characterized by a wide range of different technical approaches. This is typical for a technology space with limited deployments and closely resembles the wind technology space of about 20 years ago. And because global deployment is limited, no technology lock-in-typical for more established technology sectors-has occurred. This makes transformational technology shifts easier to accommodate in the marketplace and opens up the possibility for rapid cost reduction pathways. The following illustration shows some possible cost reduction pathways and critical market hurdle rates. 


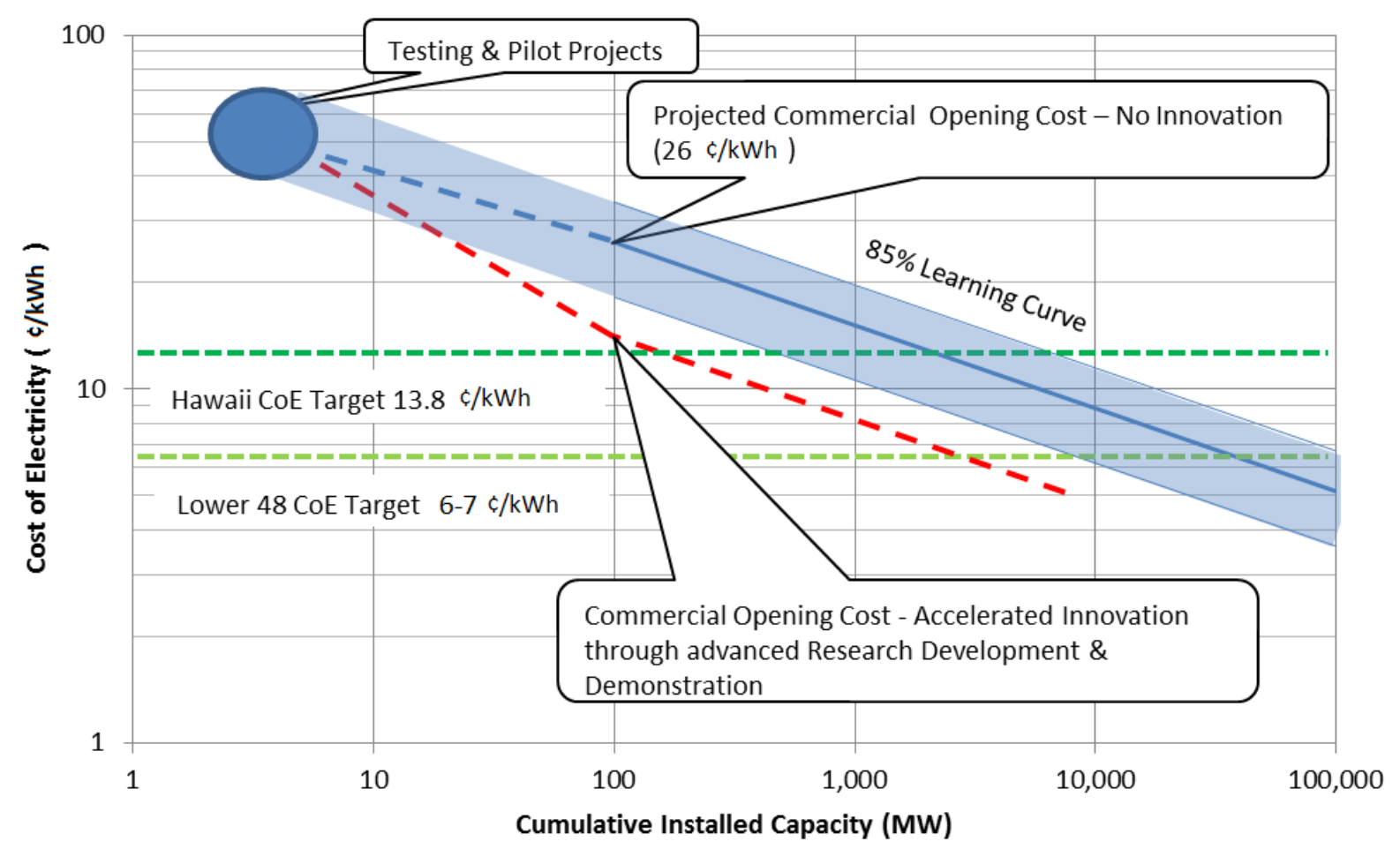

\section{Figure 61 - Potential cost reduction pathways}

If the marketplace is to adopt WEC technology without any subsidy, significant levels of cost reductions will need to be achieved. This level of cost reduction is dependent on the region of deployment and was identified as $52 \%$ for Hawaii and $73 \%-75 \%$ for the Lower 48 and Alaska. Naturally that points to an interesting opportunity for Hawaii to play a role as an early adopter market of technology, which could be used to gain operational experience and drive down cost. Ultimately, this technology will have to compete at a COE of 6-7 $\phi / \mathrm{kWh}$ to supply power at competitive prices in the Lower 48.

If this sector can address the technical and economic challenges within a reasonable time frame, this resource has significant potential to make a robust contribution to meeting the U.S. electricity needs. The following figure shows how the wave installed capacity expands under the optimal scenario, assuming that $\mathrm{COE}$ reduction and extraction density targets can be met. 


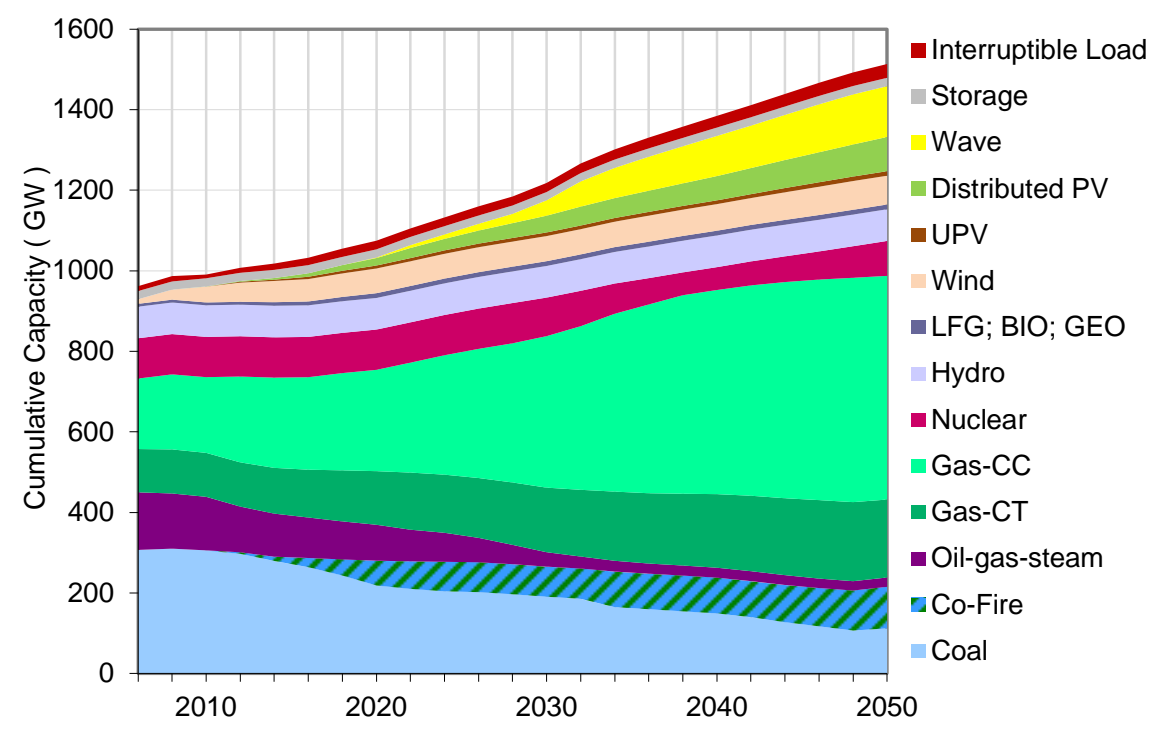

Figure 62 - Optimal scenario capacity expansion in the lower 48

\section{Uncertainties and Additional Research Needs}

This is the first time such an assessment has been carried out in the United States, and many uncertainties remain to be addressed in terms of resource assessment, life-cycle cost predictions, and scenario modeling. The following section briefly outlines these uncertainties and discusses how they can be addressed through targeted research.

Resource assessments identify geographic location and relative strength of a given resource. Significant uncertainty exists, however, around assumptions that associate that resource strength with the amount of electricity that can be extracted from it. In this study the team assumed that wave power deployment density is $15 \%$, which represents a mid-range value of deployment densities of current technologies being developed. The theoretical limit, though, is above $70 \%$, which could provide a four- to five-fold increase in deployment density from this resource, which is modeled under the $70 \%$ scenario. This deployment density does not consider any environmental limitations, which should be studied further.

Computational modeling of high levels of power extraction from waves and evaluating the effects on shoreline processes would allow critical levels of extraction to be identified.

The team assumed that these emerging technologies will not be deployed in environmentally protected areas and excluded these areas from the deployment areas considered. Although this exclusion is probably a safe present-day assumption, given the regulatory environment in the United States, it is unclear if this exclusion is really warranted because of the limited environmental impact of these technologies. 
Addressing this issue will likely require experience with the operation of small commercial arrays to aid in solidifying the environmental effects.

Life-cycle cost predictions were established based on technical, performance, and cost data obtained from manufacturers active in this industry. Because experience with deployment and operation of these technologies is limited, significant uncertainties remain in these economic profiles. This is especially true for the wave energy cost profiles because uncertainties surrounding performance and cost projections have a compounding effect on the results of this study.

Further efforts should be directed at developing a more comprehensive understanding of the current cost of commercial systems that various entities are developing. This could be accomplished by reviewing a large percentage of commercial systems under development and applying a consistent life-cycle cost, performance, and economic framework. In addition, cost reduction pathways should be identified to direct $R \& D$ efforts in a strategic manner.

Deployment scenarios focused solely on reducing the technology cost of WEC systems to demonstrate future deployment. Given the long time horizon considered in this study (about 40 years) a number of other factors could alter the selection of electricity generation technologies. These include (1) the potential for disruptive technologies in energy storage and/or transmission changing the accessibility of these resources; (2) fuel price escalation or volatility associated with restrictions in supply of conventional resources; and (3) societal changes, such as a concentrated effort to reduce carbon emissions.

Additional analysis of possible future electricity generation scenarios is warranted to understand how sensitive MHK deployment could be to these varied influences. This in turn would serve to solidify the potential contribution these technologies could make in the United States over time. Using hourly load data, the grid penetration of these emerging technologies could be more fully quantified for Alaska and Hawaii.

Cost reduction pathways are understood conceptually by industry participants. If this industry is to become commercially competitive, these cost reduction pathways need to be fully evaluated from a technical and economic perspective.

Additional work in collaboration with commercial partners could be targeted at refining baseline cost of electricity commercial opening costs and identifying cost reduction pathways. Based on these findings, core areas of $R \& D$ interest and their contribution to reducing COE across a wide range of devices could be quantified. 


\section{References}

\section{References}

Allan, G., M. Gilmartin, P. McGregor, and K. Swales. (2010). Levelised Costs of Wave and Tidal Energy in the UK: Cost Competitiveness and the Importance of "banded" Renewables Obligation Certificates. Energy Policy 39: 21-39.

Brealey, R., S. Myers, and F. Allen. (2008). Principles of Corporate Finance. 9th Ed. McGraw-Hill, pp. 530.

Board of Governors of the Federal Reserve (Fed). (July 2010). Federal Reserve Statistical Release, Table H.15, Moody's Seasoned AAA Corporate Bonds, Monthly Data. http://www.federalreserve.gov/releases/h15/data/Monthly/H15 AAA NA.txt. Accessed July 2010.

Carbon Trust. (July 2011). Accelerating Marine Energy: The Potential for Cost Reduction - Insights from the Carbon Trust Marine Energy Accelerator. Carbon Trust, UK.

Carbon Trust. (2006). Future Marine Energy: Results of the Marine Energy Challenge: Cost Competitiveness and Growth of Wave and Tidal Stream Energy. http://www.carbontrust.co.uk/Publications/pages/PublicationDetail.aspx?id=CTC601. March 16, 2012.

Clément, A. H., and A. Babarit. (2012). Discrete Control of Resonant Wave Energy Devices. Philos Transact A Math Phys Eng Sci, 370(1959):288-314.

Dalton, G.J., and T. Lewis. (2011) Performance and Economic Feasibility Analysis of 5 Wave Energy Devices Off the West Coast Of Ireland. Hydraulics and Maritime Research Centre (HMRC), University College Cork, Ireland.

EEI. (2010), 2010 Q1 Rate Case Data.

http://www.eei.org/whatwedo/DataAnalysis/IndusFinanAnalysis/Documents/2010_Q1_Rate_Case_Data.xls.

EEI. (2009), 2008 Financial Review Plus 2009 Developments, Annual Report of the U.S. Shareholder-Owned Electric Utility Industry. http://www.eei.org/whatwedo/DataAnalysis/IndusFinanAnalysis/finreview/Documents/09_FinRevF.pdf

EIA. (2012). Monthly Energy Review, April 2012. http://www.eia.gov/electricity/monthly/ Accessed May 18, 2012.

EIA. (2011a), Generation Capacity from Electric Power. Annual 2010 Data Tables.

http://www.eia.gov/electricity/annual/html/table1.2.cfm. May 18, 2012.

EIA. (2011b). Annual Energy Outlook with Projections to 2035. DOE/EIA-0383(2011). EIA, Washington.

http://www.eia.gov/oiaf/aeo/aeoref tab.html. Accessed December, 2011.

EIA. (2010). Annual Energy Outlook 2010, Reference Case Tables, Table 20.

http://www.eia.doe.gov/oiaf/aeo/excel/aeotab 20.xls. Accessed.December, 2011.

EPRI. (2011). Mapping and Assessment of the United States Ocean Wave Energy Resource. EPRI Product ID: 1024637. Palo Alto, CA: EPRI. http://www1.eere.energy.gov/water/pdfs/mappingandassessment.pdf. Accessed March 2012.

Ernst \& Young. (2010). Cost of and Financial Support for Wave, Tidal Stream and Tidal Range Generation in the UK: A Report for the Department of Energy and Climate Change and the Scottish Government.

http://www.decc.gov.uk/assets/decc/What\%20we\%20do/UK\%20energy\%20supply/Energy\%20mix/Renewable\%20en ergy/explained/wave tidal/798-cost-of-and-finacial-support-for-wave-tidal-strea.pdf. Accessed August 25, 2012.

Falnes, J. (2002). Ocean Waves and Oscillating Systems, Cambridge University Press, Cambridge, UK.

Fay, G., A.V. Meléndez, and S. Pathan (July 2011). Alaska Fuel Price Projections 2011-2035, Institute of Social and Economic Research (ISER). ISER working paper 2011. http://www.iser.uaa.alaska.edu/Publications/Fuel_price_proje ction_2011-2035 final.pdf.

Fusco, F., G. Nolan, and J. Ringwood. (2010). Variability Reduction through Optimal Combination of Wind/Wave Resources - An Irish Case Study. Energy 35:314-325.

Hals, J., J. Falnes, and T. Moan. (2011). Constrained Optimal Control of a Heaving Buoy Wave-Energy Converter. Journal of Offshore Mechanics and Arctic Engineering, Vol. 133.

Harper, J., M. Karcher, and M. Bolinger, (2007). Wind Project Financing Structures: A Review \& Comparative Analysis. Lawrence Berkeley National Laboratory technical report LBNL-63434, September. http://eetd.lbl.gov/ea/ems/reports/63434.pdf.

Highers, D. (January 2009). Southcentral Power Project Execution Plan draft. http://www.chugachelectric.com/pdfs/agenda/opsagenda 011409 xii.pdf. 
Junginger, M., and A. Faaij. (2004). Cost Reduction Prospects for the Offshore Wind Energy Sector. Department of Science, Technology and Society, Copernicus Institute, Utrecht University.

Klein, J. (2009). Comparative Costs of California Central Station Electricity Generation

Technologies, California Energy Commission, CEC-200-2009-017-SD.

http://www.energy.ca.gov/2009publications/CEC-200-2009-017/CEC-200-2009-017-SD.PDF.

National Data Buoy Center - NOAA. Station 46076 - Cape Cleare, AK and Station 51004 SE Hawaii. Accessed December 15, 2011.

National Research Council. (July 2011). Assessment of Marine and Hydrokinetic Energy Technology: Interim Letter Report, Committee of Marine and Hydrokinetic Energy Technology Assessment.

NERC (North American Electric Reliability Corporation). (October 2010). 2010 Long-Term Reliability Assessment. http://www.nerc.com/files/2010\%20LTRA.pdf.

NETL. (September 2008). Recommended Project Finance Structures for the Economic Analysis of Fossil-Based Energy Projects. DOE/NETL-401/090808. http://www.netl.doe.gov/energyanalyses/pubs/Project\%20Finance\%20Parameters\%20-\%20Final\%20Report\%20-\%20Sept\%202008 1.pdf.

Previsic, M. (2010). RE Vision DE-001: Deployment Effects of Marine Renewable Energy Technologies, Wave Energy Scenarios. U.S. Department of Energy, Advanced Water Power Program, Washington.

Previsic, M., R. Bedard, G. Hagerman, and O. Siddiqui. (2005). System Level Design, Performance and Costs Hawaii State Offshore Wave Power Plant. E2I EPRI Global WP - $006-\mathrm{HI}$.

http://oceanenergy.epri.com/attachments/wave/reports/006 Hawaii System Level Conceptual Design RB 01-1205.pdf. Accessed March 16, 2012.

Previsic, M., R. Bedard, G. Hagerman, and O. Siddiqui. (2004a). System Level Design, Performance and Costs Maine State Offshore Wave Power Plant. E2I EPRI Global WP - 006 - ME.

http://oceanenergy.epri.com/attachments/wave/reports/006_Maine_System_Level_Design_RB_12-01-04.pdf.

Accessed March 16, 2012.

Previsic, M., R. Bedard, G. Hagerman, and O. Siddiqui. (2004b). System Level Design, Performance and Costs Massachusetts State Offshore Wave Power Plant. E2I EPRI Global WP - 006 - MA.

http://oceanenergy.epri.com/attachments/wave/reports/006_Mass_System_Level_IDesign_RB_11-30-04.doc.pdf. Accessed March 16, 2012.

Previsic, M., R. Bedard, G. Hagerman, and O. Siddiqui. (2004c). System Level Design, Performance and Costs Oregon State Offshore Wave Power Plant. E2I EPRI Global WP - 006 - OR.

http://oceanenergy.epri.com/attachments/wave/reports/006_Oregon_System_Level_Design_RB_11-29-04.pdf. March 16, 2012.

Previsic, M., R. Bedard, G. Hagerman, and O. Siddiqui. (2004d), System Level Design, Performance and Costs San Francisco California Energetech Offshore Wave Power Plant. E2I EPRI Global WP - 006B - SF.

http://oceanenergy.epri.com/attachments/wave/reports/006_San_Francisco_Energetech_Conceptual_Design_RB_12 -20-04.pdf. March 16, 2012.

Previsic, M., R. Bedard, G. Hagerman, and O. Siddiqui. (2004e), System Level Design, Performance and Costs San Francisco California Pelamis Offshore Wave Power Plant. E2I EPRI Global WP - 006A - SF.

http://oceanenergy.epri.com/attachments/wave/reports/006_San_Francisco_Pelamis_Conceptual_Design_12-1104.pdf. March 16, 2012.

Short, W., P. Sullivan, T. Mai, M. Mowers, C. Uriarte, and A. Martinez. (December 2011). Regional Energy Deployment System (ReEDS); Report No. NREL/TP-6A20-46534. NREL, Golden, CO.

http://www.nrel.gov/docs/fy12osti/46534.pdf._Accessed June 4, 2012.

Short, W., D.J. Packey, and T. Holt, T. (March 1995) A Manual for the Economic Evaluation and Energy Efficiency and Renewable Energy Technologies. Report No. NREL/TP-462-5173. NREL, Golden, CO.

http://www.nrel.gov/docs/legosti/old/5173.pdf. Accessed August 25, 2012.

Stermole, F., and J. Stermole. (2009), Economic Evaluation and Investment Decision Methods 12th Ed., Investment Evaluation Corporation, pp. 381. 


\section{References}

Stoutenburg, E., N. Jenkins, and M. Jacobson. (2010). Power Output Variations of Co-Located Offshore Wind Turbines and Wave Energy Converters in California. Renewable Energy 35:2781-2791.

Tegen, S., M. Hand, B. Maples, E. Lantz, P. Schwabe, and A. Smith. (2012). 2010 Cost of Wind Energy Review. NREL/TP-5000-52920. NREL, Golden, CO.

http://www.windpoweringamerica.gov/pdfs/economic development/2012/2010 cost wind energy.pdf. Accessed August 25, 2012.

UK Department of Trade \& Industry. (2007). Impact of Banding the Renewables Obligation - Costs of Electricity production (URN 07/948). http://webarchive.nationalarchives.gov.uk/+/http://www.berr.gov.uk/files/file39038.pdf. Accessed March 16, 2012. Wall Street Journal. (July 2010). LIBOR Rates History: Historical LIBOR Rate Information. http://www.wsjprimerate.us/libor/index.html. Accessed July 2010.

Weiss, L., and S. Spiesak, editors. (1998). Wheeling and Transmission Manual. 3rd Ed. 334 pp.

Yelle, L. (1979). The Learning Curve: Historical Review and Comprehensive Survey. University of Massachusetts Lowell. 


\section{Appendices}

\section{Appendix I: Simplified Electricity Market Assessment for Hawaii and Alaska}

The grid on the Hawaiian island of Oahu, which includes Honolulu, serves about $72 \%$ of the electrical load in Hawaii (see Figure 61). In Alaska, the Railbelt electrical grid meets about $85 \%$ of the state's electrical load. Even though these two minigrids serve the majority of the load in each state, they are still relatively small compared to the load centers and grids in the contiguous United States. For example, the smallest interconnect in the contiguous United States is the Electric Reliability Council of Texas (ERCOT) system with approximately $73 \mathrm{GW}$ of generation capacity. The Alaskan and Hawaiian systems each have less than $3 \mathrm{GW}$ as shown in Table 26. The other remarkable characteristic of the generation in both Alaska and Hawaii is the constancy throughout the months of the year. Compare the flat annual generation in Figure 63 and Figure 64 to the loads in the contiguous United States where air-conditioning demands result in significantly greater loads during the summer.

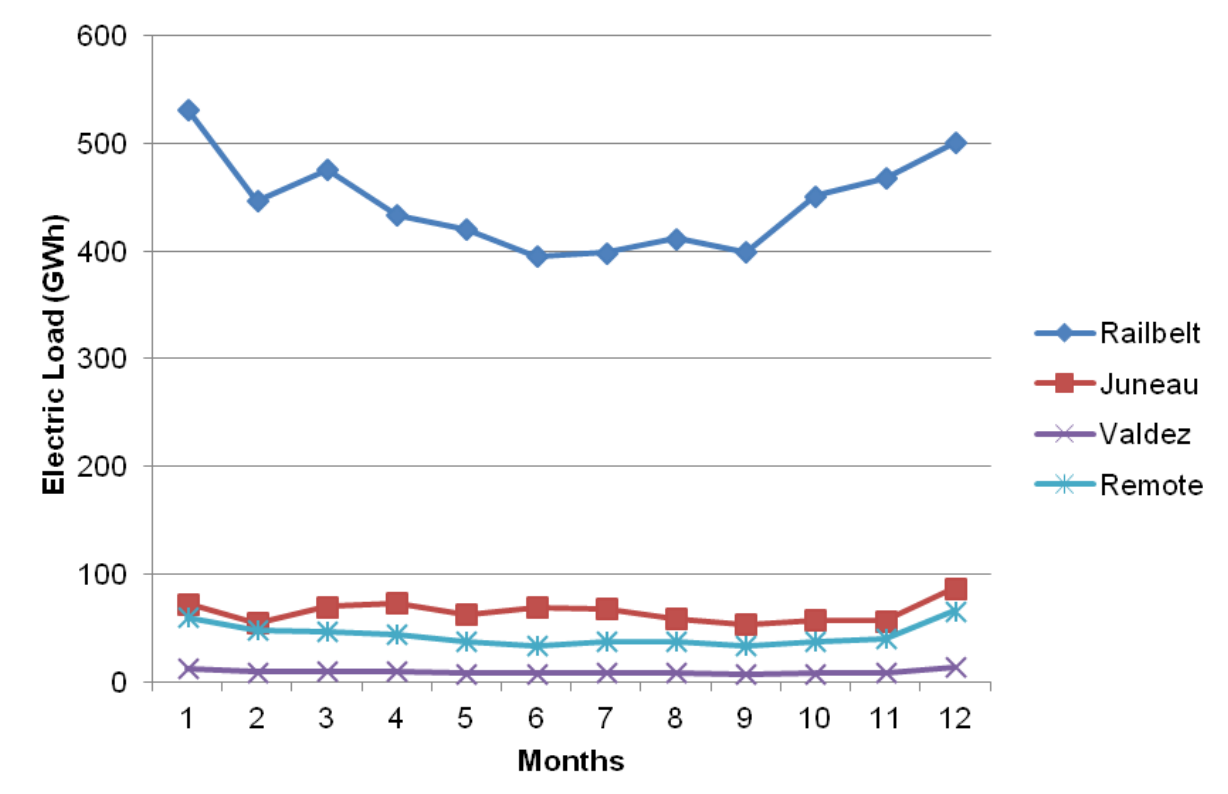

Figure 63 - Monthly generation in Alaska

Electric loads are slightly higher for the Alaskan grids in the winter than in the summer. Hawaiian electric loads are even more constant throughout the year as seen in Figure 64. 


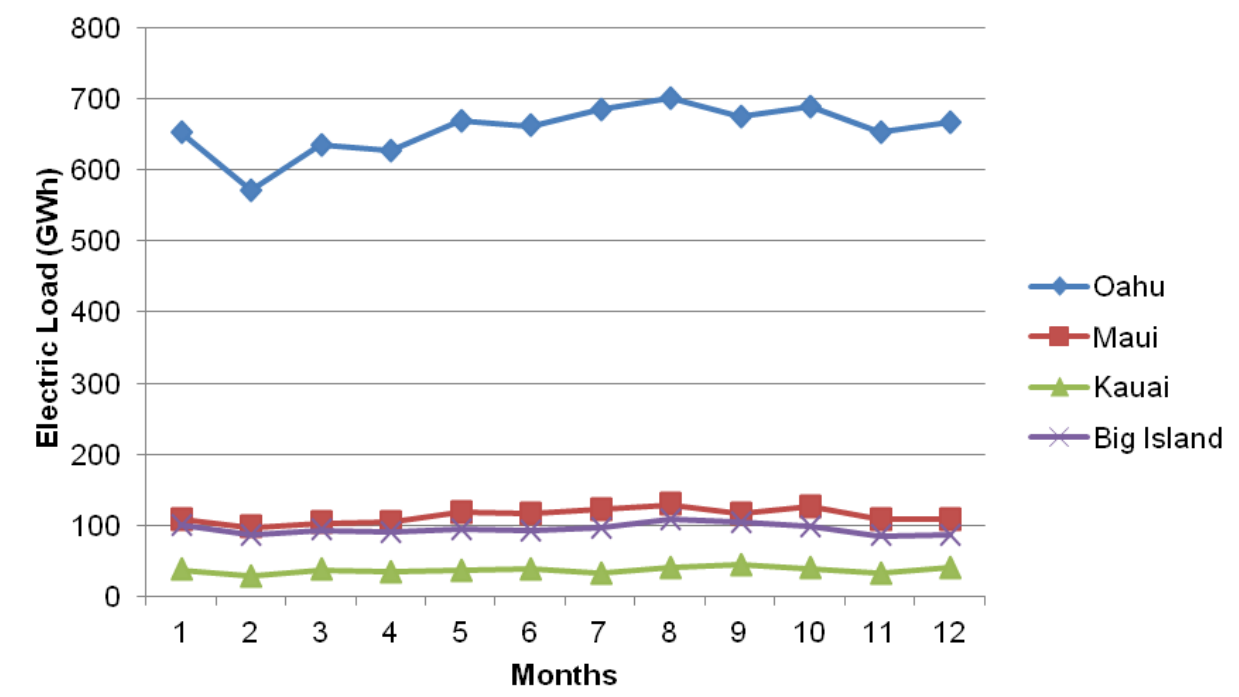

Figure 64 - Monthly generation in Hawaii (Source: data from Ventyx Velocitysuites)

Table 26 summarizes the generation type and capacity for both Alaska and Hawaii.

Table 26 - Generation Capacity (MW) by State and Fuel (Source: Ventyx Velocitysuites)

\begin{tabular}{|l|r|r|r|}
\hline Generation Type & Alaska & Hawaii & Total \\
\hline Coal & 80 & 200 & 280 \\
\hline Oil & 820 & 2,170 & 2,990 \\
\hline Gas & 1,120 & 0 & 1,120 \\
\hline Hydro & 430 & 30 & 460 \\
\hline Nonhydro RE & 10 & 210 & 220 \\
\hline Total & 2,460 & 2,610 & 5,070 \\
\hline
\end{tabular}

Another unique characteristic of both these state electricity markets is that they are isolated and do not have an extensive distribution system for coal and natural gas. Consequently both rely heavily on oil-fired generation. The Railbelt in Alaska is able to take advantage of local natural gas supplies as shown by Table 27.

Table 27 - 2010 Alaska Annual Generation (MWh) by Fuel Type (Source: Ventyx Velocitysuites)

\begin{tabular}{|l|r|r|r|r|}
\hline Generation Type & Railbelt & Juneau & Valdez & Total \\
\hline Coal & 430,964 & 0 & 0 & 430,964 \\
\hline Distillate Fuel Oil & 14,995 & 15,699 & 17,574 & 48,268 \\
\hline Residual Fuel Oil & 192,177 & 0 & 0 & 192,177 \\
\hline Natural Gas & $3,700,222$ & 0 & 0 & $3,700,222$ \\
\hline Hydro & 467,865 & 767,099 & 62,359 & $1,297,323$ \\
\hline Other & 525,802 & 0 & 30,044 & 555,846 \\
\hline Total & $5,332,025$ & 782,798 & 109,977 & $6,224,800$ \\
\hline
\end{tabular}


Table 28 details the 2010 annual generation by type for four of the Hawaiian Islands.

Table 28 - 2010 Hawaii Annual Generation (MWh) by Fuel Type (Source: Ventyx Velocitysuites)

\begin{tabular}{|l|r|r|r|r|r|}
\hline Generation Type & Oahu & Maui & Kauai & Big Island & Total \\
\hline Coal & $1,496,139$ & 49,375 & 0 & 0 & $1,545,514$ \\
\hline Distillate Fuel Oil & 32,556 & 877,281 & 194,994 & 210,333 & $1,315,164$ \\
\hline Residual Fuel Oil & $5,845,035$ & 192,063 & 0 & 276,393 & $6,313,491$ \\
\hline Variable Generation & 0 & 121,997 & 0 & 140,894 & 262,891 \\
\hline Hydro & 0 & 11,580 & 30,236 & 28,606 & 70,422 \\
\hline Other & 509,822 & 111,188 & 221,864 & 485,683 & $1,328,557$ \\
\hline Total & $7,883,552$ & $1,363,484$ & 447,094 & $1,141,909$ & $10,836,039$ \\
\hline
\end{tabular}

Because Hawaii's oil must all be imported by ship, its power generation costs are high, with retail prices ranging from $15-20 \phi / \mathrm{kWh}$. Retail prices in Anchorage are closer to $10 \phi / \mathrm{kWh}$ because of a combination of oil and gas use and transmission and distribution costs, but they are clearly not as high as those in Hawaii. ${ }^{a}$ Although the team is more interested in wholesale power costs against which MHK would compete, limited data are available on such costs.

HECO has also established the FITs shown in Table 30 that apply to all power sold to the utility. Although these do not include MHK technologies, they do give some indication of the relative cost of power on Oahu and can be used to help decipher the competitiveness of MHK technologies in Hawaii.

Table 29 - FIT Rates in Oahu (Source: http://www.heco.com/)

\begin{tabular}{|c|c|}
\hline Renewable Generator Type and Size ${ }^{a}$ & FIT Energy Payment Rate (c/kWh) \\
\hline Tier $1 \mathrm{PV} \leq 20 \mathrm{~kW}$ & 21.8 \\
\hline Tier 1 Concentrating Solar Power (CSP) $\leq 20 \mathrm{~kW}$ & 26.9 \\
\hline Tier I Onshore Wind $\leq 20 \mathrm{~kW}$ & 16.1 \\
\hline Tier 1 In-line Hydropower $\leq 20$ kW & 21.3 \\
\hline Tier $2 \mathrm{PV}>20 \mathrm{~kW}$ and $\leq 500 \mathrm{~kW}$ & 18.9 \\
\hline Tier 2 CSP > $20 \mathrm{~kW}$ and $\leq 500 \mathrm{~kW}$ & 25.4 \\
\hline Tier 2 Onshore Wind $>20 \mathrm{~kW}$ and $\leq 100 \mathrm{~kW}$ & 13.8 \\
\hline Tier 2 In-line Hydropower >20 kW and $\leq 100$ kW & 18.9 \\
\hline Baseline FIT Rate & 13.8 \\
\hline
\end{tabular}

${ }^{\mathrm{a}}$ http://www.heco.com. Accessed November 23, 2011.

\footnotetext{
${ }^{a}$ Open EI (OPENENERGYINFO). http://en.openei.org/wiki.
} 
Another source of data to compare wave generation to is the official "avoided cost" of power used in Hawaii for valuing renewable generation purchased to meet the state RPS. Hawaiian Electric Company's (HECO's) published avoided cost for power in Oahu varies between 10 and $27 \notin / \mathrm{kWh}$ depending on the year, season, and time of day (peak versus off-peak) as shown in Table 30.

Table 30 - Avoided Costs (c/kWh) in Hawaiian Electric Markets

\begin{tabular}{|c|c|c|c|c|c|c|}
\hline \multirow{2}{*}{ Date } & \multicolumn{2}{|r|}{ HECO } & \multicolumn{2}{|r|}{ HELCO } & \multicolumn{2}{|r|}{ Maui } \\
\hline & On-Peak & Off-Peak & On-Peak & Off-Peak & On-Peak & Off-Peak \\
\hline $11 / 1 / 2011$ & 26.399 & 18.862 & 21.055 & 18.18 & 20.765 & 19.937 \\
\hline $10 / 1 / 2011$ & 26.538 & 19.037 & 20.75 & 17.776 & 20.103 & 19.3 \\
\hline $9 / 1 / 2011$ & 26.155 & 18.776 & 20.881 & 17.801 & 20.496 & 19.679 \\
\hline $8 / 1 / 2011$ & 26.084 & 18.838 & 21.317 & 18.318 & 21.434 & 20.581 \\
\hline $7 / 1 / 2011$ & 26.713 & 19.211 & 20.721 & 17.662 & 21.873 & 21.004 \\
\hline $6 / 1 / 2011$ & 25.3690 & 18.292 & 20.677 & 17.586 & 22.51 & 21.617 \\
\hline $5 / 1 / 2011$ & 23.397 & 17.063 & 22.321 & 19.995 & 20.615 & 19.788 \\
\hline $4 / 1 / 2011$ & 22.035 & 15.995 & 18.277 & 15.846 & 18.707 & 17.947 \\
\hline $3 / 1 / 2011$ & 20.656 & 15.214 & 17.928 & 15.644 & 17.669 & 16.945 \\
\hline $2 / 1 / 2011$ & 19.748 & 14.32 & 16.75 & 14.447 & 16.902 & 16.207 \\
\hline $1 / 1 / 2011$ & 19.295 & 13.762 & 15.92 & 13.651 & 16.417 & 15.738 \\
\hline $12 / 1 / 2010$ & 16.318 & 12.441 & 15.668 & 13.664 & 15.141 & 14.517 \\
\hline $11 / 1 / 2010$ & 16.11 & 12.252 & 15.388 & 13.453 & 14.37 & 13.778 \\
\hline $10 / 1 / 2010$ & 15.811 & 11.981 & 15.492 & 13.503 & 14.509 & 13.913 \\
\hline $9 / 1 / 2010$ & 15.889 & 12.132 & 14.627 & 12.567 & 13.709 & 13.135 \\
\hline $8 / 1 / 2010$ & 15.838 & 12.051 & 14.908 & 12.838 & 13.918 & 13.347 \\
\hline $7 / 1 / 2010$ & 16.123 & 12.061 & 14.967 & 12.788 & 14.819 & 14.211 \\
\hline $6 / 1 / 2010$ & 15.811 & 11.901 & 15.013 & 12.859 & 14.706 & 14.103 \\
\hline $5 / 1 / 2010$ & 15.187 & 11.582 & 14.183 & 11.984 & 13.858 & 13.289 \\
\hline $4 / 1 / 2010$ & 14.888 & 11.291 & 14.452 & 12.798 & 13.324 & 12.778 \\
\hline $3 / 1 / 2010$ & 15.226 & 11.501 & 15.002 & 13.483 & 13.713 & 13.155 \\
\hline $2 / 1 / 2010$ & 13.886 & 10.781 & 14.651 & 13.05 & 13.245 & 12.711 \\
\hline $1 / 1 / 2010$ & 13.716 & 10.472 & 14.511 & 12.859 & 13.879 & 13.312 \\
\hline
\end{tabular}

Notes: As of August 1, 2008, the calculation of avoided cost is based on the methodology approved in Docket No. 7310, D\&O 24086. Hawaii Electric Light Company (HELCO) and Maui avoided cost values were updated to reflect the 5-1-2010 filing.Source: http://www.heco.com. Accessed November 24, 2011.

Power costs are lower in Alaska because approximately $70 \%$ of the Railbelt's electricity comes from natural gas generators. Wholesale power prices from these gas plants are generally not available because transactions are limited and the data is proprietary. Similarly, Alaska does not have competitive gas markets. Gas is sold to utilities through bilateral contracts that are overseen by the Regulatory Commission of Alaska. Generally the price has been set by an index based on prices in the contiguous 
United States (Production Area Composite Index [PACI]) and has closely followed Henry Hub gas prices. ${ }^{a}$ Although Alaska does not have the shale gas resources that have reduced Henry Hub prices, and gas resources available in the Cook Inlet are strained, the Institute of Social and Economic Research (ISER) estimates that the relationship between Alaskan and Henry Hub natural gas prices will largely maintain and projects future natural gas prices ranging from \$5-\$9/MBtu (Fay et al. 2011).

The team used these natural gas prices to arrive at an estimate of the value of power that could be displaced by MHK technologies in Alaska. Power displaced by MHK technologies in Alaska could come from existing plants or could offset the need to build new plants. The team developed rough estimates of the costs from each of these plant types. The largest gas-fired plant in Alaska is a multiple-unit plant of 430 MW at Belugah owned by Chugash Electric Association. This plant has multiple units of combustion and steam turbines. Assuming gas prices of \$5-49/MBtu from the range of ISER projections and heat rates in the vicinity of $10,000 \mathrm{Btu} / \mathrm{kWh}$ and modest $\mathrm{O} \& \mathrm{M}$ costs, the variable cost of electricity (i.e., excluding capital and fixed O\&M costs) from these existing units would be approximately $5-9 \phi / \mathrm{kWh}$.

Similar estimates result if the MHK were to displace the construction and operation of new gas-CC power plants. Chugash Electric Association has started construction on a new gas-CC power plant scheduled for completion in 2012-2013. This GE LM6000 PF plant will have a power rating of 182.5 MW with a net plant heat rate of 6,382 Btu/kWh. In 2008 its total engineering, procurement, and construction (EPC) project cost was estimated to be $\$ 274,254,677$ in 2008 USD (Southcentral Power Project 2009). Combining these data with a gas price of approximately $\$ 5-\$ 9 / \mathrm{MBtu}$ from the ISER projections yields an COE of $5.5-8.5 \phi / \mathrm{kWh}^{\mathrm{b}}$

\footnotetext{
${ }^{a}$ See http://www.cmegroup.com/trading/energy/natural-gas/natural-gas.html for more information.

${ }^{\mathrm{b}}$ Assumes an FCR of 10\%, an annual CF of $90 \%$, and O\&M costs of $0.5-1.0 \phi / \mathrm{kWh}$.
} 


\section{Appendix II: ReEDS Assumptions for Modeling MHK Scenarios}

ReEDS is an electric sector capacity expansion model that optimizes investment and dispatch decisions of electricity-generating technologies for the contiguous United States through 2050. ReEDS chooses the optimal mix of technologies that meet all regional and temporal electric power demand requirements, grid reliability (reserve) requirements, technology resource constraints, and policy constraints.

ReEDS yields a detailed treatment of electrical generation and storage technologies, and specifically addresses a variety of issues related to renewable energy technologies. These issues include accessibility and cost of transmission; regional quality of renewable resources; seasonal and diurnal generation profiles; correlations between different renewable resource sites; variability and nondispatchability of wind, solar, and wave energy; and the influence of variability on curtailment of energy generated from these renewable resources and on the reliability of the electrical grid. ReEDS addresses these issues through a highly discretized regional structure; temporal resolution; explicit statistical treatment of the variability in wind, solar, and MHK output over time; and consideration of ancillary services requirements and costs. More detail on ReEDS can be found in Appendix III and in the official ReEDS documentation (Short et al. 2011).

\section{Modeling Ocean Technologies with ReEDS}

As with all technology modeled by ReEDS, technology costs, resource limits, and performance characteristics are necessary inputs for the wave energy technology. GIS data inputs provide supply curves to characterize costs and resource limits, as well as annual average capacity factors, seasonal and diurnal variations in capacity factors, and correlations between potential wave generation capacities at different sites. The same GIS-based data used to develop the national resource supply curves shown in Section 0 were used to develop the regional wave resource supply curves of Figure 65 with discrete resource bins for use in ReEDS. Each bin defines the COE (including the cost to build transmission to the local grid) for a specified resource quantity. Figure 65 shows an example of the discrete bin supply curve, superimposed in gray on the regional wave resource supply curve for northern California. 


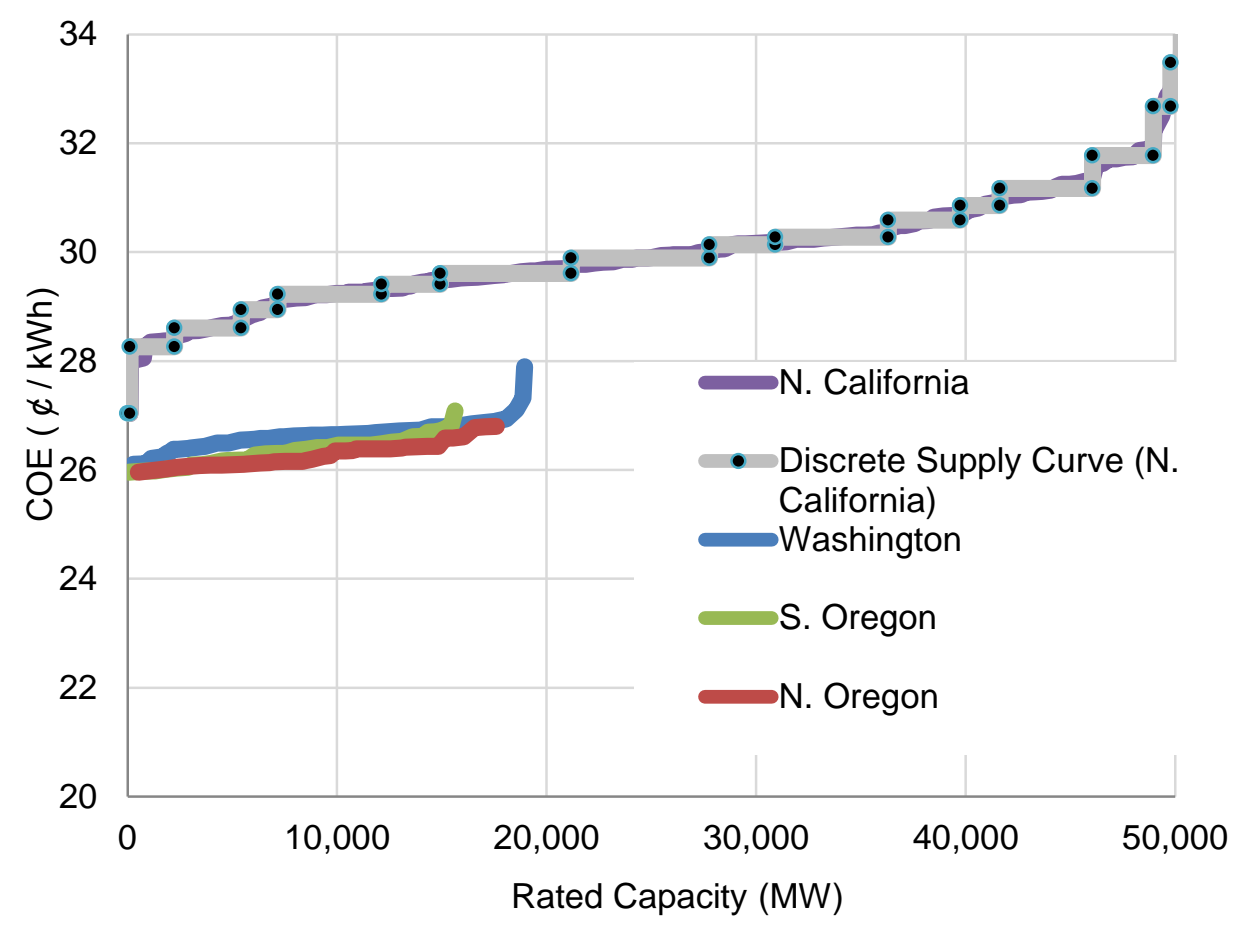

Figure 65 - Pacific Coast wave resource regional supply curves $-70 \%$ scenario supply curve

ReEDS assumes that WEC technology cost reductions will occur between now and 2022 based on advancements in R\&D and learning from worldwide deployment, which brings the cost of each nonutilized resource bin down to a specified level. After 2022, further cost reductions occur only through learning at an assumed $85 \%$ progress ratio, which is applied to the regional supply curves based on assumed global wave capacity installations. ReEDS assumes that initial capacity deployment of commercial wave technologies can begin by 2016 .

The model decides to use the resource in any given supply curve bin based on its cost competitiveness, its contribution to planning and operating reserves, and the transmission required. Resource variability metrics including the contributions of variable resource generators to operating reserve requirements, planning reserves (described in more detail in Appendix III), and curtailments are statistically estimated to determine the quantitative impacts on system reliability. ReEDS addresses the variability of wave resource based on historical ocean data measurements and the correlation with the wave energy output at locations where WEC technologies have already been deployed in the model. 
Temporal variations in wave resource temporal variations in wave power output. Hourly wave data from the National Data Buoy Center (NDBC) is used to calculate ReEDS inputs for seasonal/diurnal capacity factors and correlations between sites. ${ }^{a}$ Figure 66 shows the seasonal/diurnal capacity factor variations for four Pacific Coast wave resource regions (Washington, northern Oregon, southern Oregon, and northern California) modeled by ReEDS. In general, energy capture from waves is expected to be greater in the winter months and less in the summer months. Figure 67 shows the seasonal/diurnal wave resource correlations between the same four Pacific coast wave resource regions as a function of region-to-region centroid distance. ReEDS uses these inputs and its estimates of prior deployments to estimate the marginal capacity value, operating reserves, and curtailments that would be associated with new deployment.

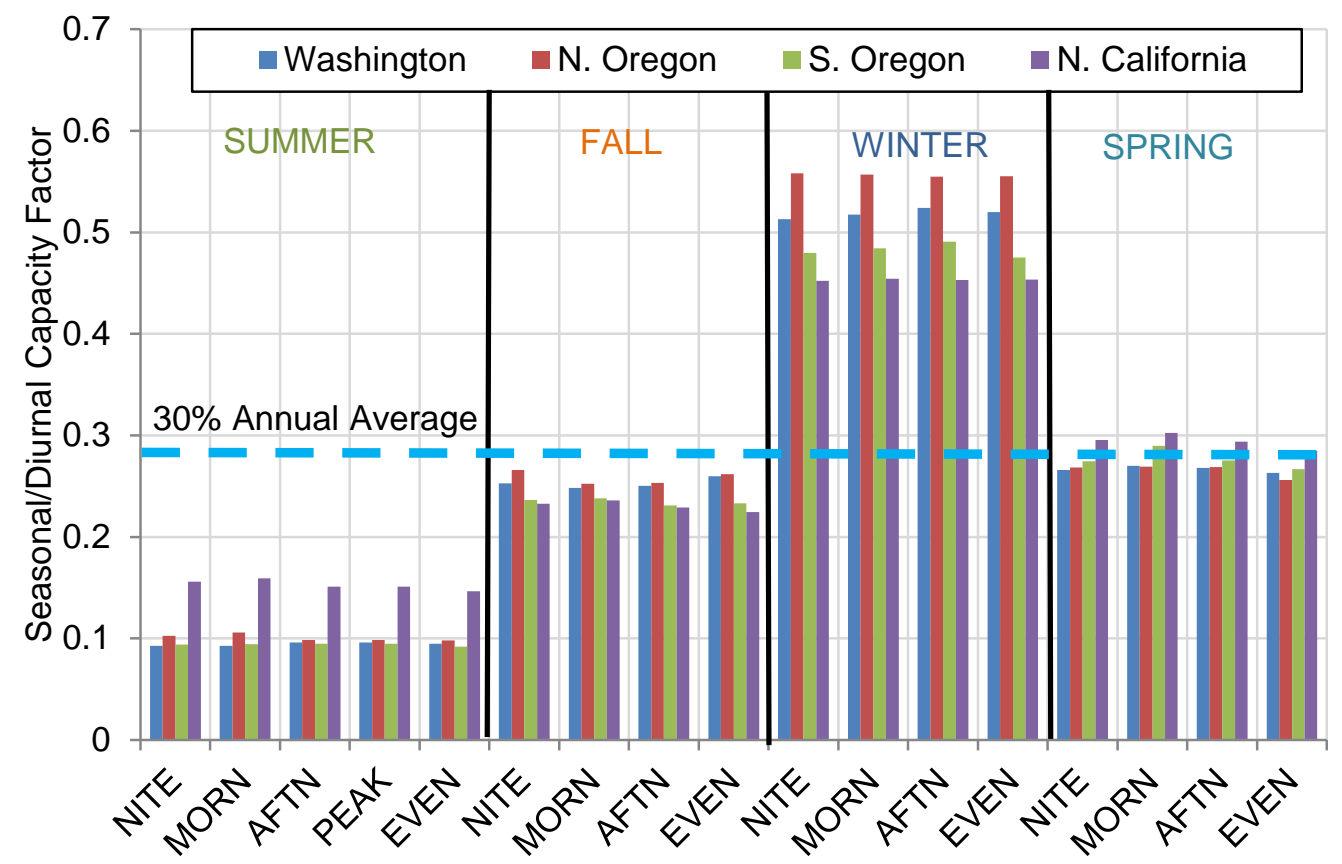

Figure 66 - Pacific Coast region's seasonal and diurnal capacity factors ${ }^{b}$

\footnotetext{
${ }^{a}$ ReEDS considers correlations between different resource regions to account for the benefits of geographic resource diversity. In general, as the distance between two resource sites increases, the resource data become uncorrelated. Utilizing variable resources at sites that are uncorrelated will increase the probability that the variable generator capacity in these regions can supply power during peak load hours. Uncorrelated resource sites will be less likely to suffer curtailments simultaneously in the event of excess generation.

${ }^{\mathrm{b}}$ Note: NITE,night; MORN, morning; AFTN, afternoon; EVEN, evening; PEAK, summer peak. (See Appendix III for ReEDS temporal definitions.)
} 


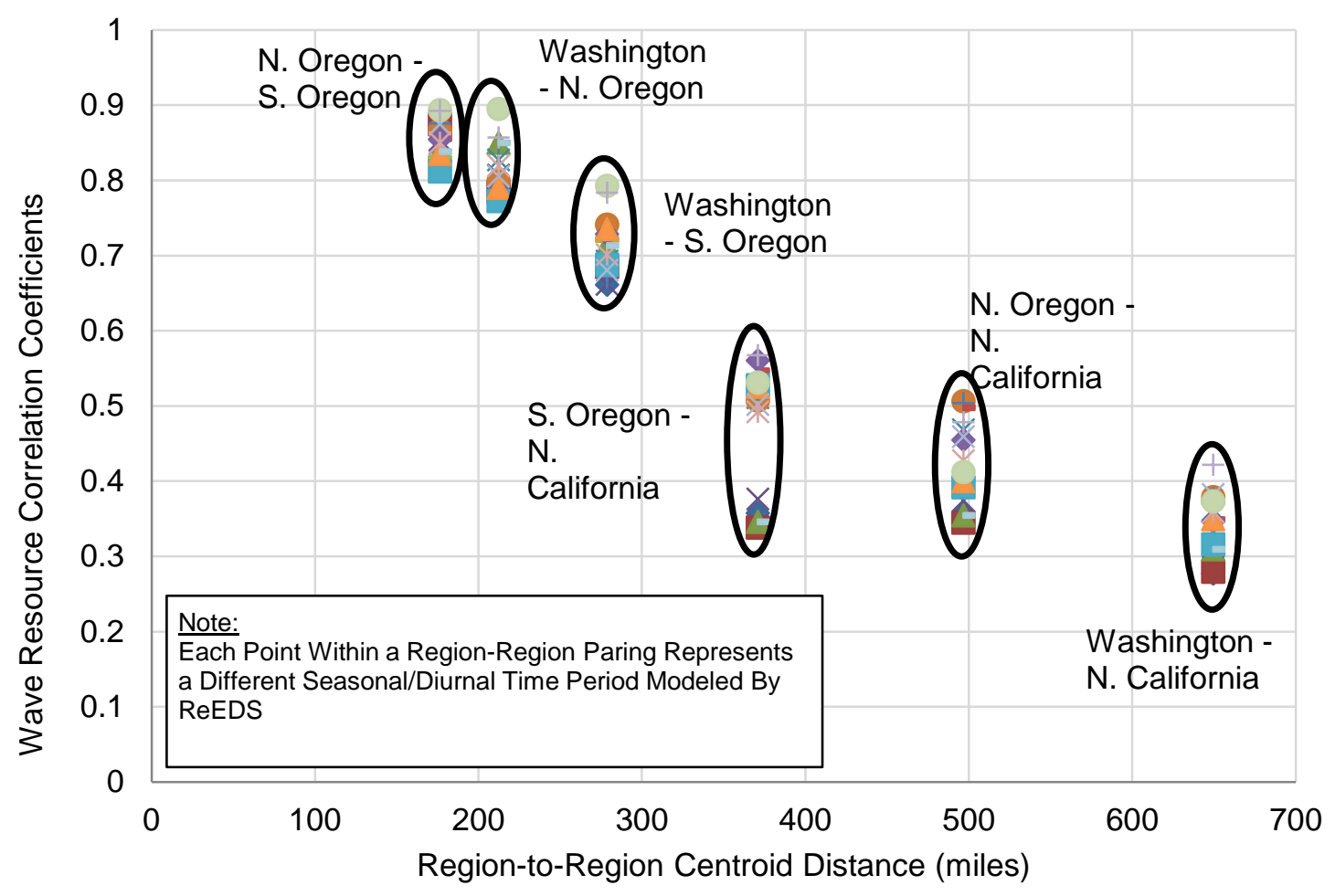

Figure 67 - Seasonal/diurnal wave resource correlations between resource regions as a function of regionto-region centroid distance

Because ocean waves are generated in part by wind forces, possible interactions between wave and offshore wind ought to be addressed. These interactions are captured on a basic level in these scenarios. Although not considered in this analysis, cross correlations between wave and wind resource variability and potential benefits of co-location of wave energy converters with offshore wind farms would be ideal. Studies in the United States (Fusco et al. 2010; Stoutenburg et al. 2010) explore the interactions between variable wave and wind resource and the potential for co-location of wave energy converters and wind turbines.

\section{BAU Assumptions}

The detailed inputs for a standard ReEDS BAU case have been amassed from a variety of sources. Fuel prices and electricity demands are taken from EIA (2010) and extrapolated from 2035 to 2050 at the AEO growth rate between 2030 and 2035. Figure 68 shows the AEO fuel prices vis-à-vis the national average fuel prices outputs from ReEDS. Differences between the AEO2011 and the ReEDS natural gas prices are attributed to ReEDS natural gas supply elasticity. 


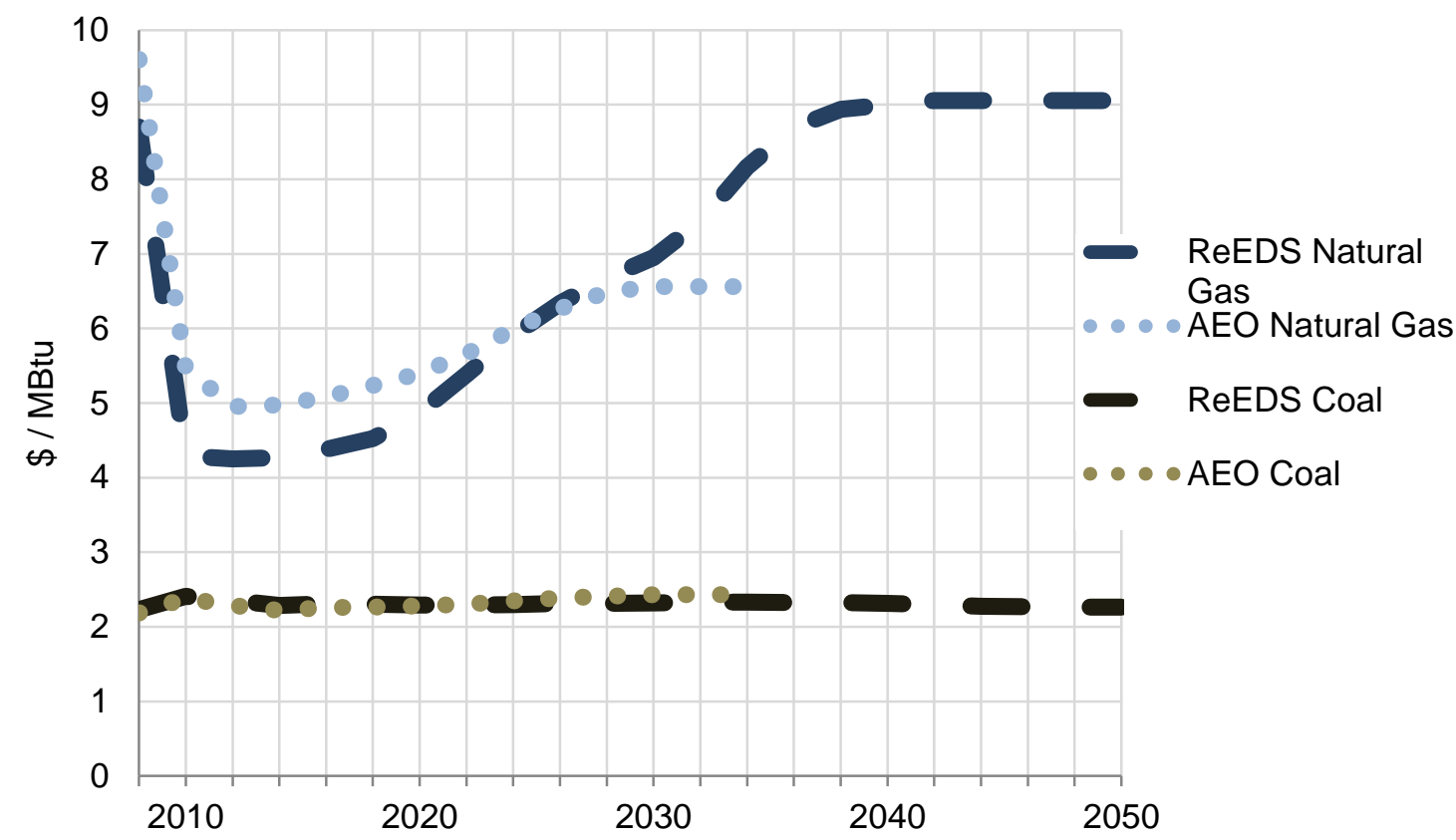

Figure 68 - Comparison of AEO 2011 and ReEDS natural gas and coal prices over time

ReEDS uses Black \& Veatch cost and performance values over time for non-MHK technologies. Figure 69 shows the ReEDS assumptions of capital cost inputs for non-MHK technologies. Thermal power generators are shown as solid lines, wind turbines as dashed lines, and solar technologies as dotted lines. Capital cost improvements are assumed to occur for offshore wind, solar, and nuclear technologies.

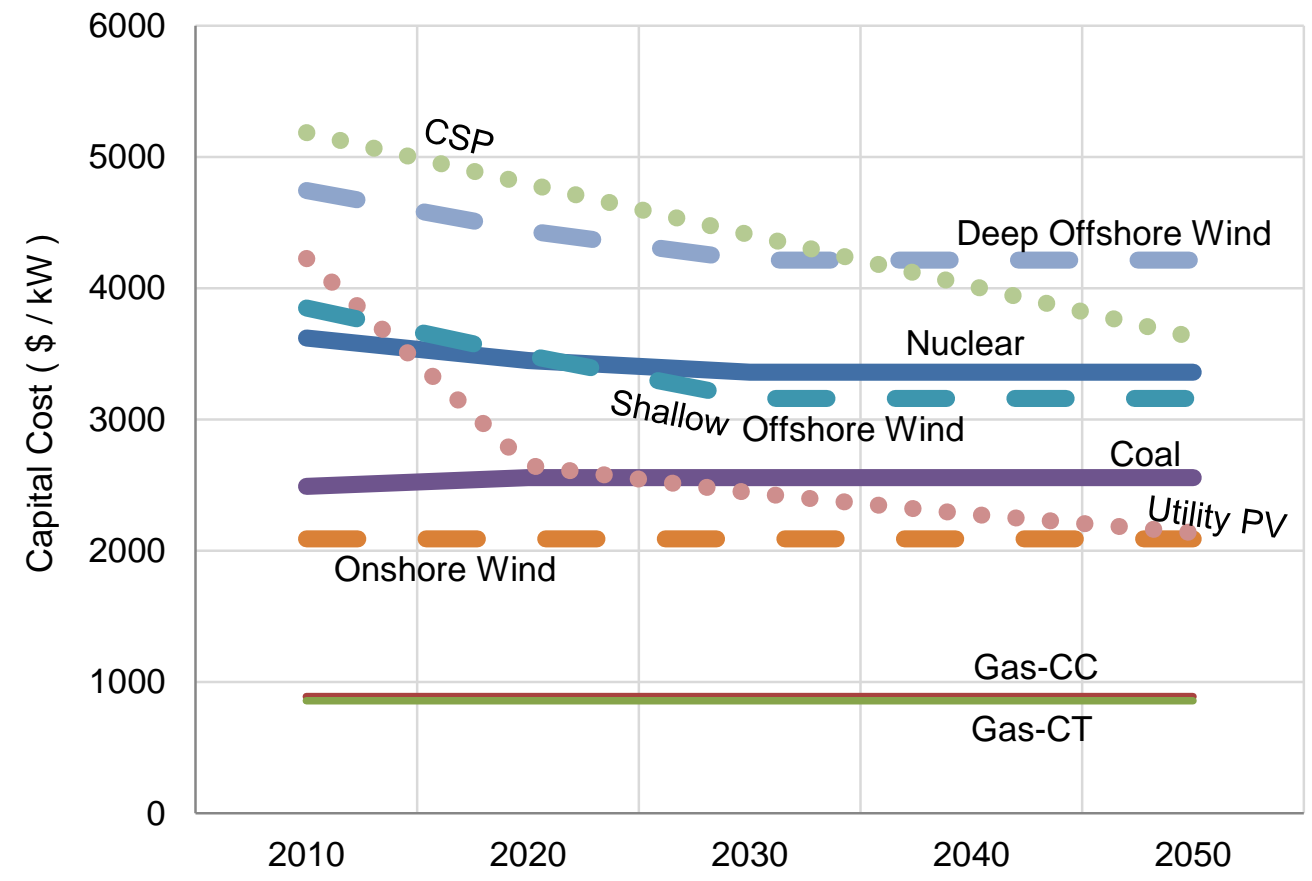

Figure 69 - Black and Veatch non-MHK capital costs over time 


\section{Appendix III: ReEDS Model Background}

This appendix includes a thorough description of electric power reliability and a comprehensive description of the ReEDS model, as well as detailed modeling assumptions for wave, ocean current, and tidal flow technologies.

\section{Electric Power Reliability}

Electric power must be available to meet loads with exceptionally high reliability. This is currently accomplished by generating sufficient power at all times and ensuring that reserve generation is available. These reserves guarantee that sufficient power can be generated at all times even with frequent variations in loads, unplanned outages of generators and/or transmission lines, and unforeseen generation variations from variable generation (or variable generator; VG) sources like MHK, wind, and solar.

Reserves are ensured when planning and operating. To accommodate maintenance and breakdowns of generators, utilities have typically planned capacity reserves 15\%-20\% larger than the highest peak load during the year. Although utilities count the full nameplate capacity of thermal power plants toward their capacity reserve needs, they cannot do the same for VG capacity because its output is variable. Nonetheless, they do usually give VG capacity some credit toward meeting the planning reserve requirement because VG capacity does increase the probability that sufficient capacity will be available at the time of peak load. This capacity value of VG is difficult to calculate because it depends on the following factors:

- The type of VG (e.g., PV output is often coincident with peak loads that are often caused by airconditioning loads, while wind does not usually blow much during hot summer afternoons)

- The amount of VG installed relative to the size of the load (e.g., the first PV system installed will have a higher capacity value than one installed when PV is already generating $20 \%$ of load, because at that level, the summer afternoon air-conditioning loads will have been met and the remaining peak load will have shifted to late summer evenings when the intensity of the sunlight has already decreased significantly)

- The geographic diversity of the VG systems (e.g., $500 \mathrm{MW}$ of wind capacity spread over 5 sites will have more capacity value than $500 \mathrm{MW}$ at one site because the probability that there will be some wind from the 5 sites during the peak load moment is higher than for the $500 \mathrm{MW}$ at one site case).

Operating reserves are even more complicated. They largely address the fact that although sufficient capacity may be available, it cannot necessarily turn on (or off) fast enough to provide the additional (or 
reduced) generation needed. One way to classify operating reserves is by how large and unexpected the need is for changes in generation:

- "Following" reserves furnish a response to anticipated increases or decreases in generation needed over a sustained period (e.g., increasing loads as a workday gets under way), which can require further reserves if VG output is expected to decline at the same time. Units providing these reserves can be scheduled for as much as a day or more ahead of time.

- "Regulation" reserves provide near instantaneous response to meet small, short-lived (less than 1 minute) random variations in loads and generation from VGs. They are usually automatically dispatched through centralized control.

- "Contingency" reserves are usually substantial generation needed instantaneously and for a sustained period to make up for the unexpected loss of a generator and/or transmission line. Contingency reserves are provided by an assortment of generation technology determined by the time it takes for each technology to respond. At the instant of loss, the frequency of alternating current (AC) power begins to drop immediately. The inertia of rotating generators provides the first level of contingency reserves; they simply slow the rate at which the frequency of AC power declines. Next, automatic generation control further slows and may arrest the decline in frequency. At this point, spinning reserves are dispatched to increase frequency. Spinning reserves are provided by rotating generators that are already supplying power to the grid, but not at their maximum power level. This means that they can ramp their power output up in a matter of minutes. Spinning reserves can be supplemented by nonspinning reserves that can be started and synchronized to the grid within 10 minutes. To bring the frequency back to $60 \mathrm{~Hz}$, slower-starting secondary reserves are manually dispatched once it is determined that a contingency has occurred. With frequency restored and stabilized at $60 \mathrm{~Hz}$, tertiary reserves are dispatched to displace these primary and secondary reserves so that they can be available to address another contingency if necessary.

Renewable VGs increase the need for following reserves and regulation reserves because their output varies from second to second, and because their output can gradually ramp up or down over hours. As with planning reserves, the additional operating reserves required by renewable VGs depends on the type of VG, the number of VGs in the system, and the geographic diversity of the VGs. They also depend on the ability to forecast the variation in output from the VG. Renewable VGs do not require additional contingency reserves because they are typically modular (e.g., many wind turbines make up a wind farm) and therefore an entire installation does not fail at once. 


\section{re vision}

The variability of generation from renewable VGs creates another issue in addition to reserve requirements. At significant levels of VG penetration, there can be times when more VG is available than can be used. In this case the VG must be curtailed and the VG owner may not be paid for that generation. This affects the economic viability of a new VG investment. Once again, the level of curtailments depends on the type of VG, the number of VGs in the system, and the geographic diversity of the VGs.

\section{Detailed ReEDS Overview}

ReEDS is an optimization model of the deployment of electric power generation technologies and transmission infrastructure throughout the contiguous United States through 2050. The model, developed by NREL's Strategic Energy Analysis Center (SEAC), is designed to analyze the critical energy issues in the electric sector, especially with respect to potential energy policies such as clean energy and renewable energy standards or carbon restrictions.

To determine competition between the many electricity generation, storage, and transmission options throughout the contiguous United States, ReEDS chooses the cost-optimal mix of technologies that meet all regional and temporal electric power demand requirements, grid reliability (reserve) requirements, technology resource constraints, and policy constraints. This cost minimization routine is performed for each of 23 modeled years from 2006 to 2050 (every 2 years). The major outputs of ReEDS include the amount of generator capacity and annual generation from each technology, storage capacity expansion, transmission capacity expansion, total electric sector costs, electricity price, fuel prices, and carbon dioxide $\left(\mathrm{CO}_{2}\right)$ emissions.

ReEDS yields a detailed treatment of electricity-generating and electrical storage technologies, and specifically addresses a variety of issues related to renewable energy technologies, including accessibility and cost of transmission; regional quality of renewable resources; seasonal and diurnal generation profiles; variability and nondispatchability of wind, solar, and MHK power; and the influence of variability on curtailment of those resources and the reliability of the electrical grid. ReEDS addresses these issues through a highly discretized regional structure, temporal resolution, explicit statistical treatment of the variability in wind and solar output over time, and consideration of ancillary services requirements and costs.

The ReEDS model uses a much greater level of geographic disaggregation than do other long-term largescale capacity expansion models. At its finest resolution, ReEDS uses 356 different resource regions in the contiguous United States to characterize wind and CSP resources. These 356 resource supply regions 
are grouped into four levels of larger regional groupings-134 BAs, 21 reserve-sharing groups, 13 NERC regions (NERC 2010), and 3 interconnects. States are also represented for the inclusion of state policies.

ReEDS also has significant temporal resolution as compared to other capacity expansion models. Time in ReEDS is subdivided within each 2-year period, with each year divided into four seasons with a representative day for each season. This is further divided into four diurnal time slices. There is also one additional summer-peak time slice. These 17 annual time slices enable ReEDS to capture the intricacies of meeting electric loads that vary throughout the day and year-with both dispatchable and nondispatchable generators.

The following is a list of generation and storage technologies considered in the ReEDS model:

- Onshore wind

- Offshore wind

- Utility-scale PV

- $\quad$ CSP

- Biopower

- Hydropower

- $\mathrm{MHK}$

- Geothermal

- Landfill gas

- Nuclear

- Pulverized coal with and without sulfur dioxide scrubbers

- Integrated gasification combined-cycle coal (coal-IGCC)

- Cofired coal with biomass

- Coal with carbon capture and sequestration (coal-CCS)

- Gas-CT

- Gas-CC

- Natural gas combined cycle with carbon capture and sequestration (gas-CCS)

- Oil-gas-steam

- Compressed air energy storage (CAES)

- $\quad$ Pumped hydropower storage (PHS)

- Batteries

- Thermal storage in buildings 
Although ReEDS includes all major generator types, it has additional detail for renewable generators, as these generators come with concerns that many conventional dispatchable power plants do not have, including variations in regional resource quality, variability and nondispatchability, and additional transmission needs. Many of the data inputs in ReEDS for wind and CSP are tied to the 356 resource regions and derived from a detailed GIS model/database of the wind and CSP resource and transmission grid. This database is used to calculate supply curves of wind and CSP, which capture subregional resource quality variations and transmission costs, among other factors. Regional disaggregation is also used to more thoroughly capture variability of nondispatchable wind and solar plants, as well as the benefits of dispersing wind and solar plants on reducing the combined variability of those resources. The detailed treatment of wind and solar variability also has significant implications for the value of storage technologies in ReEDS, as these technologies could be used for load shifting, resource firming, and ancillary services.

Regional resource quality variations are also considered for other renewable generator types, including hydropower, biopower, and geothermal. ReEDS provides supply curves for these resources in each of the 134 BAs. The geothermal and hydropower supply curves are in megawatt of recoverable capacity and the biomass supply curve is in million British thermal units (MBtu) of annual feedstock production.

Technologies in ReEDS are characterized generally by the following cost and performance parameters, in addition to technology-specific parameters such as the supply curves for renewable energy resources discussed previously:

- $\quad$ Capital cost $(\$ / \mathrm{MW})$

- Fixed and variable operating costs (\$/MWh)

- Fuel costs (\$/MBtu) for applicable plants

- Construction period (years)

- Equipment lifetime (years)

- Financing costs (such as nominal interest rate, loan period, debt fraction, and debt-servicecoverage ratio

- Tax credits (investment or production)

- Heat rate (MBtu/MWh) for fuel-consuming plants

- Capacity factor for wind and solar plants

- Round-trip efficiency for storage technologies

- Planned and unplanned outage rates (\%) for dispatchable plants

- Minimum turndown ratio (\%) for dispatchable plants 
- Daily cycling penalties for coal plants

- Quick-start and spinning reserve capability for plants that provide operating reserves

- Emissions levels of carbon, sulfur dioxide, nitrogen oxides, and mercury.

Retirement of conventional generation and hydropower can be modeled through exogenous specification of planned retirements or based on usage characteristics of the plants. All retiring nonhydro renewable plants are assumed to be refurbished or replaced immediately, because the site is already developed and has transmission access and other infrastructure.

In its native version, annual electric loads are exogenously specified to define the system boundaries for each period of the optimization. To allow for the evaluation of scenarios that might depart significantly from the base scenario, price elasticity of demand is integrated into the model: the exogenously defined demand projection can be adjusted up or down based on a comparison of an estimated BAU electricity price path and a calculation of electricity price within the model for each of the 23 two-year periods. For coal and natural gas pricing, exogenous supply curves are based on the EIA 2011 AEO (EIA 2010).

\section{ReEDS Model Treatment of Reliability and VG Sources}

With its broad scope as a national, long-term capacity expansion model, ReEDS cannot afford to directly model the hourly variability in loads and VG output, nor the stochastic nature of contingencies. Instead it approximates this variability and stochasticity through a combination of 17 intra-annual time slices and statistical estimates. The 17 time slices consist of 4 seasons - winter (92 days), spring (120 days), summer (92 days), and fall (61 days) — each captured by a representative day that consists of 4 time slices — night ( 8 hours), morning ( 7 hours), afternoon (4 hours), and evening (5 hours). The 17 th time slice consists simply of the 40 hours of highest loads during the year (almost all of these occur in the summer). With these time slices, ReEDS can get a broad handle on the variation in loads as well as the variation in the output from variable generators. Variation in output from a single VG site is captured by a different capacity factor in each time slice for that VG technology.

The differences between ReEDS time slices capture much of the variability issue, and the statistical calculations in ReEDS capture the remaining variation within the time slices. Statistical calculations are made for the capacity value to be used for each VG in the planning reserve constraint of ReEDS, for the additional operating reserves induced by each VG, and for the curtailment of output from each VG. These calculations are made for the existing VGs as well as for each potential new VG installation. Inasmuch as capacity value, operating reserves, and curtailments depend on the region in which the power is being 
used, the calculations are made not just as a function of the VG site, but also for the load area the VG power is contracted to supply. Finally, these statistical calculations are updated as the model proceeds through time in 2-year steps.

The capacity value, induced operating reserve requirements, and curtailments can play a major role in selecting VG sites. For example, if substantial wind power has been installed at a particular site, the generation from any new wind deployed at that site will be totally correlated with the existing wind. Thus the capacity value of new wind at that same site will be less than the capacity value that might be attained at a virgin site. Similarly, the additional operating reserves and curtailments will be greater. All else being equal, ReEDS will not select that site for the next wind installation, but will probably choose another faraway site at which any wind installation's output will have little correlation with the output of the turbines at the original site. But everything else is never equal, so ReEDS actually trades off the possibilities of geographic diversity with resource quality (i.e., annual generation) and transmission availability, among other factors. 


\section{Appendix IV: Supply Curve Allocation Method}

The electricity grid components used to develop the supply curves are transmission lines, substations, cities, and center points for the ReEDS BA.. Actual line availability varies based on a variety of factors including ownership, contractual agreements with individual generation plants, and rules and regulations of particular transmission system operation entities. Precise estimates of individual transmission line capacity as a function of time are not publicly available. In lieu of line-specific data and for simplicity, the team assumed that $10 \%$ of the existing capacity would be available for new generation.

The capacity for each transmission line is estimated based on its length and nominal voltage. Substations are linked to the transmission lines, marking their endpoints and have a total capacity equal to the cumulative value of half of each connected transmission line's capacity. ${ }^{\text {a }}$ When developable sites are assigned to a transmission line or substation, their linked component capacities are reduced accordingly. A city component has at least 10,000 people with the remaining population represented by county at its spatial center. The city's capacity is represented using annual peak load, ${ }^{\mathrm{b}}$ apportioned to each city by population. The ReEDS BA components represent locations where large transmission lines are built from the center of one balancing region to another. The inter-regional transmission capacity is unlimited. All resource points will be assigned to a grid component. When available transmission, substation, and city capacities are exhausted, the resource points will by default be assigned to the closest BA center.

The resource supply curves developed in this report are the result of iteratively evaluating the lowest cost developable sites (utilizing the cost components as described in Section 4), and allocating them to grid components based on the capacity available on the grid. The team began by calculating an initial development cost for each site to build to the lowest cost grid component. The sites were sorted by cost, and the site with the lowest cost was selected. The grid component to which the site is linked was identified, and its remaining available capacity queried.

If the grid component capacity can accept the site capacity, the site was assigned to it and the grid component's available capacity was decremented accordingly. The next lowest developable site was then evaluated. If, however, the grid component's available capacity was not sufficient to fully utilize the site, the next lowest cost grid component with enough capacity was identified and the development cost was

\footnotetext{
${ }^{\text {a }}$ Transmission line data was extracted from Platts POWERmap product in 2009 for the contiguous United States and from the Homeland Security Infrastructure Program 2011 for Alaska and Hawaii.

${ }^{\mathrm{b}}$ Regional peak load data was extracted from Platts POWERmap and POWERdat products for the contiguous United States.
} 
recalculated. The developable site was re-sorted into the remaining pool of unassigned sites, and the next lowest cost site was evaluated. Figure 70 illustrates this process.

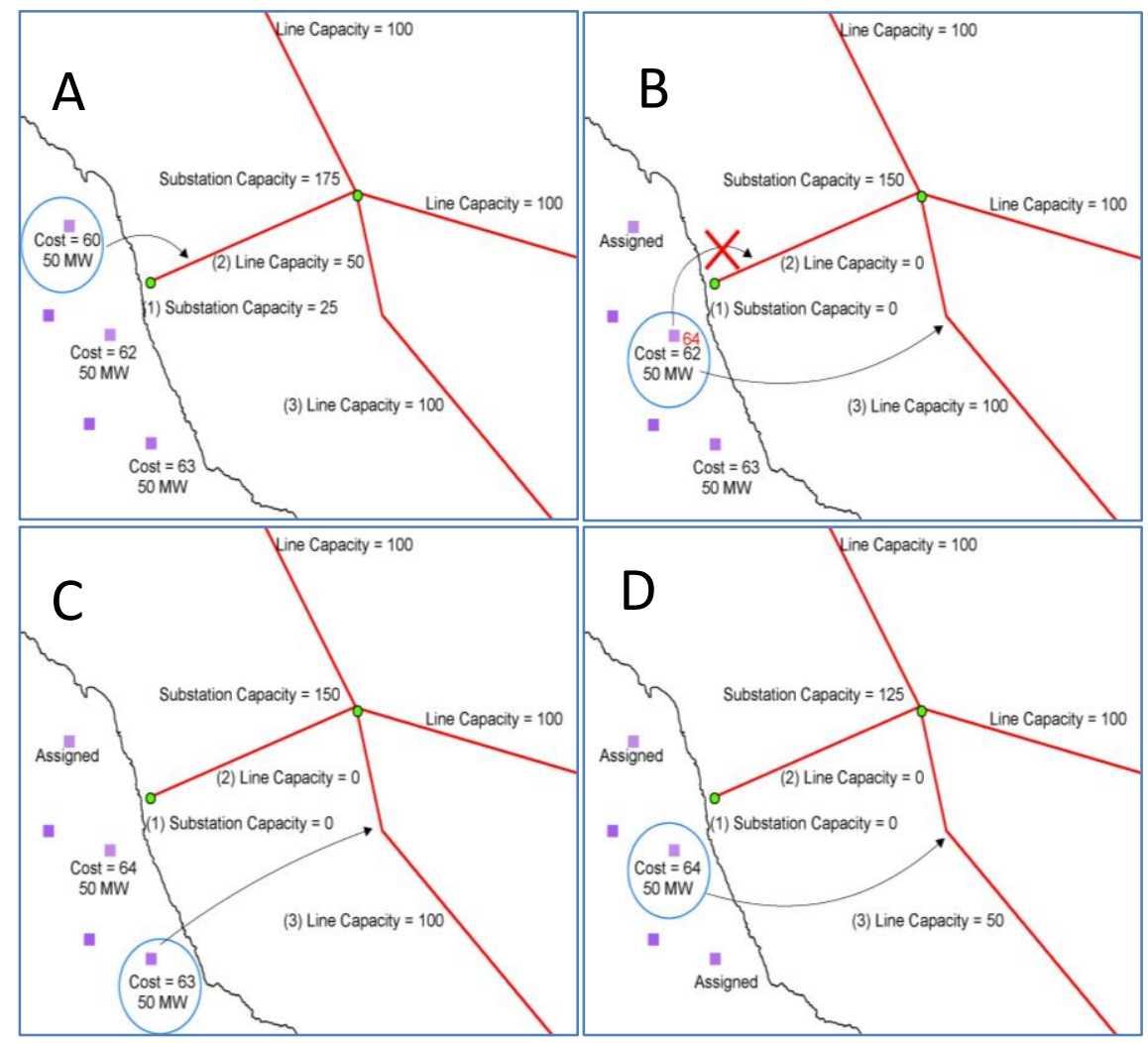

Figure 70 - Developable site to grid assignment process

In the figure, the lowest cost developable site is identified (A), and the associated transmission line has sufficient capacity. The site is assigned, and the transmission line and substation available capacities are reduced. The next lowest cost developable site is identified (B), but the associated transmission line no longer has sufficient capacity. The next lowest cost grid component with capacity is identified, and the new cost (64) is calculated and associated with the developable site. This is no longer the lowest cost site, though, so it remains unassigned. The next lowest cost sites are identified (C and D) and assigned successfully as in (A).

This process continues until all of the developable sites have been assigned to a grid component. This method allows analysis of cost trade-offs between resource quality and the amount of transmission infrastructure that would need to be built to connect a developable site to the existing infrastructure. The supply curves are derived individually for each technology, and are input into the ReEDS model where technologies can be competed against each other. 